UCRL-ID 142039

\title{
COMPARISON OF THE PSHA RESULTS OF THE 1993-EUS- UPDATE AND THE 1998-TIP STUDIES FOR WATTS BAR
}

Prepared by:

Jean Savy and Don Bernreuter

Energy and Environment Department (E\&E)

Fission Energy System Safety Program (FESSP)

Hazards Mitigation Center (HMC)

Prepared for:

Division of Research Engineering and Safety

Office of Nuclear Regulatory Research

U.S. Nuclear Regulatory Commission

Washington, DC 20555

Livermore, California

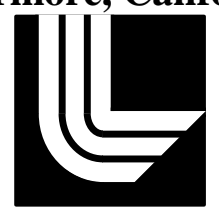

January 26, 2001 


\section{COMPARISON OF THE PSHA RESULTS OF THE 1993-EUS- UPDATE AND THE 1998-TIP STUDIES FOR WATTS BAR}

Manuscript date: January 9, 2001

Prepared by J. B. Savy and Don Bernreuter

Lawrence Livermore National Laboratory

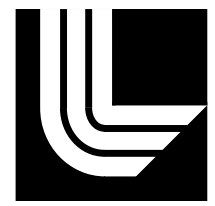

7000 East Avenue

Livermore, CA 94550

Prepared for

U.S. Nuclear Regulatory Commission 


\section{Disclaimer}

This document was prepared as an account of work sponsored by an agency of the United States Government. Neither the United States Government nor the University of California, nor any of their employees, makes any warranty, express or implied, or assumes any legal liability or responsibility for the accuracy, completeness, or usefulness of any information, apparatus, product, or process disclosed, or represents that its use would not infringe privately owned rights. Reference herein to any specific commercial product, process, or service by trade name, trademark, manufacturer, or otherwise, does not necessarily constitute or imply its endorsement, recommendation, or favoring by the United States Government or the University of California. The views and opinions of authors expressed herein do not necessarily state or reflect those of the United States Government or the University of California and shall not be used for advertising or product endorsement purposes.

This work was supported by the United States Nuclear Regulatory commission under a Memorandum of Understanding with the United States Department of Energy, and performed under the auspices of the U.S. Department of Energy by Lawrence Livermore National Laboratory under Contract

W-7405-Eng-48. 


\begin{abstract}
From 1981 to 1989, Lawrence Livermore National Laboratory (LLNL) developed for the Nuclear Regulatory Commission a method for performing Probabilistic Seismic Hazard Analysis (PSHA) in the eastern US with results documented in NUREG/CR-5250. Improvements in the handling of the uncertainties lead to updated results documented in the 1993-EUS-Update study (NUREG1488.) These results presented substantial differences with the utilities sponsored study performed by the Electric Power Research Institute (EPRI, 1989.)

In order to understand the differences between the two studies, the Nuclear Regulatory Commission (NRC), the Department Of Energy (DOE) and EPRI jointly sponsored a study led by the Senior Seismic Hazard Analysis Committee (SSHAC) the task of which was to explain the differences between the two studies and provide guidance on how to perform a state-of-the-art PSHA. The work and conclusions of the SSHAC are documented in NUREG/CR-6372, 1997.

As a follow-up to the 1997 SSHAC study, the Trial Implementation Project (TIP), (UCRL-ID133494, 1998, NUREG/CR-6607) made use of the SSHAC recommendations and developed a set of more detailed guidance for performing PSHA. The TIP project tested the more complicated issue of development of the seismic zonation and seismicity models on two sites: Watts Bar and Vogtle. It was found that the uncertainty generated by artificial disagreements among experts can be considerably reduced through interaction and discussion of the available data and by identifying the elements common to all experts' interpretation. By concentration on those elements, it was possible to develop a consensus of the group on the way to characterize them and eliminate large unnecessary differences.

The present study compares the results of the 1993-EUS-Update and the 1998-TIP studies and identifies the reasons for the differences, which were found to be:

1. Differences in the ground motion (GM) attenuation models

2. The introduction of the Eastern Tennessee Seismic Zone (ETSZ) in the TIP study.

We found that these two factors accounted for factor of 6 difference in mean estimates PGA hazard at high GM levels. The agreement between the two studies improved at lower PGA values. The results were in better agreement and only differed by about a factor of two at high ground motion levels, when the same GM model was used with each seismicity model. Finally, it was found that the composite rate of earthquakes around the Watts Bar site was about a factor of two higher for the TIP composite seismicity model than for the composite 1993-EUS-Update seismicity model.
\end{abstract}




\section{LIST OF ABBREVIATIONS}

$\begin{array}{ll}\text { APE } & \text { Annual Probability of Exceedance } \\ \text { BE } & \text { Best Estimate } \\ \text { CEUS } & \text { Central and Eastern United States } \\ \text { DOE } & \text { Department of Energy } \\ \text { EPRI } & \text { Electric Power Research Institute } \\ \text { ETSZ } & \text { Eastern Tennessee Seismic Zone } \\ \text { EUS } & \text { Eastern United States } \\ \text { GM } & \text { Ground Motion } \\ \text { LLNL } & \text { Lawrence Livermore National Laboratory } \\ \text { NRC } & \text { Nuclear Regulatory Commission } \\ \text { PGA } & \text { Peak Ground Acceleration } \\ \text { PGV } & \text { Peak Ground Velocity } \\ \text { PSHA } & \text { Probabilistic Seismic Hazard Analysis } \\ \text { RP } & \text { Return Period (Inverse of Annual Probability of Exceedance) } \\ \text { SRS } & \text { Savannah River Site } \\ \text { SSHAC } & \text { Senior Seismic Hazard Analysis Committee } \\ \text { TIP } & \text { Trial Implementation Project }\end{array}$




\section{TABLE OF CONTENTS}

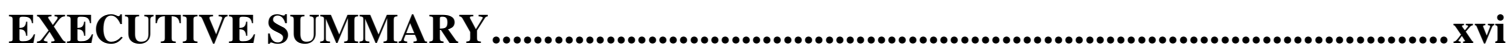

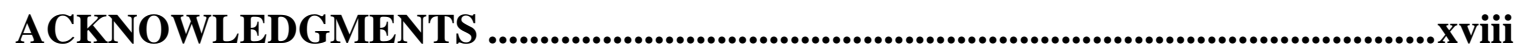

1. INTRODUCTION ..............................................................................................................1

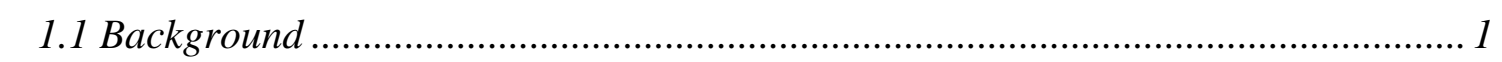

1.2 Purpose of the study, scope ............................................................................ 2

2.DIFFERENCES IN HAZARD ESTIMATES ........................................................4

3. IMPACT OF THE GROUND MOTION MODELS. .......................................8

3.1 Direct Comparison of the Ground Motion Models Used in the Two Studies ........... 8

3.2 Comparison of the Hazard Estimates .......................................................... 11

3.3 Sensitivity to the Ground Motion Models......................................................... 14

3.4 Sensitivity to the Seismic Zonation and Seismicity Models..................................... 19

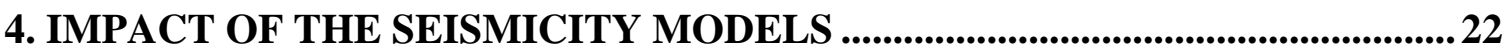

4.1 Methodological Differences ........................................................... 22

4.2 Differences of Interpretation of the Data by the Experts .................................. 22

4.3 Case of the Local Zones ............................................................................. 28

5. UNCERTAINTIES AND SENSITIVITY STUDIES. ......................................35

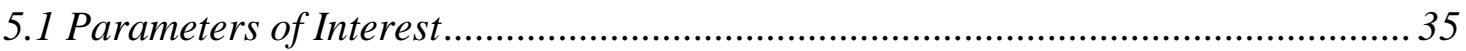

5.2 Sensitivity to the Formulation of the Zonation Maps ............................................ 36

5.3 Sensitivity to the parameters of the Monte-Carlo Simulation .............................. 37

5.4 Site Specific versus Regional Studies ........................................................ 38

5.5 ETSZ versus Local Faults .................................................................................. 39

5.6 Ground Motion Saturation .......................................................................... 40

5.7 Uncertainty in the Ground Motion Models Estimates .................................... 43

6. CASES OF THE 2.5 AND 25.0 HZ RESPONSE SPECTRAL VELOCITIES ..... 44

7. DISCUSSION AND CONCLUSIONS ............................................................53 
REFERENCES .....................................................................................................................55 


\section{LIST OF TABLES}

Table 4.1: Best Estimate Earthquake Budgets of Earthquakes with Magnitudes greater than 3.5 within $33 \mathrm{~km}$ of Watts Bar in the 1998-TIP Study, for Bollinger alone and

for the1998-TIP Composite Seismicity Model. .............................................29

Table 4.2: Contribution of Selected Seismic Zones to the Budget of Earthquakes greater than Magnitude 3.5 within $33 \mathrm{~km}$ of Watts Bar, in the 1998-TIP Study. "Tip Rate" Refers to the rates from the 1998-TIP Composite Seismicity Model and "Bol Rate"

Refers to the Seismicity Rates from Bollinger Only, in the 1998-TIP Study..........29 


\section{LIST OF FIGURES}

Figure I: Comparison of the Mean Estimates of the Seismic Hazard for the Watts Bar Site. The Curve with the Square Markers is for the Estimates of the 1998-TIP Study.

The Curve with the Crosses is for the Estimates of the 1993-EUS-Update Study. xvii

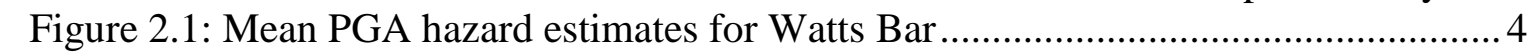

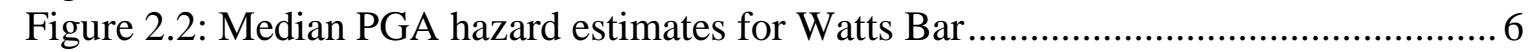

Figure 2.3: "Best Estimate" PGA hazard for Watts Bar ...........................................6

Figure 3.1a: Comparison of the median Ground Motion Attenuation Models for the 1993-

EUS-Update and 1998-TIP studies for Magnitudes 5, 6 and 7 ........................ 8

Figure 3.1b: Ratios of the median PGA estimates from the 1998-TIP study, divided by

the 1993-EUS-Update median estimates, as a function of distance.......................9

Figure 3.2a Comparison between the 1-sigma 1998-TIP and the 85\% 1993-EUS Update

Ground Motion Attenuation models. ..................................................... 10

Figure 3.2b: Ratios of the 1-sigma PGA estimates from the 1998-TIP study, divided by

the 1993-EUS-Update median estimates, as a function of distance......................11

Figure 3.3: Cumulative Contribution of the Distance bins to Hazard in the 1998-TIP

Study. Seismic Source Zones within 40km of Watts Bar Contribute approximately

$80 \%$ of the Total Hazard. .................................................................................... 12

Figure 3.4: Cumulative Contribution of the Magnitude bins to the Hazard in the 1998-TIP

Study. Magnitude Events Smaller than 6 Contribute approximately $80 \%$ of the Total

Hazard.

Figure 3.5: Contribution of the Magnitude-Distance bins to the Total Hazard for a 10,000

Year Return Period.

Figure 3.6: Estimates of the Mean Hazard using the 1998-TIP Seismic Zonation.

Comparison between the 1993-EUS-Update and 1998-TIP Ground Motion

Attenuation Models............................................................................... 14

Figure 3.7: Estimates of the Median Hazard using the 1998-TIP Seismic Zonation.

Comparison between the 1993-EUS-Update and 1998-TIP Ground Motion

Attenuation Models.

. .13

Figure 3.8: Estimates of the Mean Hazard using the 1993-EUS-Update Zonation .

Comparison between the 1993-EUS-Update and 1998-TIP Ground Motion

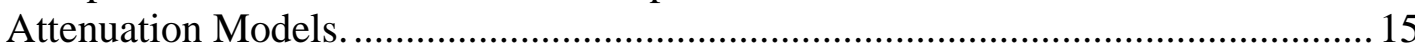

Figure 3.9: Estimates of the Median Hazard using the 1993-EUS-Update Seismic

Zonation. Comparison between the 1993-EUS-Update and 1998-TIP Ground

Motion Attenuation Models.

re 3.10: Contribution of Magnitude Bins to the Total Hazard in the 1998-TIP Study

for Two Peak Ground Acceleration Levels................................................... 17

Figure 3.11: Results of the 1993-EUS-Update Study. Comparison of the Mean Estimates

of the Hazard between the 11 Experts (comb) and Expert 3 (X3)....................... 18

Figure 3.12a: Contribution of Magnitude Bins in the 1993-EUS-Update Study for Two

Peak Ground Acceleration Levels for the case of Expert 3. ............................. 18

Figure 3.12b: Comparison of the Magnitude Contributions for a 1g PGA using the 1998-

TIP ground Motion Model. The Seismicity of Expert 3 (X3) leads to a strong mode

at M5.6 and the 1998-TIP Composite Seismicity leads to a monotonically decreasing

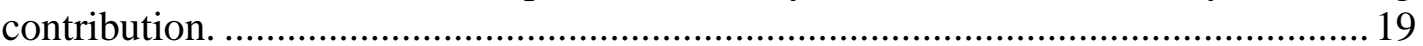


Figure 3.13: Sensitivity to the Seismicity and Zonation Model . The Two Curves Represent the Mean Hazard Estimated with the 1998-TIP and with the 1993-EUSUpdate Seismicity-Zonation Models. Both are with the same 1998-TIP Ground

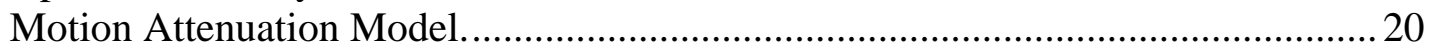

Figure 3.14: Comparing the Median Hazard Curves between the Cases of 1998-TIP Seismicity to the case of 1993-EUS-Update Seismicity, both with the same 1998TIP Ground Motion Model. .................................................................................. 21

Figure 4.1: First Order Regional Seismic Sources Zonation Map for the Study of the Watts Bar Site in the 1998-TIP Study.

Figure 4.2: Detail of the Geometry of the Local Seismic Source Zones Considered in the 1998-TIP Study.

Figure 4.3: One of the seismic Source Zone maps Submitted by Seismicity Expert 3 in the 1993-EUS-Update Study. The site location is shown by the circle on the map. 25 Figure 4.4: One of the seismic zone maps submitted by Seismicity Expert 1 in the 1993-

EUS-Update Study. The location of the site is indicated by a circle on the map. ....25 Figure 4.5: Expected Budget of Earthquakes within $35 \mathrm{~km}$ of Watts Bar from the Zonation and Seismicity Models of the 11 Seismicity Experts of the 1993-EUS-

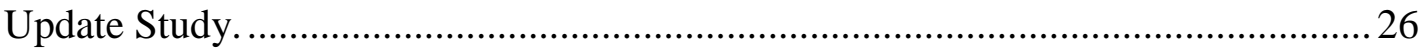
Figure 4.6: Comparison of the Earthquake Seismicity Budget within 35km of Watts Bar for the 1993-EUS-Update and the 1998-TIP Seismic Zonation and Seismicity Models. The 1993-EUS-Update Curve is an Average over the 11 Seismicity Experts, the 1998-TIP curve is from the Composite Zonation and Seismicity Model...........27 Figure 4.7: Comparison of the Best Estimate Seismicity Budget for a Region within 35 km of Watts Bar Provided by Expert 3 (X3 1993-EUS-Update) in the 1993-EUSUpdate Study and G. Bollinger in the 1998-TIP Study (1998-TIP-BOL). ...............28 Figure 4.8: Historical Seismicity in Zone 35 of 1998-TIP....................................... 30 Figure 4.9: Comparison of the Budget of Historical Earthquakes with the Expected Estimates in Zone 35 of 1998-TIP. The Composite Seismicity Model including all Experts' Input is labeled "1998-TIP" and "1998-TIP-BOL” for Bollinger's input only.

Figure 4.10: Comparison of the Budget of Historical Earthquakes with the Expected Estimates in Zone B1 of 1998-TIP. The Composite Seismicity Model including all Experts' Input is labeled “1998-TIP” and “1998-TIP-BOL” for Bollinger's input

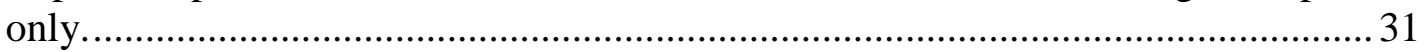

Figure 4.11: Budget of Historical Earthquakes and Modeling for Zone B2 in 1998-TIP. 32 Figure 4.12: Yearly Rates in Zone 5 for Expert 3 of the 1993-EUS-Update Study. "X3 Model" Refers to Expert's 3 Estimates. The Other Curves are for Historical Earthquakes. .................................................................................................... 33

Figure 4.13: Mean Estimates of the Seismic Hazard at Watts Bar using the 1998-TIP Composite Seismicity Model (1998-TIP composite) and Bollinger's Model (1998TIP-BOL). The Ground Motion Model is the 1998-TIP Model .............................34 Figure 5.1: Comparison of the Annual Rates of Occurrence of Earthquakes within $33 \mathrm{~km}$ of Watts Bar, for the 5 Highest Weighted Zonation Maps of the 1998-TIP Study.

The Relative Weights of the Maps are given in Table 4.1................................. 35 Figure 5.2: Comparison of the Mean Estimates of the Hazard for each of the Five Highest Weighted Maps with the Overall Mean Hazard............................................... 36 
Figure 5.3: Sensitivity of the Mean Estimates to the Seed of the Monte-Carlo Simulation

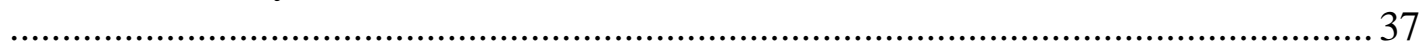

Figure 5.4: Historical Seismicity in Expert 3's Zone 5 of the 1993-EUS-Update Study. 38 Figure 5.5: Location of the Faults Relative to the Site and the Eastern Tennessee Seismic

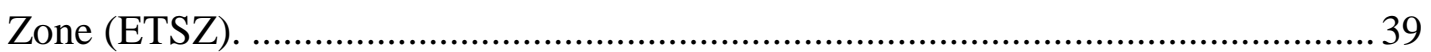
Figure 5.6: 1998-TIP Study. Comparison of the Best Estimate Hazard Curves Obtained Using the Highest Weighted Map (Map 1) to that of a Typical Fault Map.............. 40

Figure 5.7: Effect of the Ground Motion Saturation at $10 \mathrm{~km}$ in the Ground Motion Model. Comparison of Best Estimate Hazard Estimates with and without Saturation. …........................................................................................ 41

Figure 5.8a: 1998-TIP Study. Contribution of the Bins of Distance to the Total Hazard at the Watts Bar Site with the non-Truncated Ground Motion Model......................... 42

Figure 5.8b: 1998-TIP Study. Contribution of the Bins of Distance to the Total Hazard at the Watts Bar Site with the Ground Motion Model Truncated at distances below 10

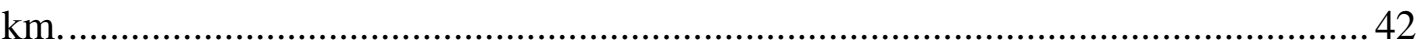

Figure 5.9: Range of Earthquake Magnitudes that Contribute to the Hazard for the 1998TIP Seismicity Model Combined with the 1993-EUS-Update Ground Motion Model

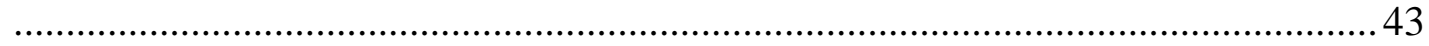

Figure 6.1: Comparison of the Mean Uniform Hazard Spectra for Return Periods of 100,000 and 10,000 years between the1998-TIP Seismicity Model and Expert 3 of the 1993-EUS-Update study both using the TIP Ground Motion model.

Figure 6.2: Mean Spectral Hazard Curves for $2.5 \mathrm{~Hz}$ and $25 \mathrm{~Hz}$ using the 1998-TIP Ground Motion Model and both the 1998-TIP and 1993-EUS-Update Expert 3 Seismicity Models.

Figure 6.3: Cumulative Contribution of the Magnitude Bins to the Total Hazard for a

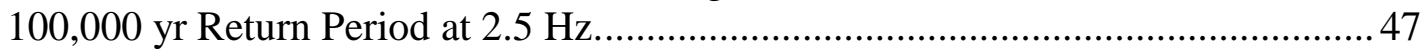

Figure 6.4: Cumulative Contribution of the Distance Bins to the Total Hazard for a 100,000 yr Return Period at $2.5 \mathrm{~Hz}$ 47

Figure 6.5: Comparison of the Yearly Rate of Earthquakes Occurrence within 75km of the Watts Bar site between the Best Estimate 1998-TIP Seismicity model (Map 1), the Median Best Estimate 1993-EUS-Update Seismicity Model and Expert 3's Seismicity model ..................................................................................... 48

Figure 6.6: Rate of earthquakes versus Magnitude around the site using the 1998-TIP Seismicity model for Distances of $33 \mathrm{~km}, 81 \mathrm{~km}$ and $156 \mathrm{~km}$ all normalized to $35 \mathrm{~km}$.

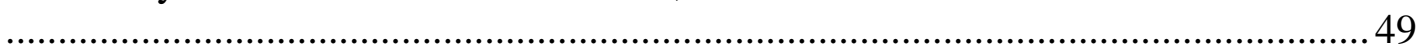

Figure 6.7: Rate of Earthquakes around the Site using the 1993-EUS-Update Expert 3's Seismicity Model (X3), for distances of $35 \mathrm{~km}, 75 \mathrm{~km}$ and $150 \mathrm{~km}$ all normalized to

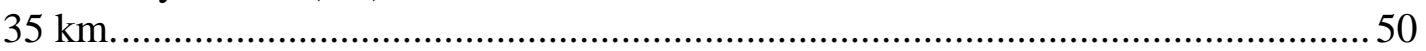

Figure 6.8: Enlarged view of Expert 3's Seismic Source Map Showing Zone 1 as a Large Background Zone with Low Rate of Seismicity ...................................................... 51 


\section{EXECUTIVE SUMMARY}

Probabilistic Seismic Hazard Analysis (PSHA) is a methodology that estimates the likelihood that various levels of earthquake-caused ground motion will be exceeded at a given location in a given future time period. Due to large uncertainties in all the geosciences data and in their modeling, multiple model interpretations are often possible. This leads to disagreement among experts, which in the past has led to drastically different estimates of the seismic hazard at a site and it can lead to disagreement on the selection of ground motion for design at a given site.

From 1981 to 1989, Lawrence Livermore National Laboratory (LLNL) developed for the U.S. Nuclear Regulatory Commission (NRC) a method for performing PSHA in the eastern US with results documented in NUREG/CR-5250. Improvements in the handling of the uncertainties lead to updated results documented in the 1993-EUS-Update study (NRC, 1993, NUREG-1488.) These results presented substantial differences with the utilities sponsored study performed by the Electric Power Research Institute (EPRI.)

In order to improve on the overall stability of the PSHA process, the NRC, the Department Of Energy (DOE), and EPRI co-sponsored a project to provide methodological guidance on how to perform a PSHA with the goal of narrowing the spectrum of possible estimates of hazard at a given site.

The project was carried by out a seven-member Senior Seismic Hazard Analysis Committee (SSHAC) supported by a large number other experts, who examined ways to improve on the state-of-the-art, the results of which are documented in NUREG/CR6372, 1997.

As a follow-up to the SSHAC study, the Trial Implementation project (TIP) made use of the SSHAC recommendations and developed a set of more detailed guidance for performing PSHA. The TIP project tested the more complicated issue of development of the seismic zonation and seismicity models. It was found that the uncertainty generated by artificial disagreements among experts can be considerably reduced through interaction and discussion of the available data and by identifying the elements common to all experts' interpretations. By concentrating on those elements, it was possible to develop a consensus of the group on the way to characterize them and eliminate large unnecessary differences. The TIP study considered two sites with different seismic environment in the Southeast U.S. Vogtle, in South Carolina, which is affected by the issue of the Charleston earthquake, and Watts Bar, close to the eastern Tennessee seismic zone (ETSZ) which is the theater of small to medium magnitude seismic events. The results of the TIP study (UCRL-ID-133494, 1998, NUREG/CR-6607) were found to be different from those of the 1993-EUS-Update study for the Watts Bar site.

This study compares the results of the 1993-EUS-Update and the 1998-TIP studies and identifies the reasons for the differences, which were found to be:

1. Differences in the ground motion (GM) attenuation models

2. The introduction of the Eastern Tennessee Seismic Zone (ETSZ) in the TIP study. 
It was found that these two factors accounted for a factor of 6 in the ratio of mean estimates PGA hazard at high GM levels as shown in figure I below. The agreement between the two studies improved at lower PGA values. The results were in better agreement and only differed by about a factor of two at high GM levels when the same GM model was used with each seismicity model . Finally, it was found that the composite rate of earthquakes around the Watts Bar site was about a factor of two higher for the TIP composite seismicity model than for the composite 1993-EUS-Update seismicity model.

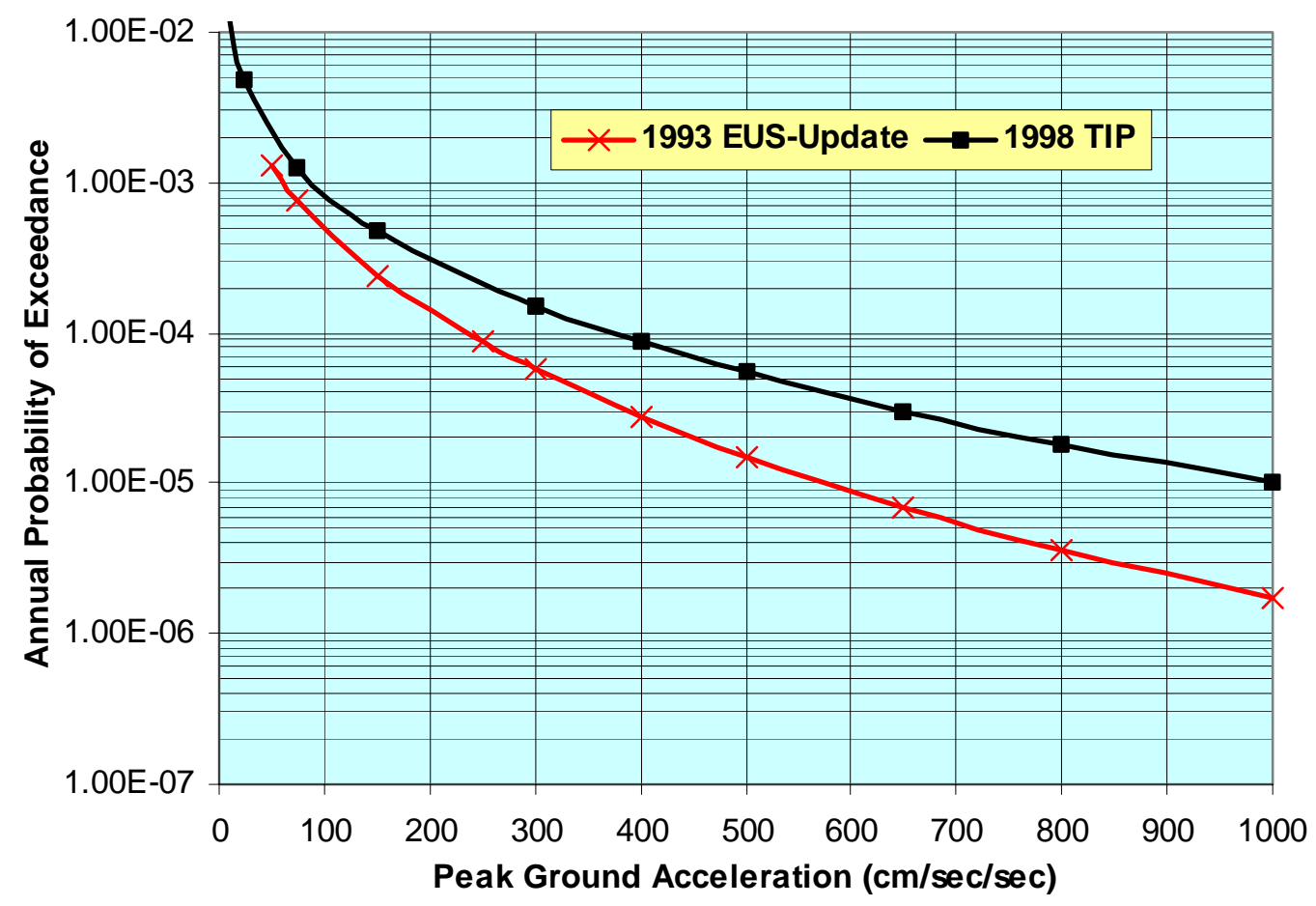

Figure I: Comparison of the Mean Estimates of the Seismic Hazard for the Watts Bar Site. The Curve with the Square Markers is for the Estimates of the 1998-TIP Study. The Curve with the Crosses is for the Estimates of the 1993-EUS-Update Study. 


\section{ACKNOWLEDGMENTS}

This project was sponsored by the U.S. Nuclear Regulatory Commission (NRC). The project manager for the NRC was Ernst Zurflueh, and Jean Savy led the project for Lawrence Livermore National Laboratory. Don Bernreuter, who has been working on these methodologies and specifically on the NRC projects at LLNL until 1994 did all the calculations and sleuthing for the sections 2 to 7. 
xix 


\section{INTRODUCTION}

\subsection{Background}

Probabilistic Seismic Hazard Analysis (PSHA) is a methodology that estimates the likelihood that various levels of earthquake-caused ground motion will be exceeded at a given location in a given future time period. Due to large uncertainties in all the geosciences data and in their modeling, multiple model interpretations are often possible. This leads to disagreement among experts, which in the past has led to disagreement on the selection of ground motion for design at a given site.

From 1981 to 1989, Lawrence Livermore National Laboratory (LLNL) developed for the Nuclear Regulatory Commission a method for performing PSHA in the eastern US with results documented in NUREG/CR-5250. Improvements in the handling of the uncertainties led to updated results documented in the 1993-EUS-Update study (NUREG1488.) These results presented substantial differences with the utilities sponsored study performed by the Electric Power Research Institute (EPRI.)

In 1994, in order to review the present state-of-the-art and improve on all the overall stability of the PSHA process, the U.S. Nuclear Regulatory Commission (NRC), the U.S. Department of Energy (DOE), and the Electric Power Research Institute (EPRI) cosponsored a project to provide methodological guidance on how to perform a PSHA.

The project was carried out by a seven-member Senior Seismic Hazard Analysis Committee (SSHAC) supported by a large number of other experts.

The SSHAC reviewed past studies, including the Lawrence Livermore National Laboratory and the EPRI landmark PSHA studies of the 1980's and examined ways to improve on the present state-of-the-art.

The Committee's most important conclusion was that differences in PSHA results are due to procedural rather than technical differences. Thus, in addition to providing a detailed documentation on state-of-the-art elements of PSHA, the SSHAC report (NRC 1997), provided a series of procedural recommendations. As part of the SSHAC effort, the recommendations of the SSHAC were partially tested in the development of a ground motion attenuation model for North America. That test had been selected because of the relative simplicity of formulation of the ground motion attenuation models. The issues to be discussed and the input to be generated is limited to the characterization of a few, well defined single parameters. In contrast to the case of the development of ground motion attenuation models, the development of seismic zonation maps involves the evaluation of multi dimensional data sets. The description of future seismicity through the use of seismic zonation maps and occurrence models are multiparameter models with very complex formulation and correlation structure.

Although the SSHAC did not test its recommendations on the development of zonation and seismicity models it was understood that the recommendations provided were general enough to apply to any problems in which it is important to characterize the epistemic uncertainty through the use of multiple experts inputs including for the case of seismic source zonation modeling. 
Under the TIP project (W6496, Testing and Implementation of SSHAC Guidelines), new expert elicitations and seismic hazard calculations were performed by Lawrence Livermore National Laboratory (LLNL) for the southeastern United States using the SSHAC guidelines. Included in the study were site-specific hazard evaluations for the Savannah River and Eastern Tennessee areas. It was found that, for the Eastern Tennessee area, the hazard in terms of annual probability of exceedance was several times larger than that of the previous regional LLNL hazard estimates for the central and Eastern U.S. (CEUS) (1993-EUS-Update study).

This observation emphasizes the importance of conducting site-specific hazard assessments, for instance for plant site investigations. Because a part of Eastern Tennessee Seismic Zone (ETSZ) was included in the specific location for which a hazard value was derived, the question of using an exclusion zone, as in Appendix A siting regulations, arises.

\subsection{Purpose of the study, scope}

The results of the testing and implementation project have raised several questions that need to be resolved. This study investigates the causes of differences in probabilistic hazard estimate between the 1998-TIP and the 1993-CEUS-Update studies:

(a) It evaluates the validity of the new results, which may be affected by the replacement of the ETSZ boundaries, the seismicity rates in the subunits of the ETSZ, and the choice of the ground motion attenuation parameters;

(b) It compares the two studies and identifies the reasons for the differences; and

(c) It performs sensitivity studies to isolate the parameters responsible for the differences. 


\section{DIFFERENCES IN HAZARD ESTIMATES}

The 1993-EUS Update Study was actually an update of the 1989 study performed by LLNL for the NRC (Bernreuter et.al. 1989). The seismic zonation models were developed by sampling the interpretations of 11 experts and the ground motion attenutations were developed by sampling a set of 8 ground motion experts. In 1992, LLNL performed a new PSHA for the Savannah River Site (SRS), located at the boundary between South Carolina and Georgia. The concept of a composite ground motion, model was developed for SRS and applied to the entire EUS. These results are summarized in Figure 2.1.

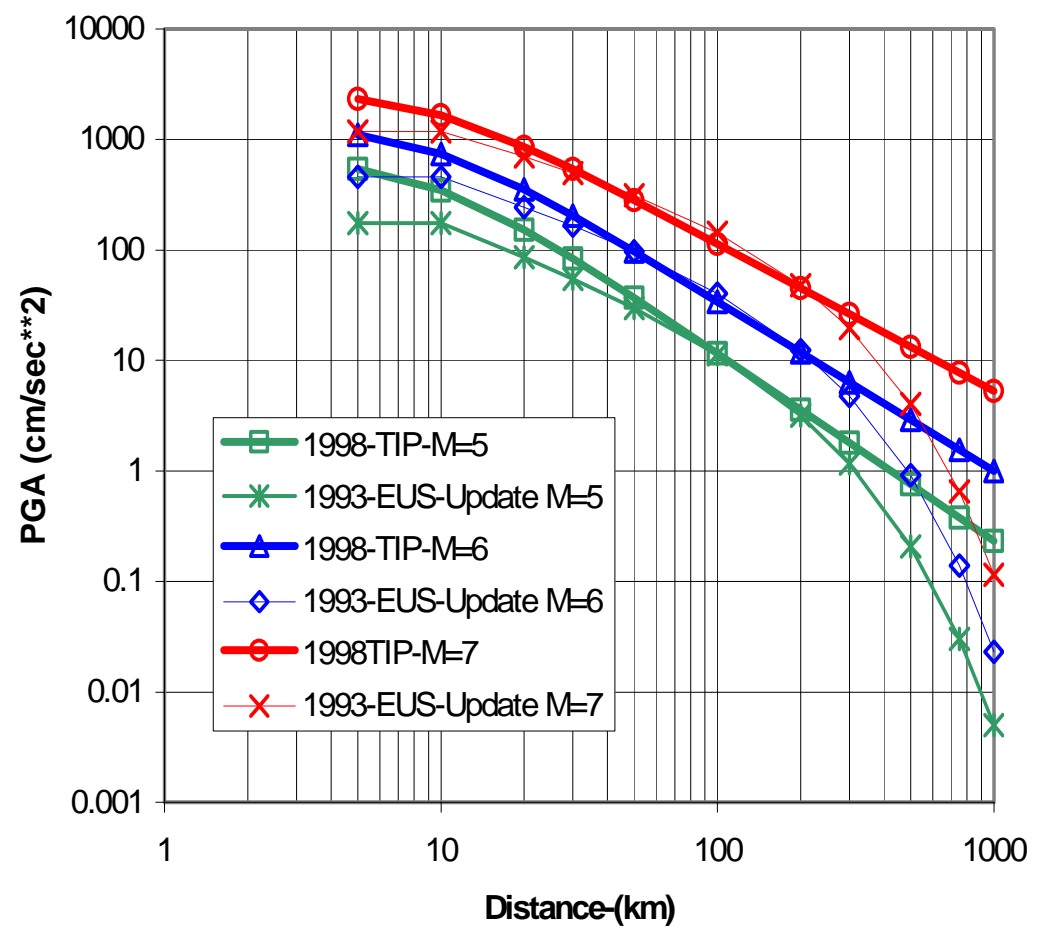

Figure 2.1: Mean PGA hazard estimates for Watts Bar

The development of the composite ground motion model was based on sampling the interpretation of the GM experts and generating an artificial data base of estimates of ground motion for many pairs of distances and magnitudes. The epistemic uncertainty was included by including the full distributions of possible models for each expert, and the physical correlation was modeled by preserving the correlation observed in the original models in the final composite model. The elicitation of the experts' interpretation was performed according to a process which in large part became the process adopted by 
SSHAC. It had all the essential elements that constitute the SSHAC recommendations. This composite model was very different from the GM models used in the previous NRC study (Bernreuter et al. 1989) and warranted a re-estimation of the seismic hazard at the 69 EUS sites. The 1993-EUS-Update, then essentially used the same seismic zonations as the 1989 study, but it used the newly developed SRS/EUS composite GM model, and in addition all of the seismicity experts' estimates of the seismicity rates were re-evaluated, with new elicitation of the experts' interpretations, to eliminate the unrealistic seismicity which had been identifed for some of the zones of the 1989 study.The TIP study was performed later, to demonstrate that SSHAC principles could also be applied to the seismic zonation and seismicity modeling.

Figure 2.1 shows the final estimates of the mean annual probability of exceedance (APE) of the Peak Ground Acceleration (PGA) for the 1993-EUS-Update and 1998 TIP studies. At higher PGA values $\left(1000 \mathrm{~cm} / \mathrm{sec}^{* * 2}\right.$,) the APE from the 1998-TIP study is about a factor of six higher than for the 1993-EUS-Update study. However, at low PGA values $\left(100 \mathrm{~cm} / \mathrm{sec}^{* * 2}\right)$ the results from the two studies are in better agreement (a factor of 1.6).

Similarly, Figure 2.2 gives a comparison between the median APE. In this case there is over a factor of 10 differences between the two studies at high PGA values and a factor of 2.5 at $100 \mathrm{~m} / \mathrm{sec}^{2}$. Comparisons between other hazard estimators show similar differences. Figure 2.3 shows the comparison between the best estimate (BE) hazard curves from the two studies. The BE estimator is not a true statistical estimator. The so termed $\mathrm{BE}$ hazard curve is based on using only the mode of the probability distribution of each of the seismicity continuous parameters (such as rate, upper bound magnitude) and the highest weighted zonation map.

Figures 2.1 to 2.3 show consistently that there is a significant difference in the estimation of the seismic hazard between the two studies at long return periods. Since the Hazard calculation algorithms were common to the two studies, the reasons for these differences lie in the actual inputs to the calculations. The possible causes of differences in the APE estimates are listed below:

- Differences in ground models including uncertainty modeling.

- Differences in seismic zones.

- Differences in the estimation of the rates of occurrence of earthquakes ( $a$ and $b$ values) and independent estimates for discrete magnitudes.

- Differences in the estimation of the upper bound magnitudes.

- Differences in the uncertainty modeling.

In the following sections we examine these issues and their impact on the estimation of the seismic hazard at the Watts Bar site and conclusions are drawn on the causes of differences.

It is interesting to note the hazard estimates from the two studies are in reasonable agreement at return periods of less than 1000 years (PGA levels less than $0.1 \mathrm{G}$ ) where 


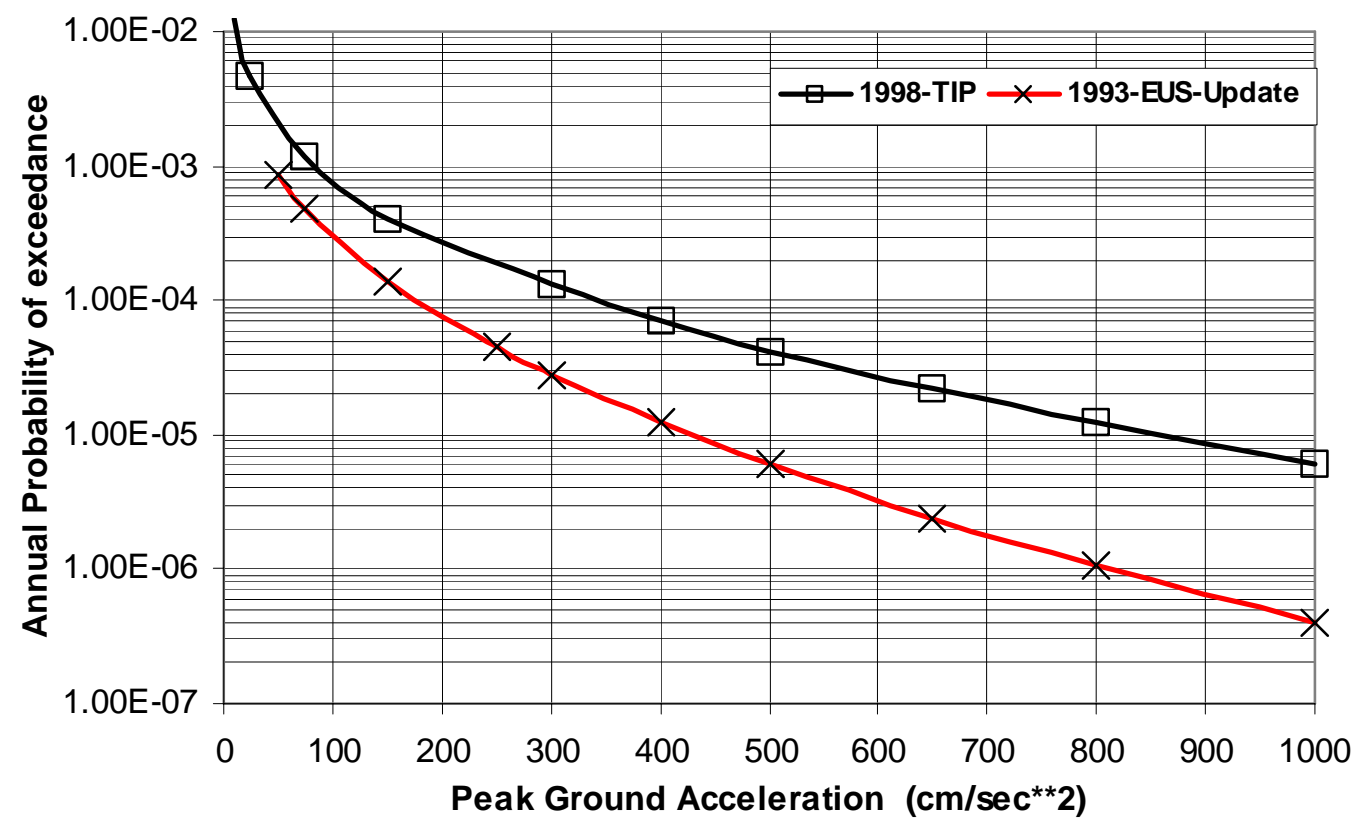

Figure 2.2: Median PGA hazard estimates for Watts Bar

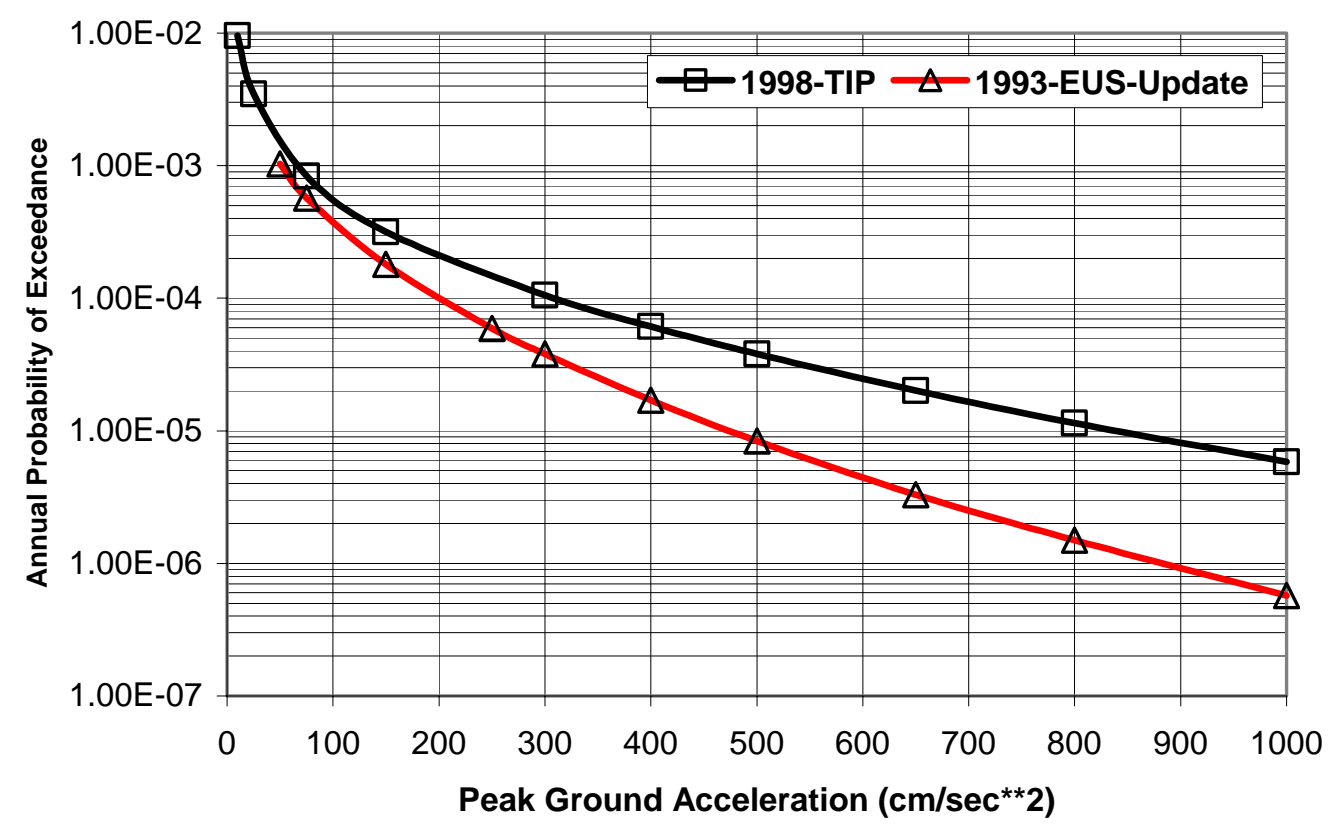

Figure 2.3: "Best Estimate" PGA hazard for Watts Bar 
estimates are primarily controlled by the data rather than by predictive models, which inherently include greater uncertainties for lack of sufficient data. At long return periods (PGA levels greater than $0.5 \mathrm{G}$ ), the estimates are controlled as much by the uncertainty models as by the historical seismicity data. 


\section{IMPACT OF THE GROUND MOTION MODELS.}

\subsection{Direct Comparison of the Ground Motion Models Used in the Two Studies}

Two different composite GM models were used in the two studies. For ease of reference, the GM model in the TIP study is referred to as the 1998-TIP GM model, and 1993-EUSUpdate GM model for the other study. Let's first examine the two GM models in terms of estimates of PGA for given pairs of magnitudes and distances. Figure 3.1a shows a comparison between the median estimates of ground motion for three magnitudes and a range of distances between 5 and $100 \mathrm{~km}$. The 1993-EUS-Update model had a built-in saturation at $10 \mathrm{~km}$, meaning that the median estimates of the PGA ground motion for distances less than $10 \mathrm{~km}$, is equal to its value for $10 \mathrm{~km}$.

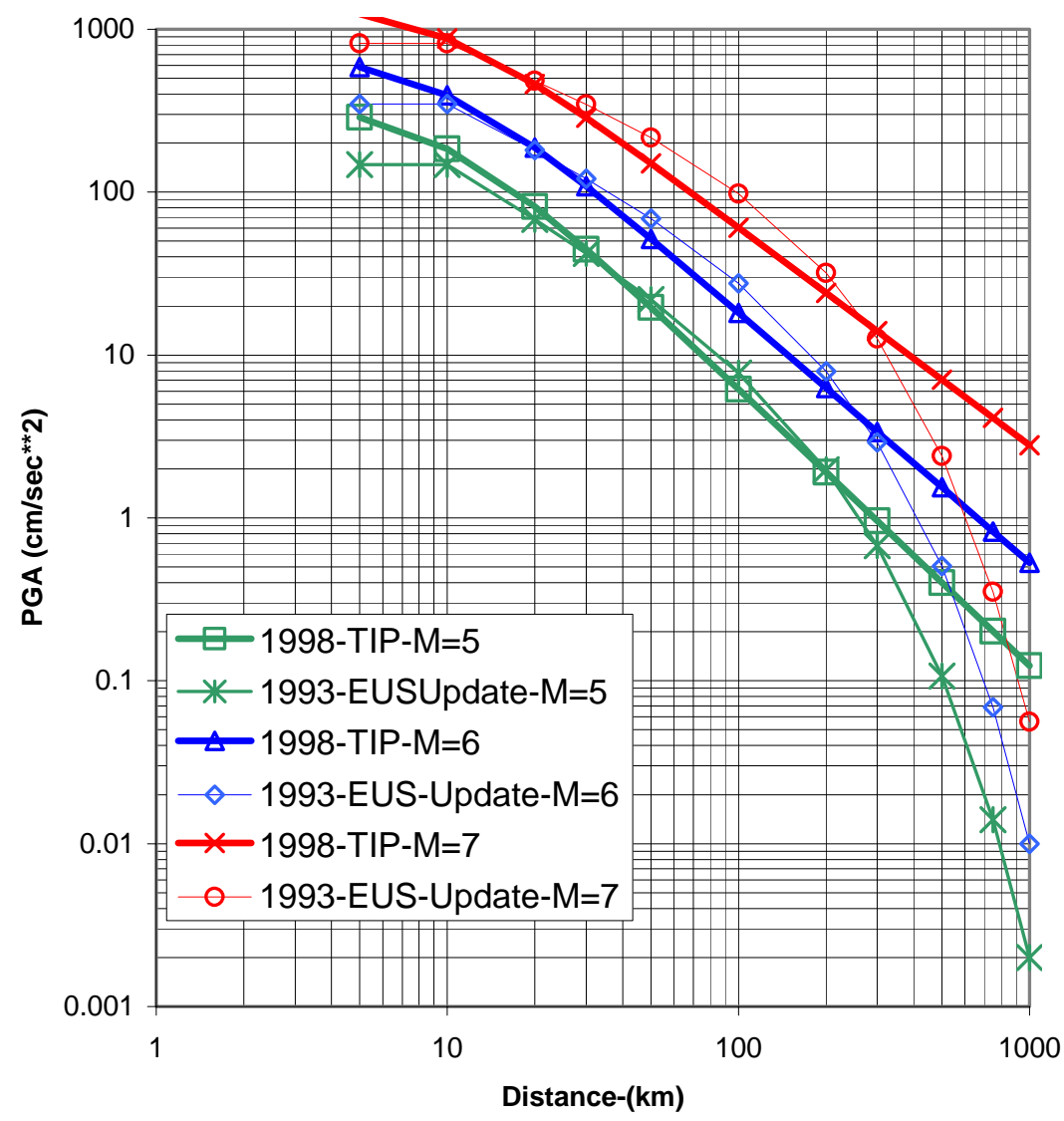

Figure 3.1a: Comparison of the median Ground Motion Attenuation Models for the 1993-EUS-Update and 1998-TIP studies for Magnitudes 5, 6 and 7. 
These estimates are shown to be in reasonable agreement for distances between $10 \mathrm{~km}$ and $100 \mathrm{~km}$, which is the range of distance in which fell most of the available data at the time of the two studies. For distances smaller than $10 \mathrm{~km}$, the saturation imposed on the 1993-EUS-Update model makes it lower than the other model. That area immediately around the site generally does not contribute enough seismicity to have an impact on the total hazard.

The epistemic uncertainty in the 1998-TIP study was included by providing a probability distribution function on the standard deviation on the Natural logarithm $(\sigma)$, with a minimum bound of 0.36 , a mode of 0.63 (also labeled BE, for "Best Estimate") and an upper bound of 0.94 .

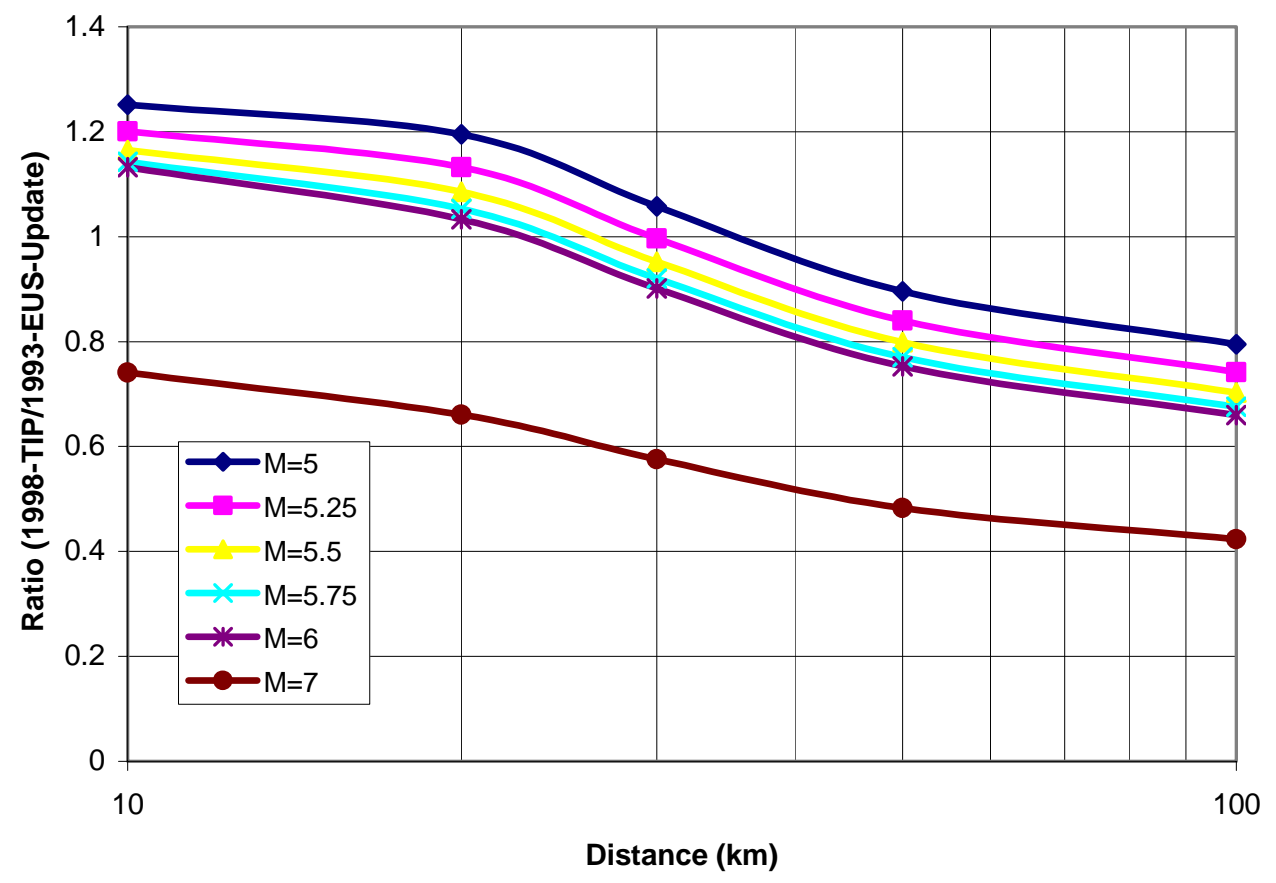

Figure 3.1b: Ratios of the median PGA estimates from the 1998-TIP study, divided by the 1993-EUS-Update median estimates, as a function of distance.

The 93-EUS-Update GM model was developed by combining the inputs of 8 GM Experts and using a simulation process to include their complete uncertainty. The experts input was in the form of estimates of the probability distribution function of the ground motion (PGA or PSV) at the sites for a selection of distances and magnitudes. The resulting model was obtained as an empirical distribution of several of the percentiles (A different empirical model for each percentile.) 
By contrast, the 1998-TIP model used a similar approach with the inputs from 5 GM experts. It assumed that the probability distribution function of GM, for a given magnitude and distance is log-normal, with a given median and $\sigma$, the standard deviation of the $\log (\mathrm{GM})$. Thus, when comparing the two models, it is important to refer to the appropriate percentiles. For example, in this study, at times, the medians are compared, i.e. the $50 \%$ percentile model for the 1993-EUS-Update and the "mean attenuation" for 1998-TIP. Similarly at other instances the $85^{\text {th }}$ percentile 1993-EUS-Update, and the (mean $+1 \sigma)$ values are computed.

To directly compare the 1998-TIP model to the 1993-EUS-Update model would have required us to run a simulation over the range of sigma then develop the percentiles. We did not attempt to carry out this simulation. The effect of the relative difference between the two models is shown in Figure 3.2a where we compare the 1-sigma value of the 1998-TIP GM model using the BE estimate for sigma (0.63) to the 85 percentile estimate for PGA from the 1993-EUS-Update GM model.

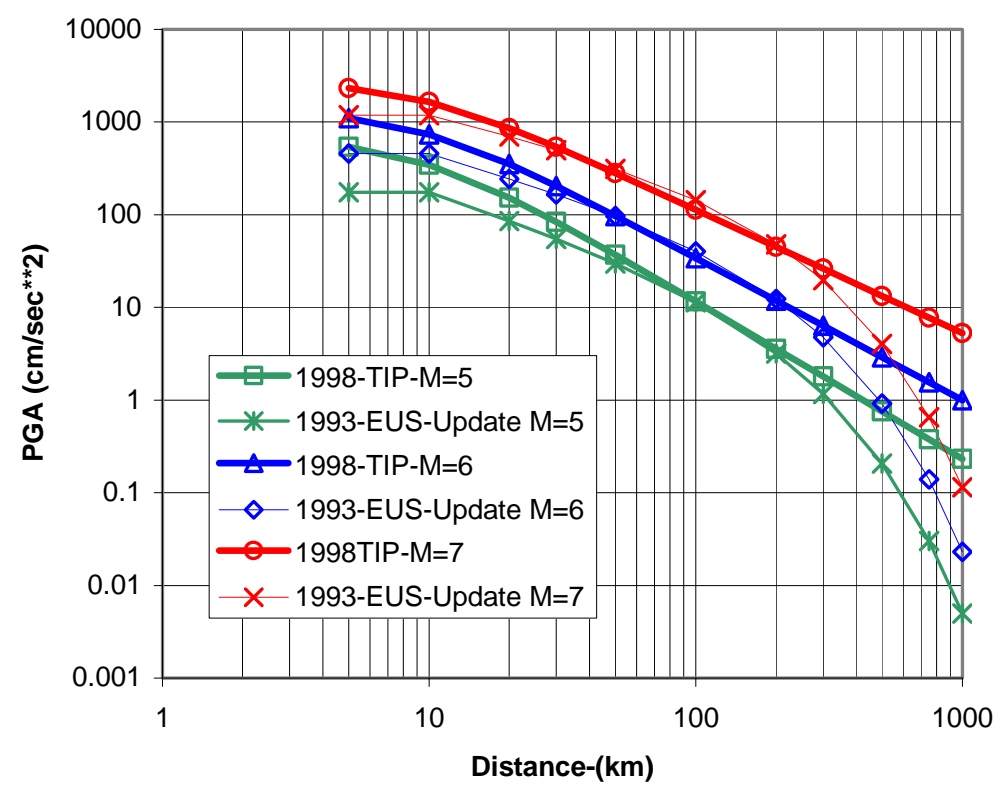

Figure 3.2a Comparison between the 1-sigma 1998-TIP and the 85\% 1993-EUS Update Ground Motion Attenuation models.

Figure $3.2 \mathrm{~b}$ shows clearly the relative impact of the two models for the range of conservatism frequently used in seismic design parameters. It shows the ratio of GM estimates (1998-TIP/1993-EUS-Update) at the $85^{\text {th }}$ percentile level, between 10 and 100 $\mathrm{km}$ of distance and for magnitudes between M5 and M7. 


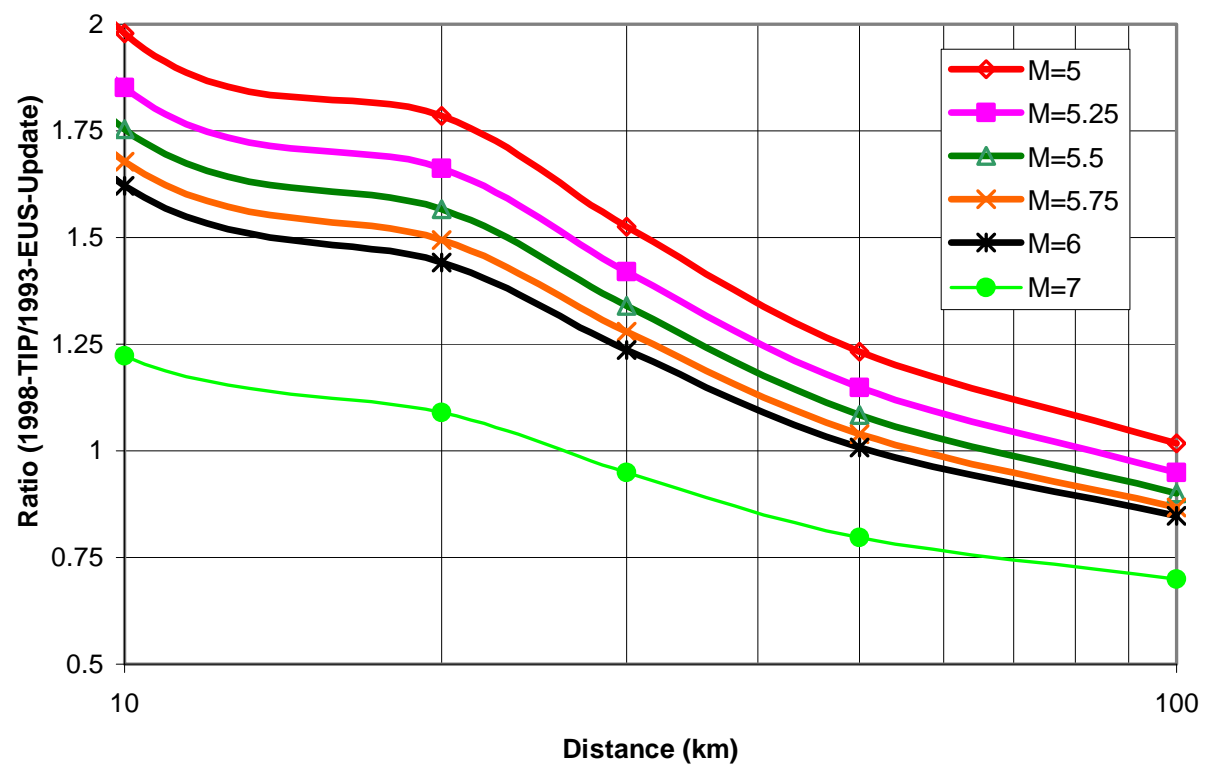

Figure 3.2b: Ratios of the 1-sigma PGA estimates from the 1998-TIP study, divided by the 1993-EUS-Update median estimates, as a function of distance.

In the magnitude range of 5-6 and distance ranges 0-30km Figure $3.1 \mathrm{~b}$ shows that the 1998 TIP GM model gives higher PGA estimates than the 1993-EUS-Update GM model. A strict comparison of the two simulated distributions could probably have led to slightly different observations. This would have made the differences between the two models even larger in the most-important range of magnitudes between 5 and 6 .

Comparing Figure 3.1b with 3.2b, shows that the total uncertainty is larger for the 1998TIP than for the 1993-EUS-Update GM model, since the aleatory uncertainty was in the same order of magnitude, the observation shows that the epistemic uncertainty was higher in the 1998-TIP the in the 1993-EUS-Update study.

\subsection{Comparison of the Hazard Estimates}

In order to understand better how the GM model affects the results, it is necessary to determine the magnitude and distance range that contribute most to the estimates of the hazard as shown in Figures 3.3,3.4 and 3.5 for the 1998-TIP study. 


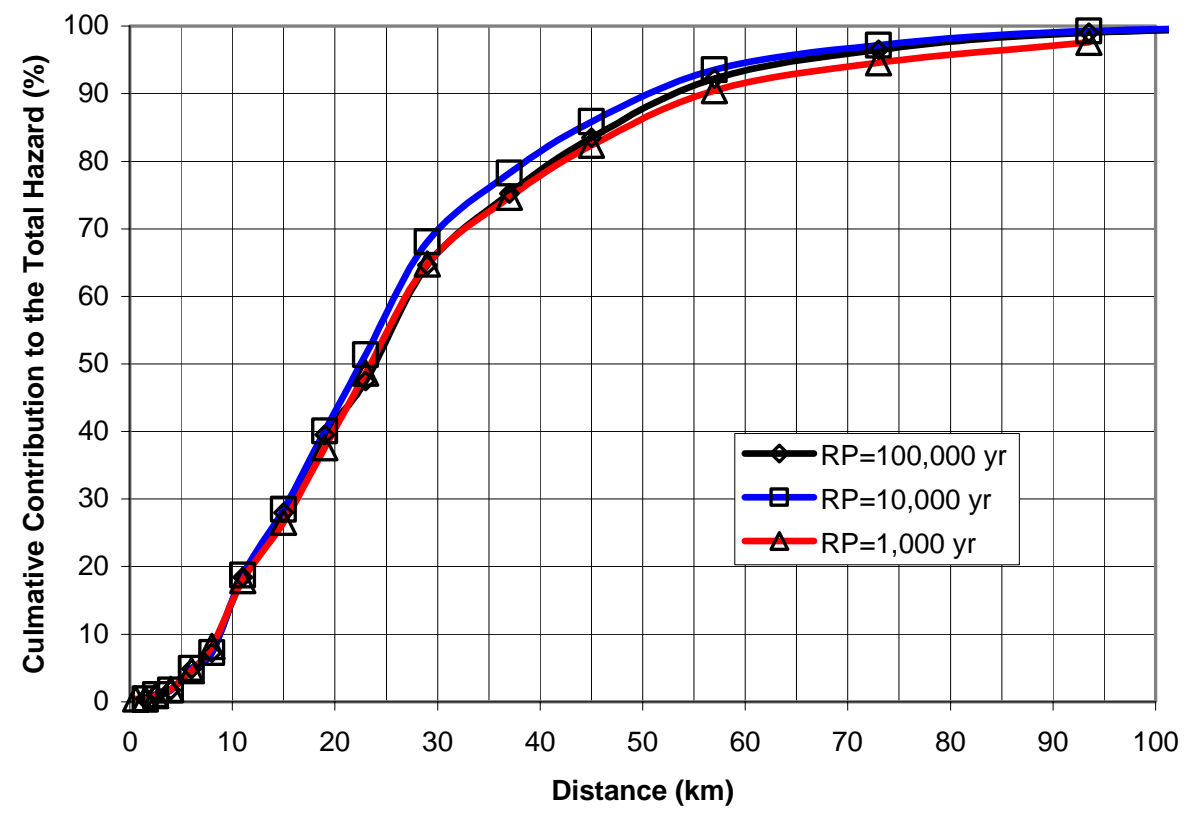

Figure 3.3: Cumulative Contribution of the Distance bins to Hazard in the 1998-TIP Study. Seismic Source Zones within $40 \mathrm{~km}$ of Watts Bar Contribute approximately $80 \%$ of the Total Hazard.

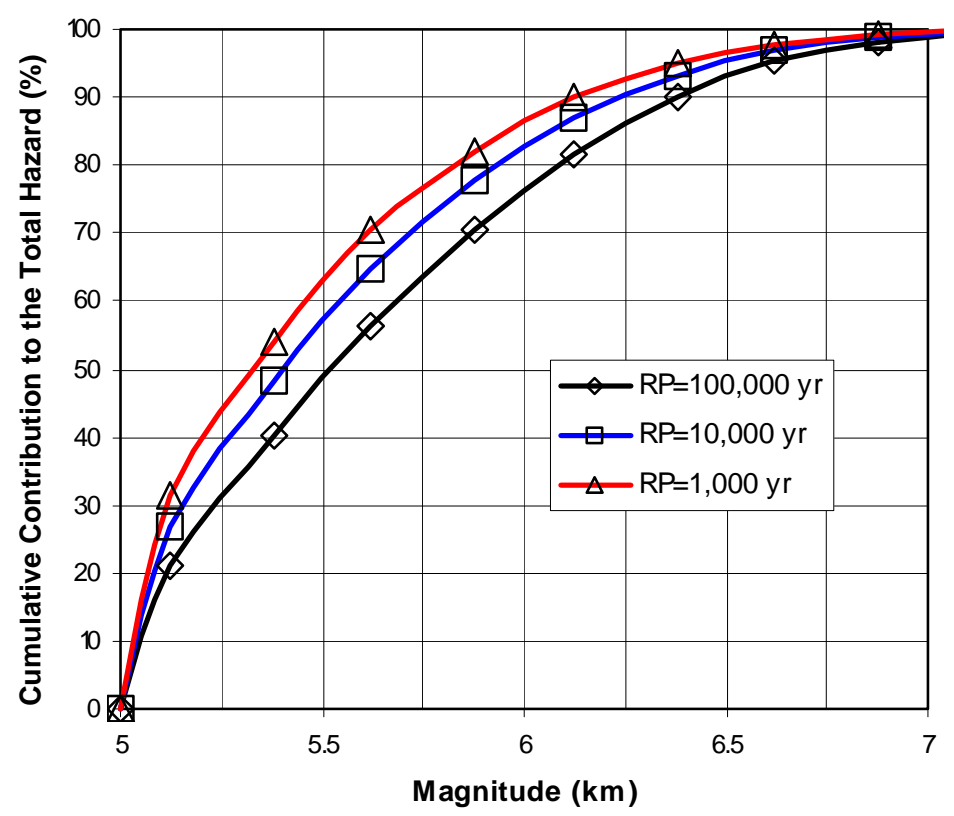

Figure 3.4: Cumulative Contribution of the Magnitude bins to the Hazard in the 1998-TIP Study. Magnitude Events Smaller than 6 Contribute approximately 80\% of the Total Hazard. 


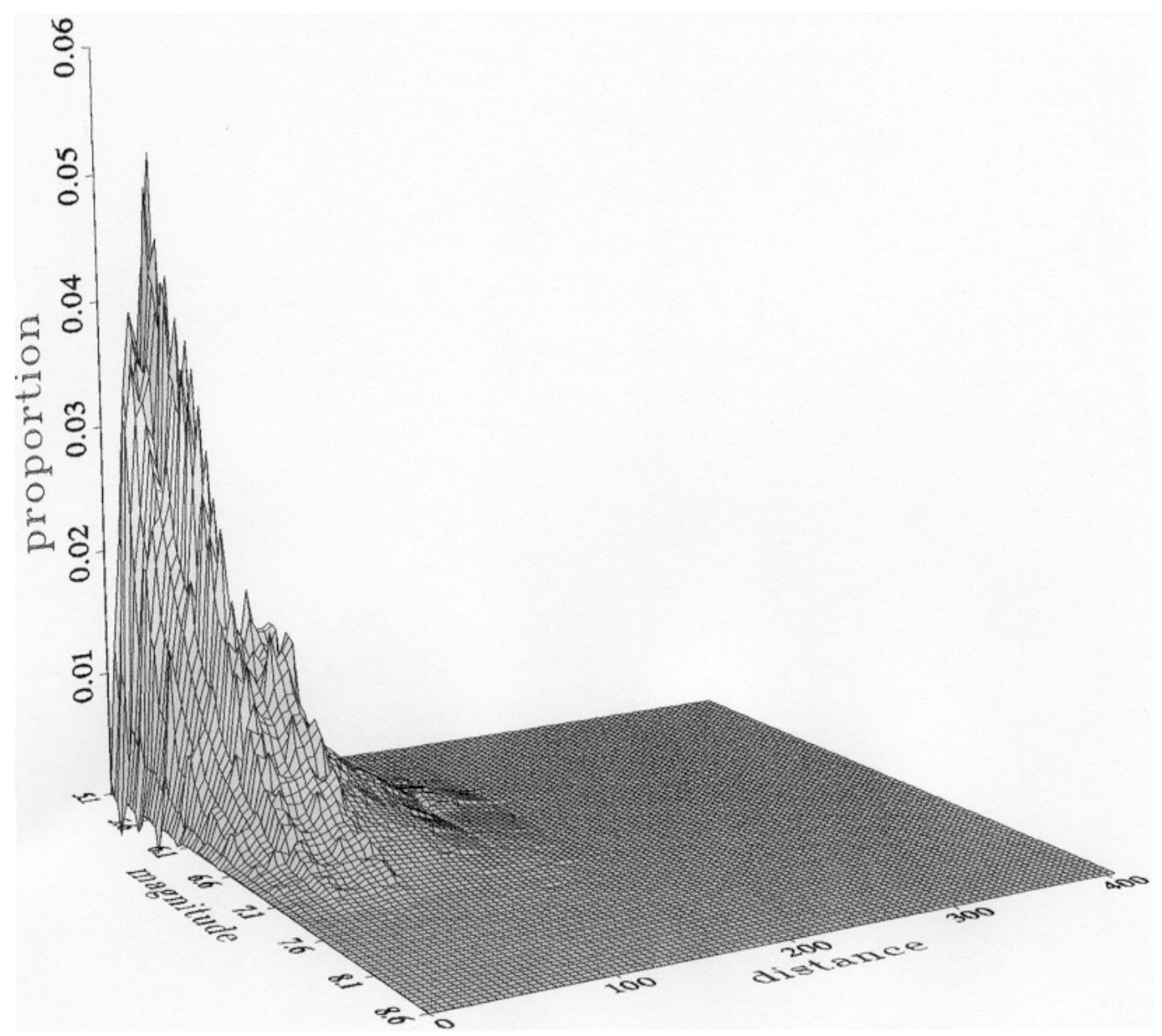

Figure 3.5: Contribution of the Magnitude-Distance bins to the Total Hazard for a 10,000 Year Return Period

These figures show that 80 percent of the hazard comes from the distance range $0-40 \mathrm{~km}$ and a magnitude range 5-6. Which was shown in Figure 3.2 to be the region where the two GM models significantly differ. In addition, the uncertainty on sigma for the 1998 TIP GM model would also increase the differences between the two GM models. Thus, everything else being equal, it is expected that the two GM models would lead to potentially different hazard results with higher estimates for the 1998-TIP GM model. 


\subsection{Sensitivity to the Ground Motion Models}

Using a common zonation and seismicity model, namely the 1998-TIP model, the hazards estimates are compared directly in terms of the mean hazard curves, in Fig 3.6, and the median hazard curves in Fig 3.7, for both 1998-TIP and 1993-EUS-Update GM models.

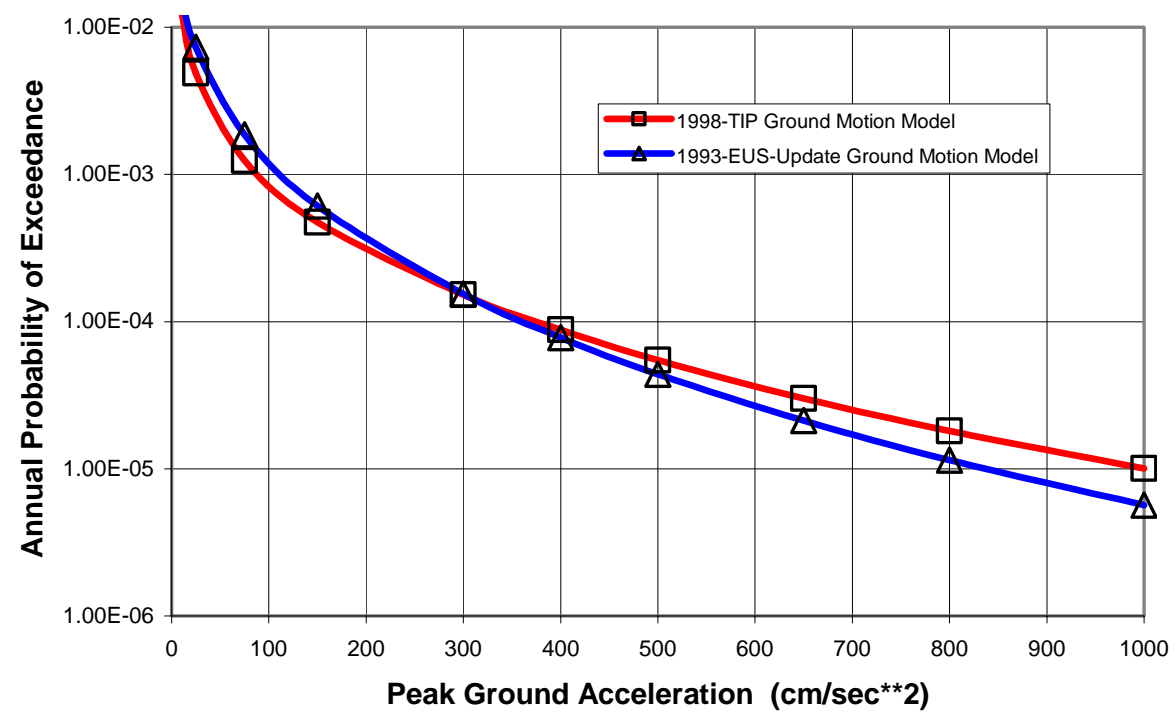

Figure 3.6: Estimates of the Mean Hazard using the 1998-TIP Seismic Zonation. Comparison between the 1993-EUS-Update and 1998-TIP Ground Motion Attenuation Models.

Similarly, Figures 3.8 and 3.9 compare the mean and median hazard curves using the 1993-EUS-Update zonation and seismicity alternatively the TIP and 1993-EUS-Update GM models. 


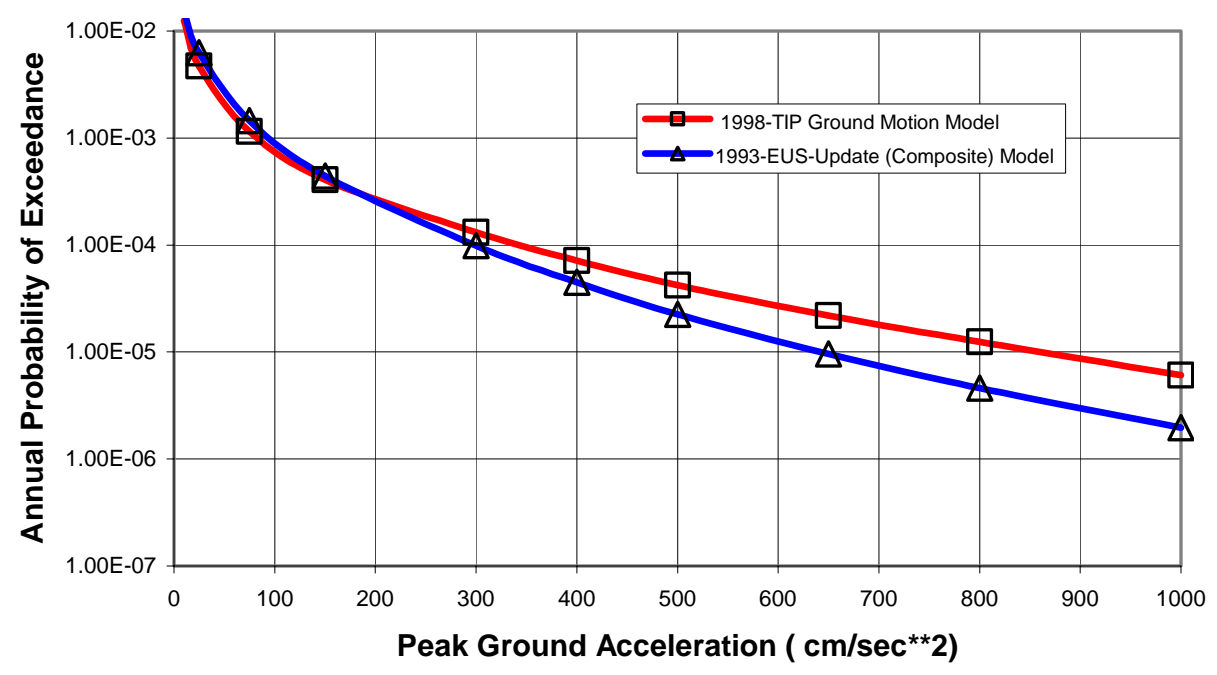

Figure 3.7: Estimates of the Median Hazard using the 1998-TIP Seismic Zonation. Comparison between the 1993-EUS-Update and 1998-TIP Ground Motion Attenuation Models.

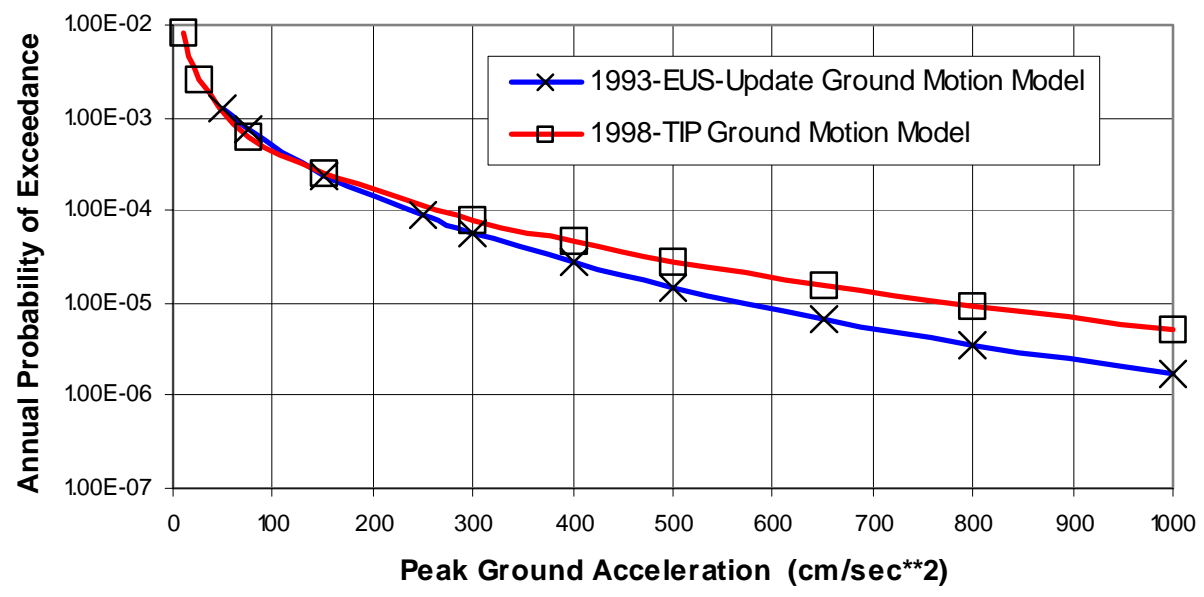

Figure 3.8: Estimates of the Mean Hazard using the 1993-EUS-Update Zonation . Comparison between the 1993-EUS-Update and 1998-TIP Ground Motion Attenuation Models. 


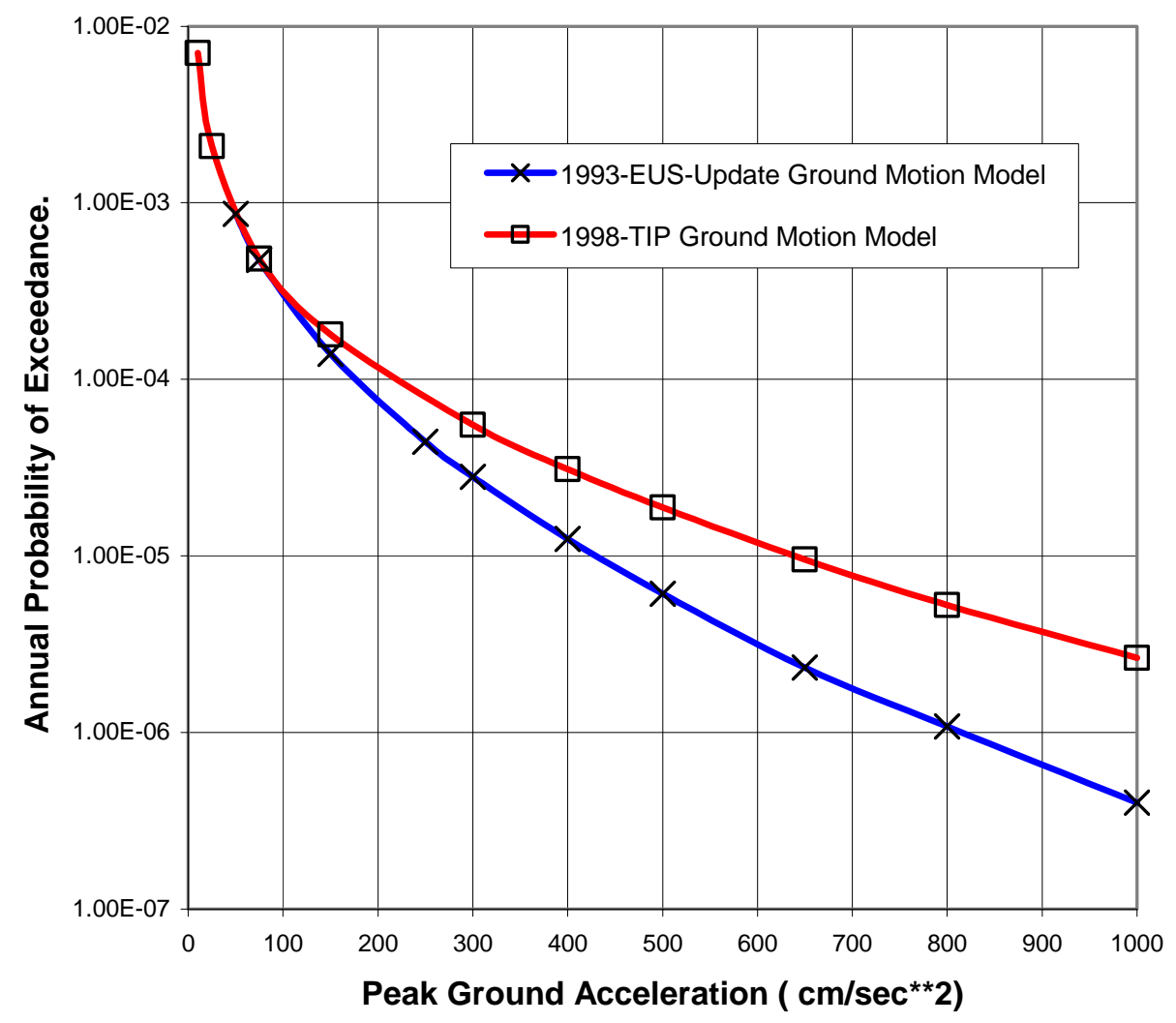

Figure 3.9: Estimates of the Median Hazard using the 1993-EUS-Update Seismic Zonation. Comparison between the 1993-EUS-Update and 1998-TIP Ground Motion Attenuation Models.

Figures 3.6 to 3.9 show that, as expected, changing GM models has a significant impact on the hazard. It is interesting to note that the difference in the hazard estimates is larger for the median hazard estimate than for the mean hazard estimate. The impact of the GM model is less for smaller PGA values than larger PGA values. Lastly, it is observed that the effect of changing GM models is larger for the 1993-EUS-Update seismicity model than for the 1998-TIP seismicity model. This last observation is consistent with the fact that the 1993-EUS-Update study had larger, area source zones including the Watts-Bar site, whereas the 1998-TIP study had smaller zones and local faults, further from the site. In the latter, the seismicity appeared to be restrained to be more distant from the site. 
Figure 3.10 shows the contribution of magnitudes to the mean and median hazard curves at PGA levels of 150 and $1000 \mathrm{~cm} / \mathrm{sec}^{* * 2} 2$ for the Watts Bar site using 1998 TIP seismicity and the 1998 TIP GM model.

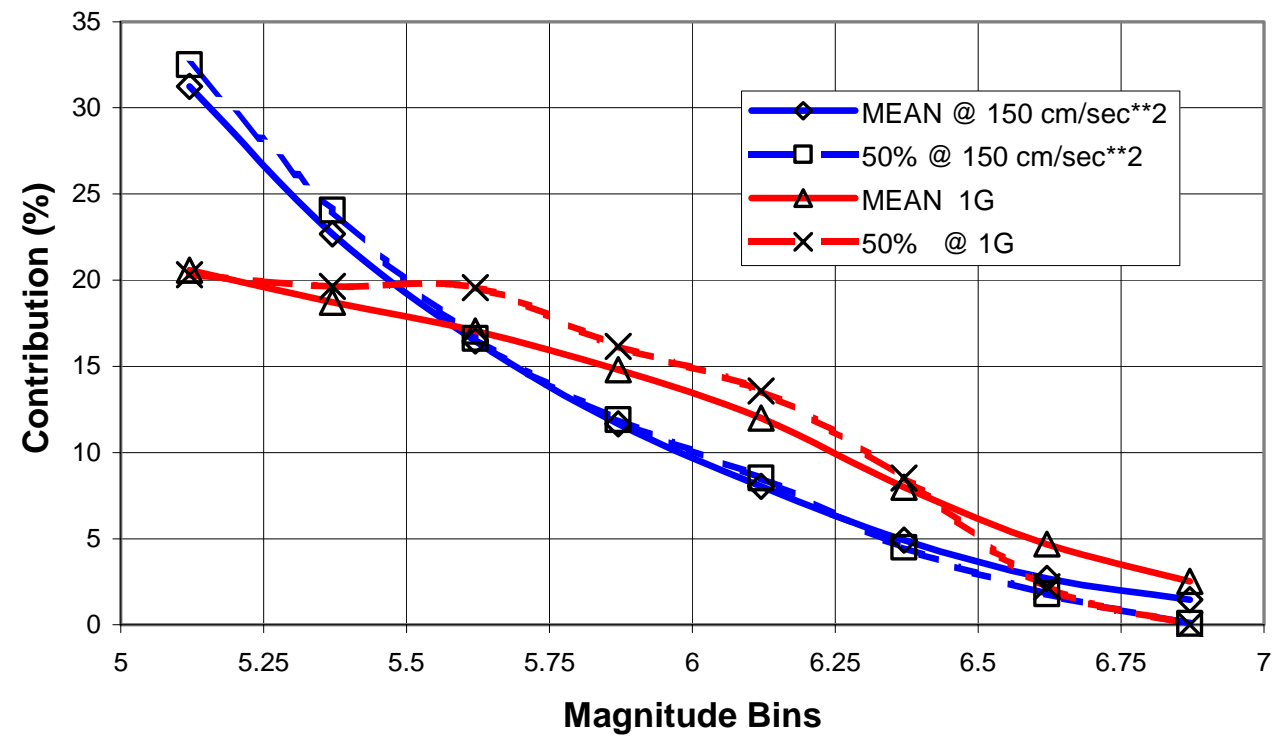

Figure 3.10: Contribution of Magnitude Bins to the Total Hazard in the 1998-TIP Study for Two Peak Ground Acceleration Levels.

A similar comparison, using 1993-EUS-Update is difficult because there are 11 seismic zonation and seismicity models and some sort of averaging would be required. However, it was found that Expert 3 (Bollinger) results were a good proxy representation of the combined 1993-EUS-Update results as shown in Figure 3.11. Based on this figure, we conclude that for the needs of this study, Expert 3's seismicity model is a reasonable proxy model for the 11 1993-EUS-Update Experts. Figure 3.12a shows results similar to those shown in Figure 3.10 but based on Expert 3's seismicity model. 


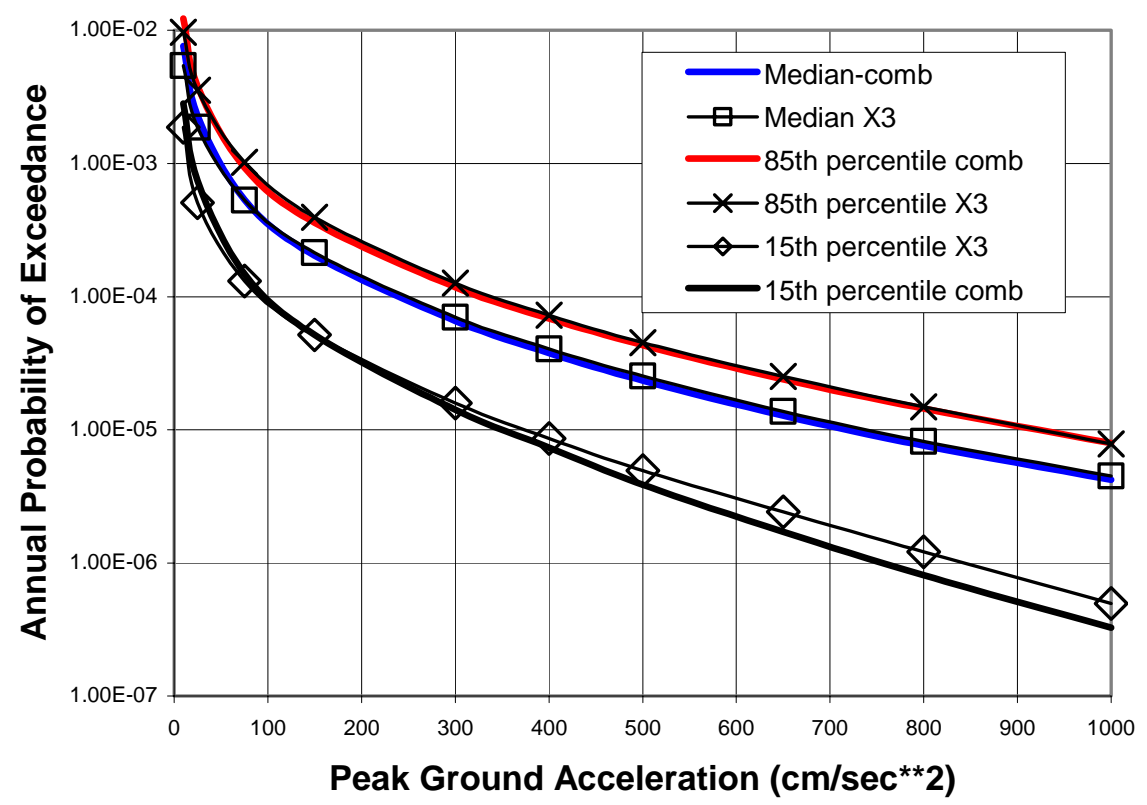

Figure 3.11: Results of the 1993-EUS-Update Study. Comparison of the Mean Estimates of the Hazard between the 11 Experts (comb) and Expert 3 (X3).

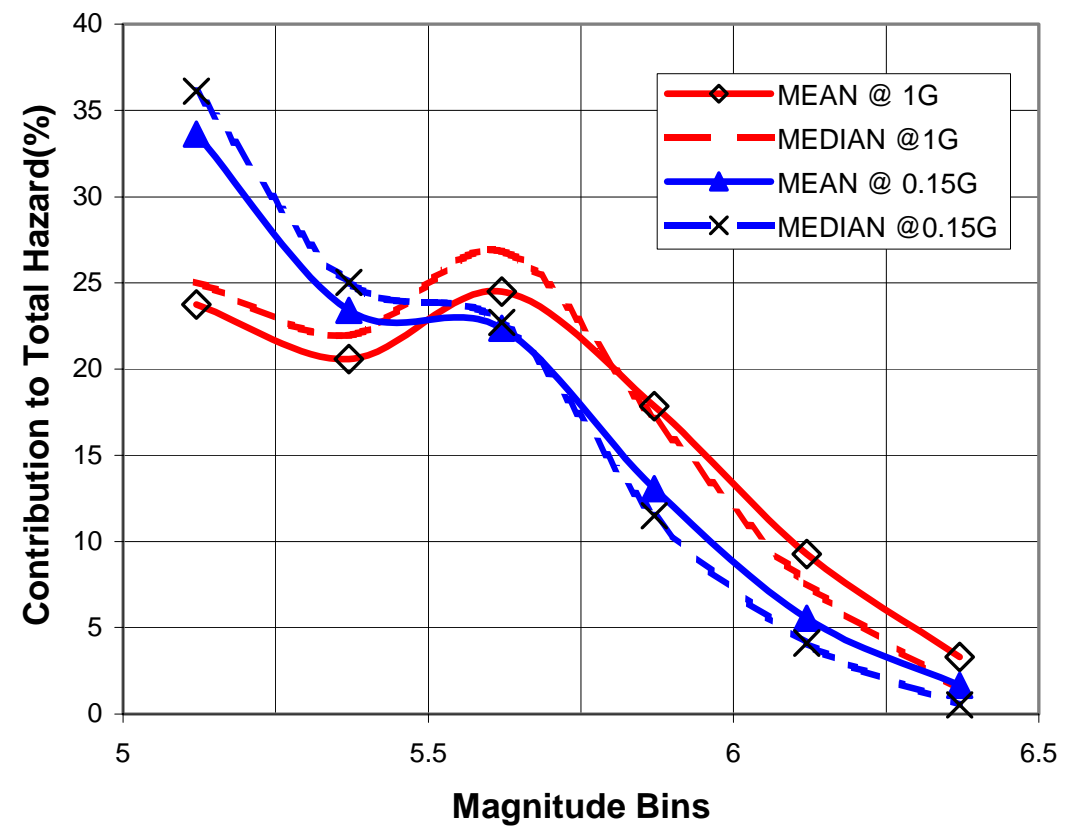

Figure 3.12a: Contribution of Magnitude Bins in the 1993-EUS-Update Study for Two Peak Ground Acceleration Levels for the case of Expert 3. 
Figure $3.12 \mathrm{~b}$ shows a comparison of the contribution to the hazard for $1 \mathrm{~g}$ PGA, from Figures 3.10 and $3.12 \mathrm{a}$.

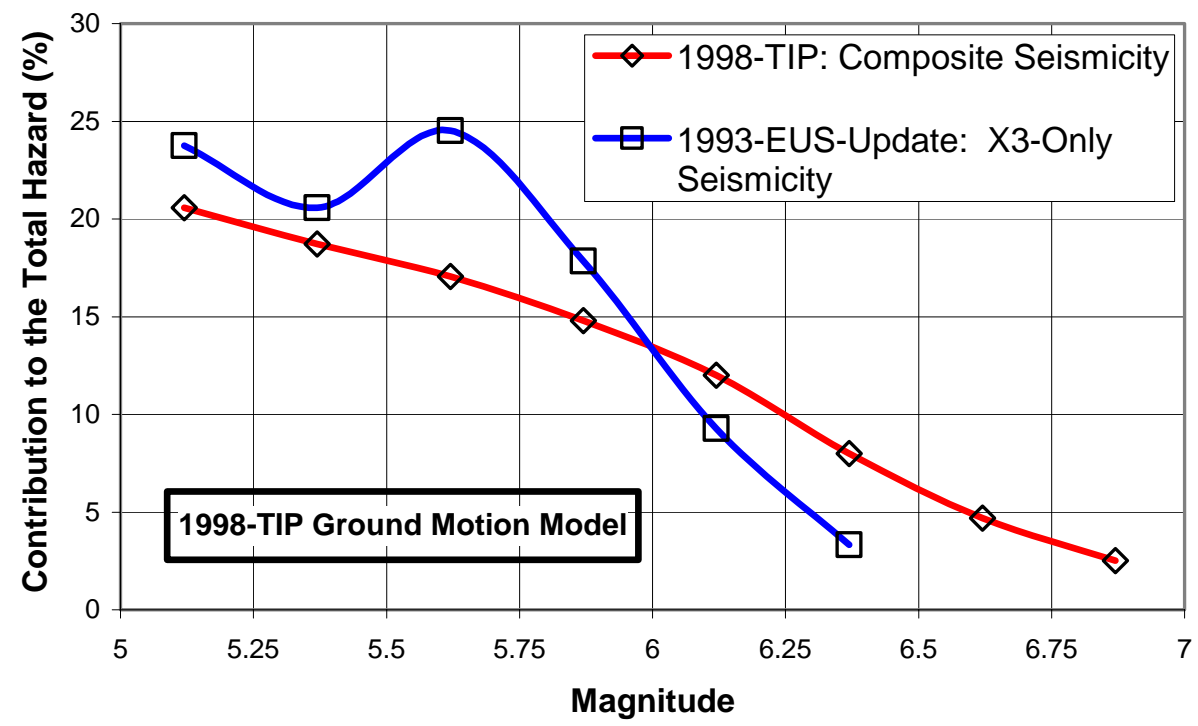

Figure 3.12b: Comparison of the Magnitude Contributions for a 1g PGA using the 1998-TIP ground Motion Model. The Seismicity of Expert 3 (X3) leads to a strong mode at M5.6 and the 1998-TIP Composite Seismicity leads to a monotonically decreasing contribution.

Figure $3.12 \mathrm{a}$ is similar to Figure 3.10 but shows that earthquakes in the magnitude 5.5 range contribute more to the hazard. This is also apparent in Figure 3.12b. Thus, we might expect that the change in the GM model would have more effect for the 1993EUS-Update seismicity case than for the 1998-TIP case, as seen in Figures 3.8 and 3.9.

\subsection{Sensitivity to the Seismic Zonation and Seismicity Models}

Figure 3.13 compares the mean hazard curves for the case of 1998-TIP seismicity and GM model to the case of the 1993-EUS-Update seismicity and the 1998-TIP GM model. This figure shows the 1998-TIP results to be a factor of two greater than with the 1993EUS-Update seismicity, as compared to a factor 6 observed from Figure 2.1 when different GM models were used.

Figure3.14 compares the median hazard curves between the case of 1998-TIP seismicity and 1998 TIP GM model to the case of the 1993-EUS-Update seismicity and the TIP GM 
model. We see from this figure that the difference between the two hazard curves is about a factor of 2.3 as compared to a factor of 10 observed in Figure 2.2. When the same GM model is used the two sets of seismicity models, the difference between the two studies is greatly reduced.

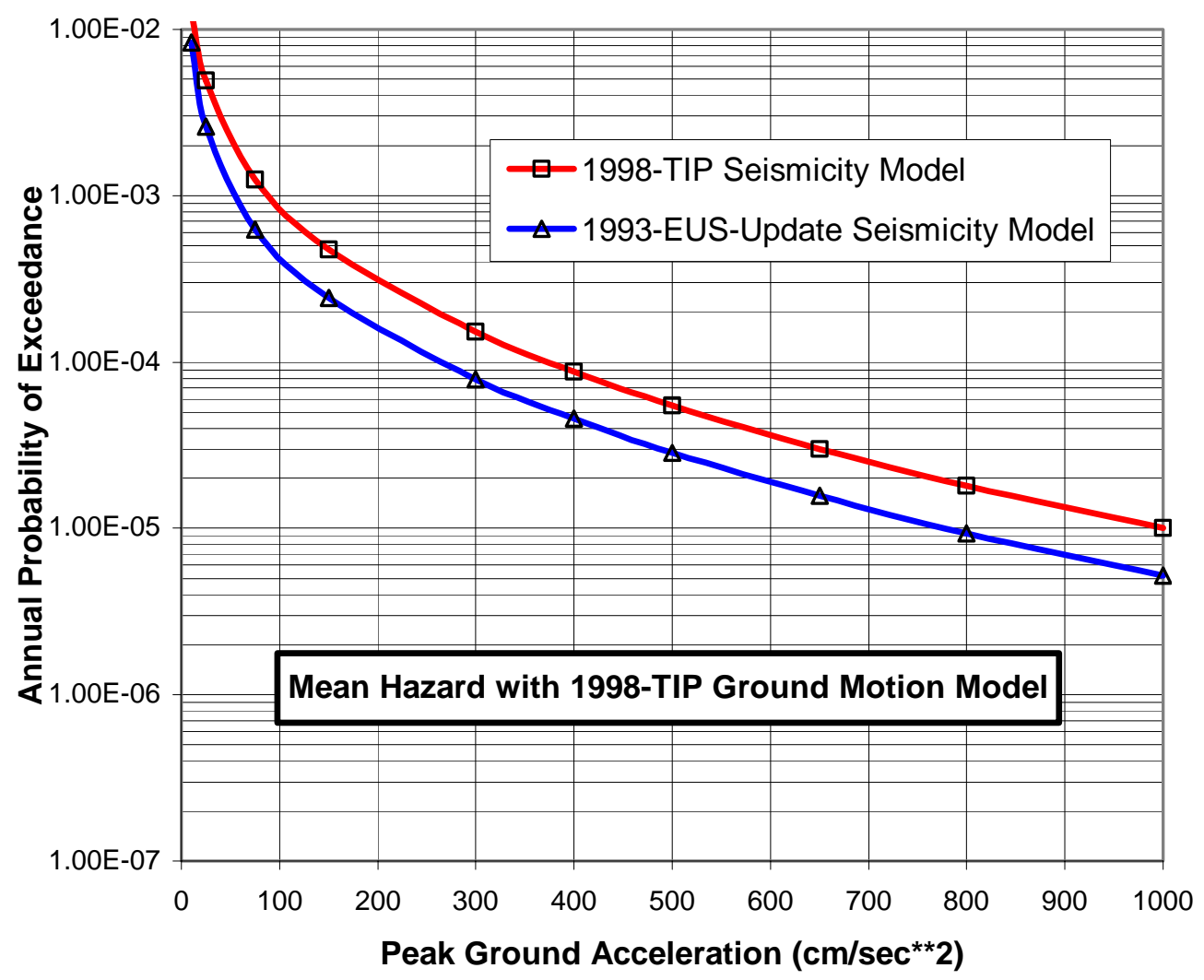

Figure 3.13: Sensitivity to the Seismicity and Zonation Model . The Two Curves Represent the Mean Hazard Estimated with the 1998-TIP and with the 1993-EUSUpdate Seismicity-Zonation Models. Both are with the same 1998-TIP Ground Motion Attenuation Model. 


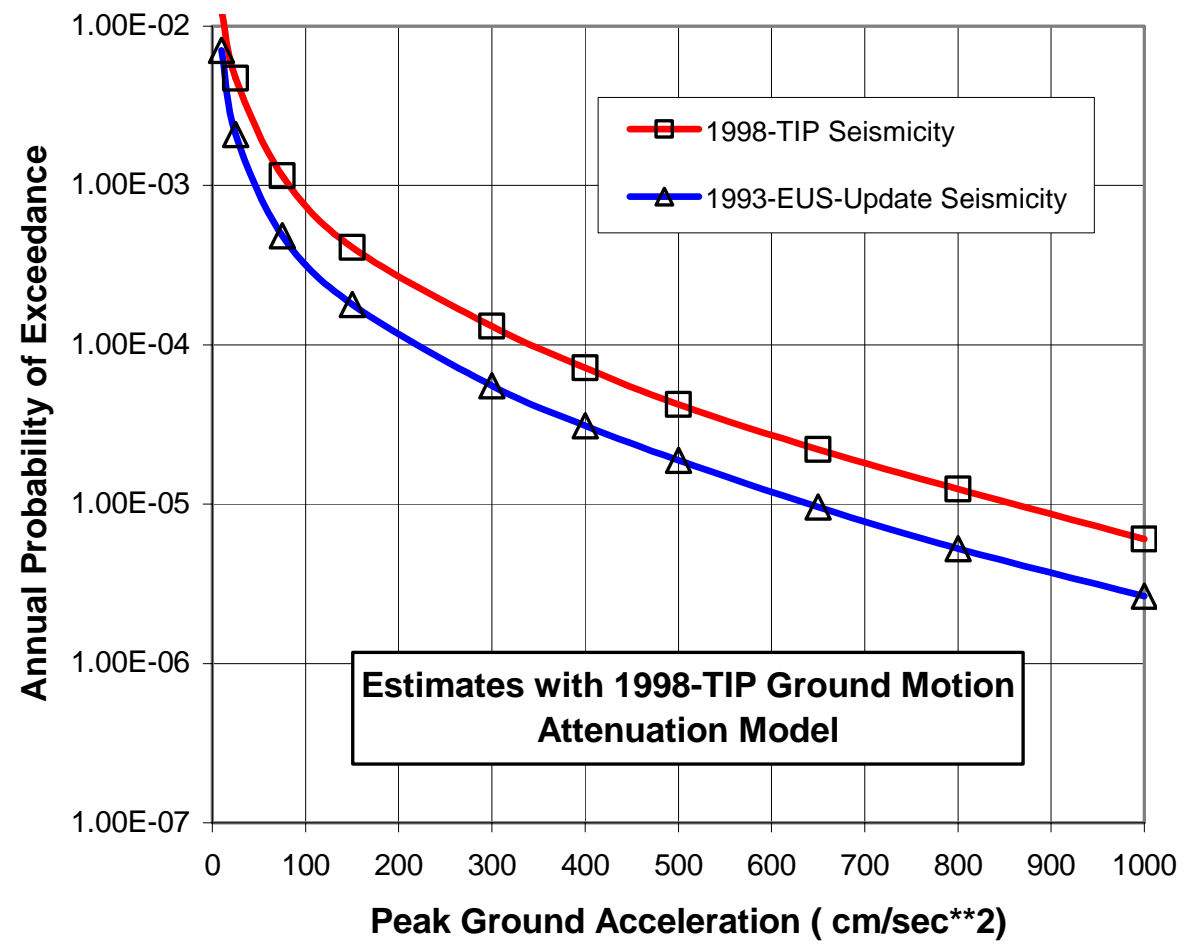

Figure 3.14: Comparing the Median Hazard Curves between the Cases of 1998-TIP Seismicity to the case of 1993-EUS-Update Seismicity, both with the same 1998-TIP Ground Motion Model. 


\section{IMPACT OF THE SEISMICITY MODELS}

\subsection{Methodological Differences}

This section examines the differences in the zonation and seismicity models between the two-studies. The 1993-EUS-Update study used 11 seismicity experts, each giving his own characterization of the seismic zones and their seismicity parameters. In the 1998TIP study, five Experts were used. One Expert was common to both studies--Dr. Bollinger. Dr. Bollinger was labelled Expert 3 in the 1993-EUS- study. In the rest of this study, Dr. Bollinger is referred to Expert 3 when referring to his contributions to the 1993-EUS-Update study.

The 1993-EUS-Update study used the inputs from the eleven seismicity experts as independent inputs. Each represented the interpretation of one expert. It fully described the seismic environment with the uncertainty that each expert independently perceived. The probabilistic hazard was performed for each pair of seismicity and attenuation expert and the final estimates were a weighted average of all the (paired) hazard curves. The 1998-TIP study used a different approach, similar to that of the approach used in the development of the GM models in the 1993-EUS-Update study and following the recommendations of the SSHAC (NRC, 1997). The basic principle was to decompose each of the seismicity experts' interpretations into an exhaustive set of elemental zones, feature or physical processes which globally could be used as a "LEGO" to build any of the interpretation of the experts. Consequently, every single part of this "LEGO" no longer belonged to a single expert interpretation but several and often all of them. Thus every single one of these elemental part could be the object of a reflexion, analyses, review discussions, challenges, comparison with data, by all of the experts, thereby automatically including the epistemic uncertainty, by assuming that the sample of experts represented an unbiased sample of the community at large.

In the 1998-TIP study, nine maps were introduced. Figure 4.1, taken from Savy et al. (1998), gives a typical map of the seismic zones near the Watts Bar site.

The region of most interest around the Watts Bar site is shown in Figure 4.2 as an enlarged view of the region.

\subsection{Differences of Interpretation of the Data by the Experts}

Figure 3.3 showed that 95 percent of the total hazard comes from the zones within $70 \mathrm{~km}$ of the site. Figure 4.2 shows that the corresponding important zones within this distance are zones 4A-3, 4A-2, 4A-1, 5-2 and 5-1. The 4A zone is labeled "The Eastern Tennessee Seismic Zone" (ETSZ). The nine alternative maps contain interpretation of the data and different models of the ETSZ. See Savy et al. (1998) for details. 


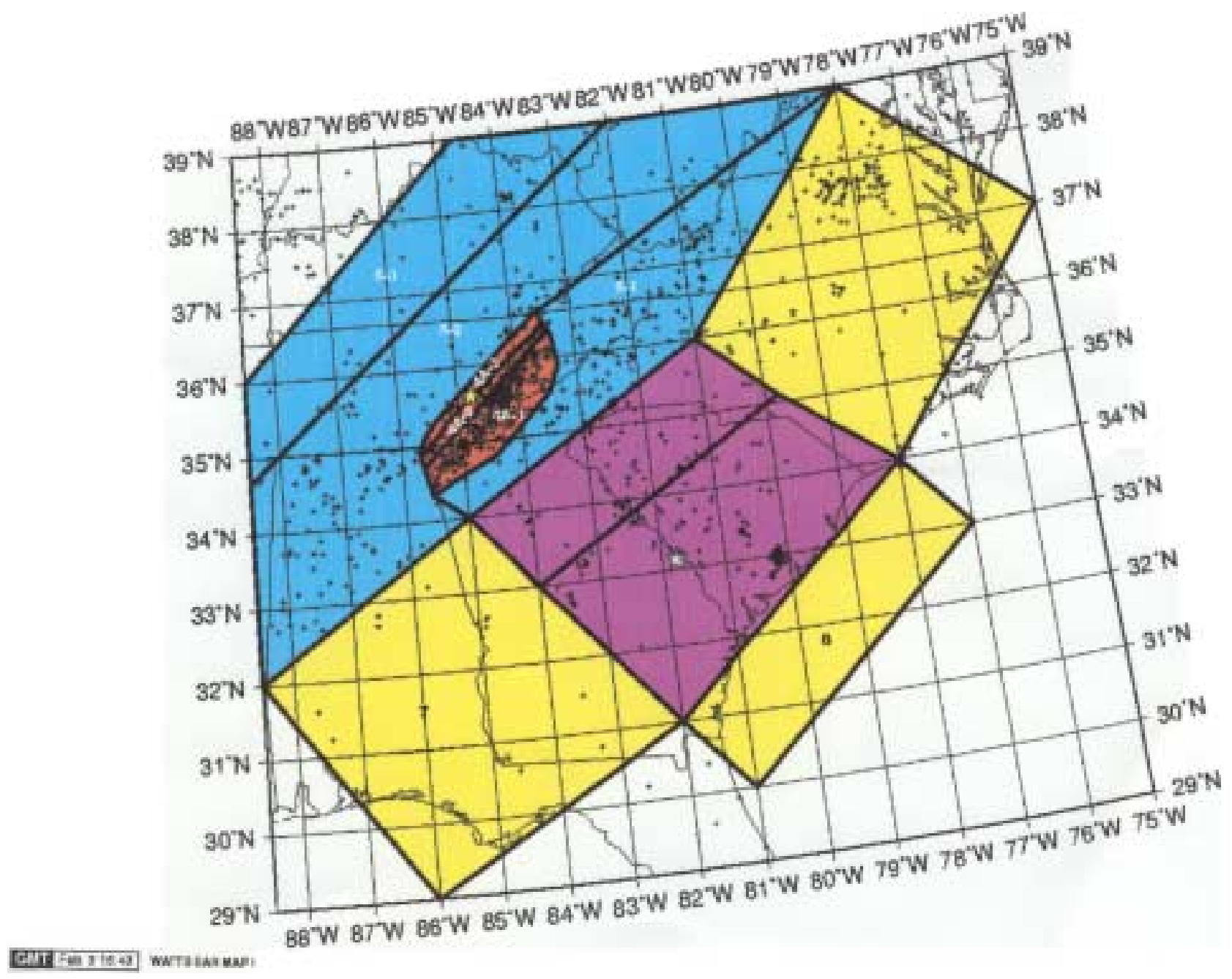

Figure 4.1: First Order Regional Seismic Sources Zonation Map for the Study of the Watts Bar Site in the 1998-TIP Study.

A great deal of research on the seismicity was performed in the late 1980's, early 1990's due to the observation of enhanced seismicity of small events in the eastern Tennessee area, leading to an evolution of the experts' thinking on the zonation of seismicity modeling of that area. In particular, this led to significant difference between the models of early 1980's and those of early 1990's. 


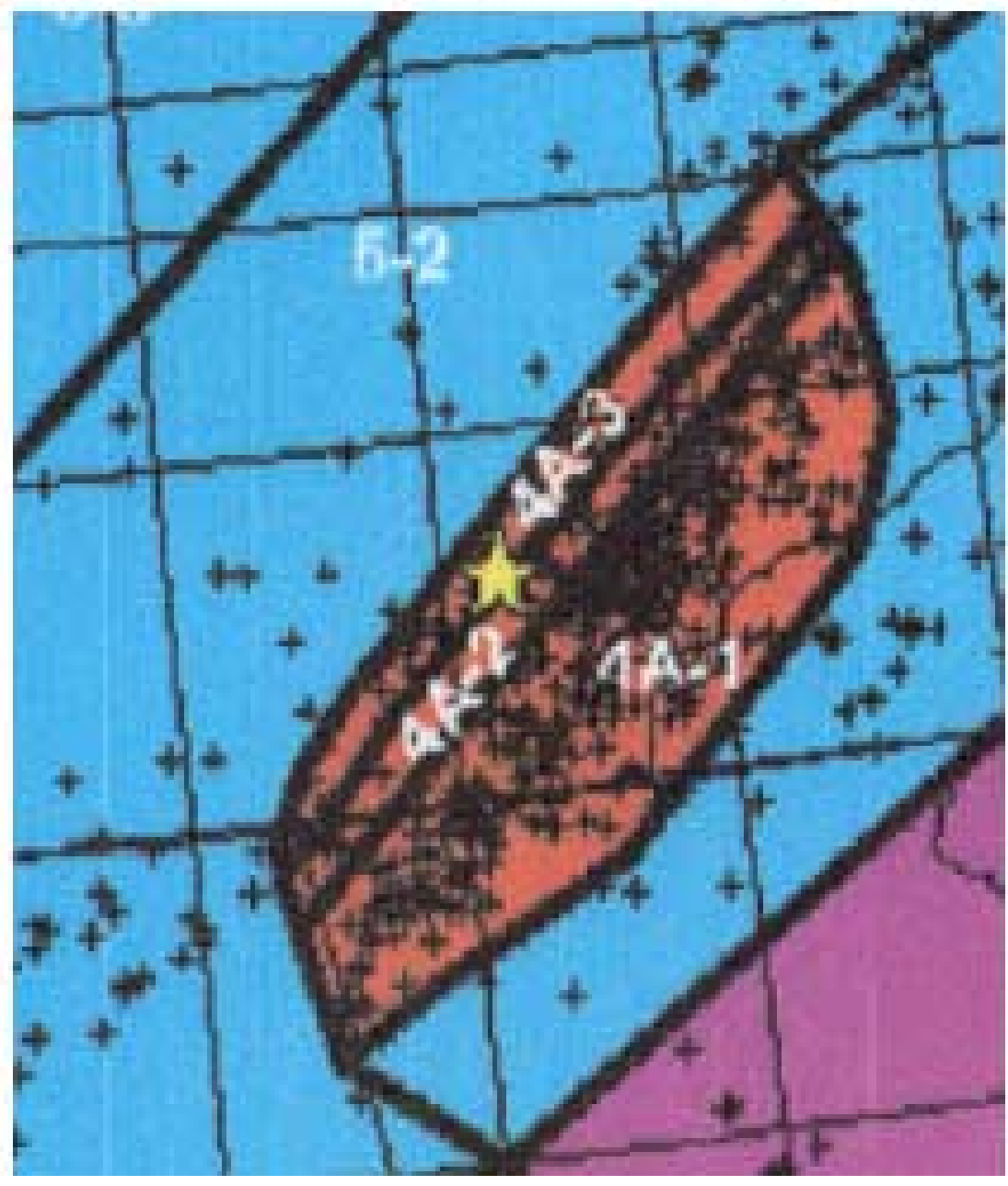

Figure 4.2: Detail of the Geometry of the Local Seismic Source Zones Considered in the 1998-TIP Study.

For the 1993-EUS-Update study, each of the eleven Seismicity Experts had a number of maps. These maps were first developed during the 1980's; see Savy et al. (1993) and Bernreuter et al. (1989). None of these maps recognized the ETSZ. The details of each Expert's map differ considerably. For example, Figure 4.3 shows Seismicity Expert 3's zones that impact the Watts bar Site. Figure 4.4 shows Seismicity Expert 1's zones that impact the Watts Bar Site.

The seismic hazard is directly influenced, in the first order, by the seismicity rate in the zones around the site. Since the hazard at Watts Bar is contributed mostly by the areas within $35-40 \mathrm{~km}$ from the site, a budget of events predicted by the models of zonation and seismicity of each of the experts in the 1993-EUS-Update study is calculated and shown in Figure 4.5. 


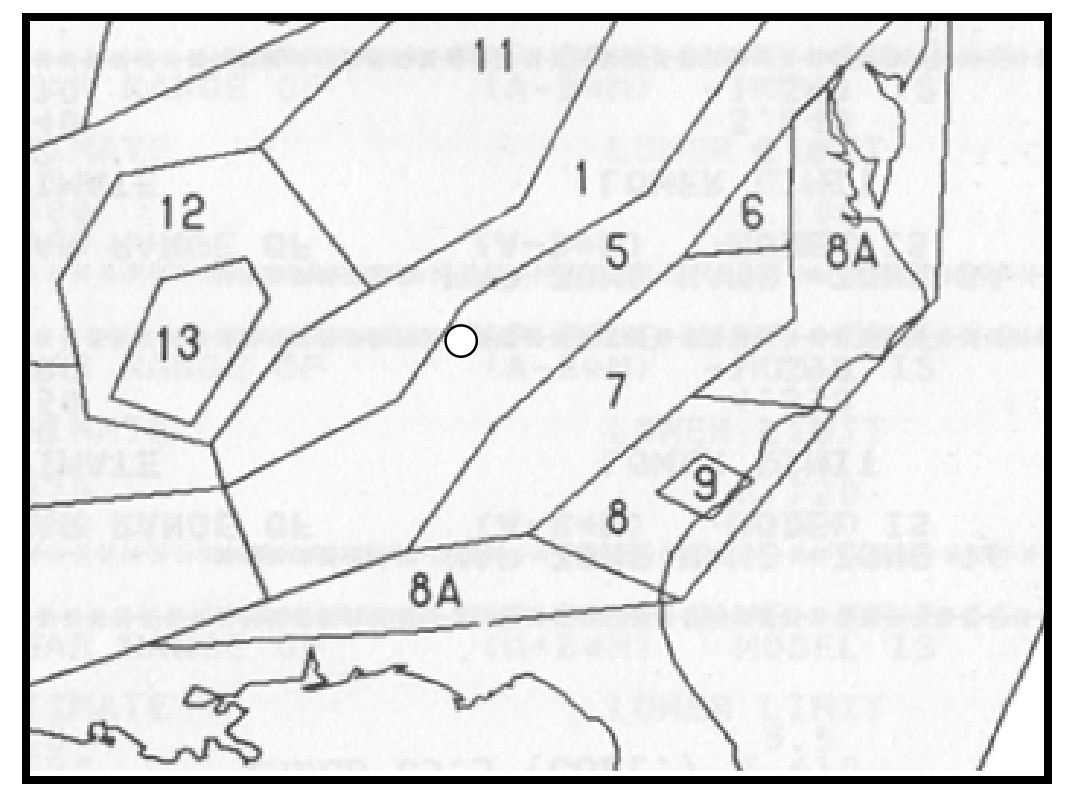

Figure 4.3: One of the seismic Source Zone maps Submitted by Seismicity Expert 3 in the 1993-EUS-Update Study. The site location is shown by the circle on the map.

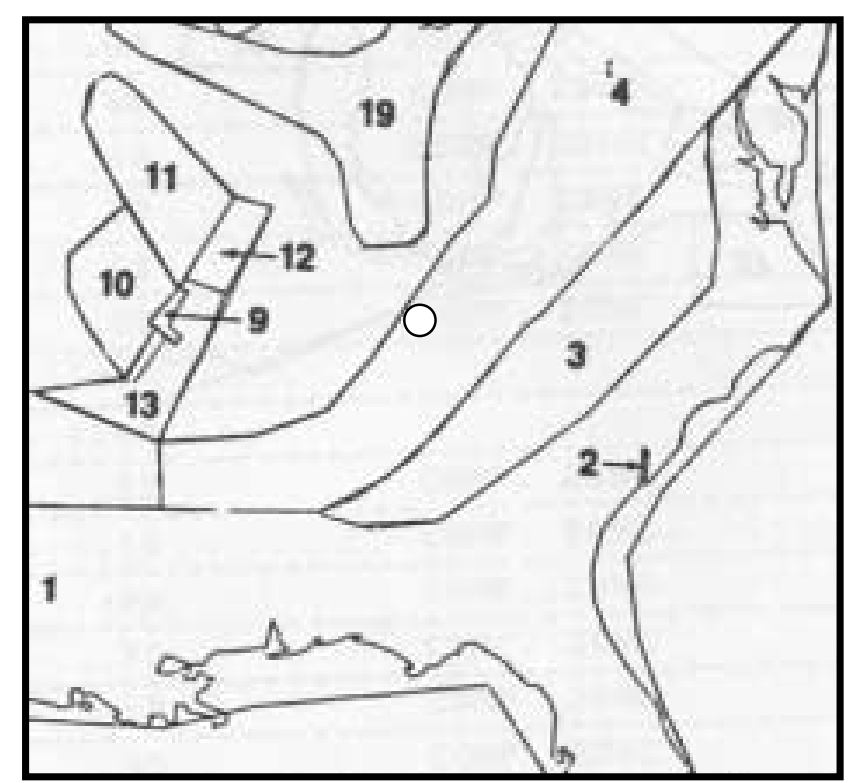

Figure 4.4: One of the seismic zone maps submitted by Seismicity Expert 1 in the 1993-EUS-Update Study. The location of the site is indicated by a circle on the map. 
Figure 4.5 shows the BE rate of earthquakes within $35 \mathrm{~km}$ of the site for each of the Eleven Seismicity Experts' inputs. In this case, the mode (BE) of the distribution of seismic rates is used. For some Experts, more than one seismic zone may be within $35 \mathrm{~km}$ of the site.

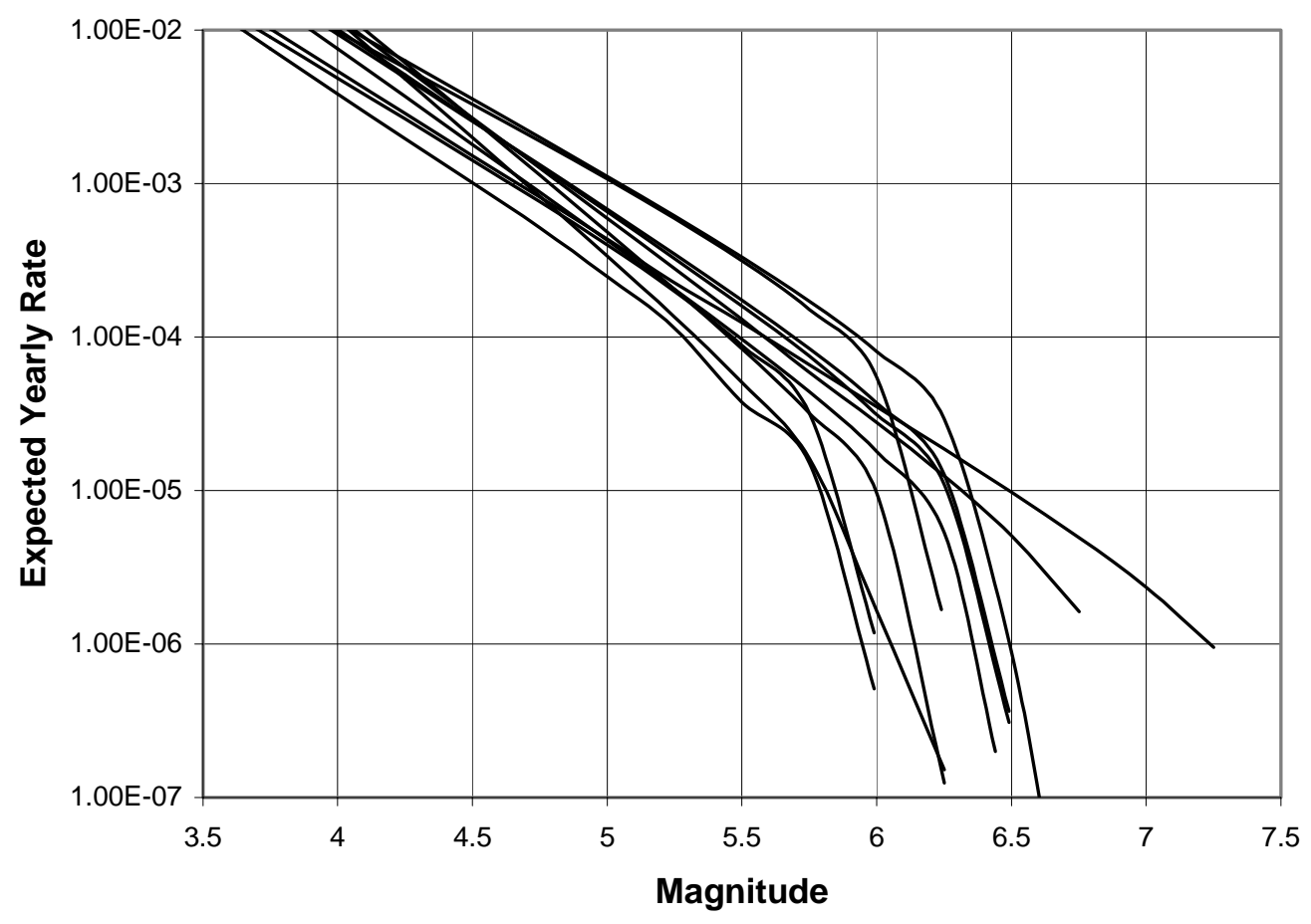

Figure 4.5: Expected Budget of Earthquakes within $35 \mathrm{~km}$ of Watts Bar from the Zonation and Seismicity Models of the 11 Seismicity Experts of the 1993-EUSUpdate Study.

Figure 4.5 shows the diversity between the eleven experts. It also shows the relative agreements for the magnitudes below 5.5. The experts had to evaluate the data to determine the maximum ever possible magnitude event for each of their postulated seismic source zones. Each came up with specific probability distribution functions, which globally represent the epistemic uncertainty on this parameter. In Figure 4.5, this translates into a range of maximum magnitudes between 6 and 7.25.

In Figure 4.6 we compare the median of the distribution of rate curves shown in Figure 4.5 to the similarly constructed BE rate curve based on the composite 1998-TIP seismicity model. It can be seen that the BE 1998-TIP rate is about a factor of two higher than the BE rate for the 1993-EUS-Update study which is about the difference we observed in Figures 3.13 and 3.14 between the hazard curves based on the two seismicity models using the same 1998-TIP GM model. 


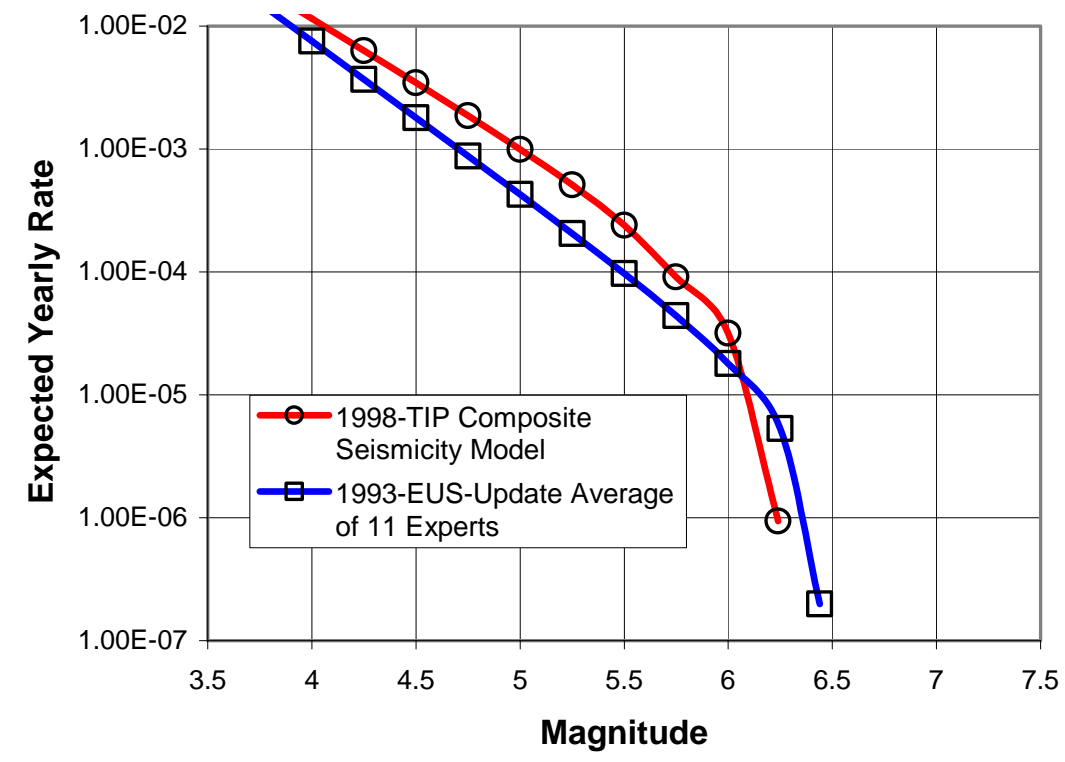

Figure 4.6: Comparison of the Earthquake Seismicity Budget within $35 \mathrm{~km}$ of Watts Bar for the 1993-EUS-Update and the 1998-TIP Seismic Zonation and Seismicity Models. The 1993-EUS-Update Curve is an Average over the 11 Seismicity Experts, the 1998-TIP curve is from the Composite Zonation and Seismicity Model.

It is instructive to see how Dr. Bollinger's seismicity model has changed between the two studies. Figure 4.3 shows Expert 3's seismicity zones used in the 1993-EUS-Update study and Figure 4.1 shows his seismicity zones for the 1998-TIP study. Comparing these two figures shows that the major change in seismic zones is the introduction of the ETSZ in the 1998-TIP study. The real test is not so much in how the zone boundaries have changed but how these changes impact the seismicity models. Figure 4.7 compares the BE seismicity models for the region within $35 \mathrm{~km}$ of the Watts Bar Site for Dr. Bollinger's inputs to the two studies. 


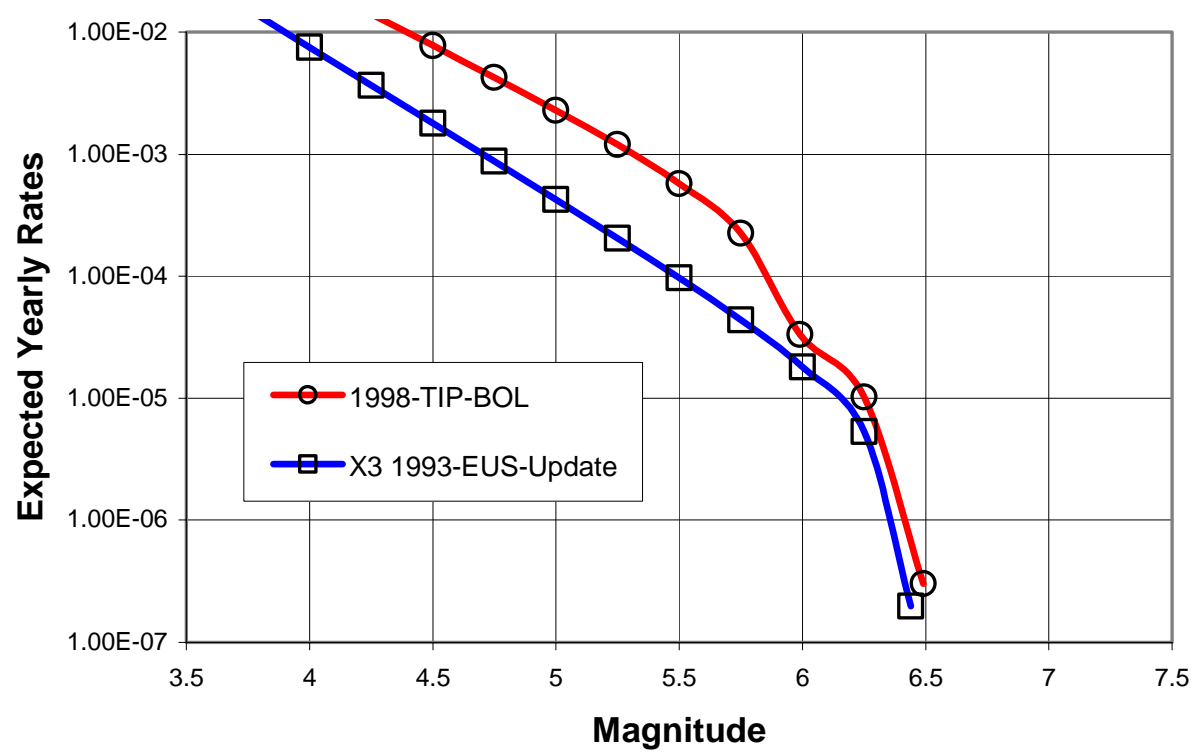

Figure 4.7: Comparison of the Best Estimate Seismicity Budget for a Region within $35 \mathrm{~km}$ of Watts Bar Provided by Expert 3 (X3 1993-EUS-Update) in the 1993-EUSUpdate Study and G. Bollinger in the 1998-TIP Study (1998-TIP-BOL).

\subsection{Case of the Local Zones}

Figure 4.7 shows that the rates in the new ETSZ are much higher than that of the zones in the 1993-EUS-Update study where the Watts Bar Site is located in the large zone 5.

Comparing Figure 4.7 to Figure 4.6 shows that the experts' rates are about a factor of two higher than the composite 1998-TIP seismicity model.

The BE rate of earthquakes of $M>=3.5$, shown in Table 4.1, are calculated for the 1998TIP composite model and Bollinger's model for the region within $33 \mathrm{~km}$ of the Watts Bar site for the five highest weighted maps. Table 4.1 shows that Bollinger's rates are significantly higher than the rates of the composite1998-TIP model for the two highest weighted maps (maps $1 \& 2$ ) within $33 \mathrm{~km}$ of the site.

Table 4.2 gives the rate of earthquakes of $M>=3.5$ for the zones within $33 \mathrm{~km}$ of the Watts Bar site that are incorporated in Maps 1 to 5. The rates are each zone's contribution to the total rate; i.e. the rates for each zone listed in Table 4.2 are equal to:

(total zone rate) *( area of the zone within $33 \mathrm{~km}$ of the site) /(total area of the zone)

The rates in Table 4.1 are for the same surface area but may be for more than one zone. 


\begin{tabular}{|c|c|c|c|}
\hline $\begin{array}{c}\text { Maps Ranked by } \\
\text { Relative Weight }\end{array}$ & $\begin{array}{c}\text { Relative Weight } \\
\text { of the Maps }\end{array}$ & $\begin{array}{c}\text { 1998-TIP } \\
\text { Bollinger }\end{array}$ & $\begin{array}{c}\text { 1998-TIP } \\
\text { Composite }\end{array}$ \\
\hline $\mathbf{1}$ & 1.0 & 0.071 & 0.034 \\
\hline $\mathbf{2}$ & 0.89 & 0.072 & 0.036 \\
\hline $\mathbf{3}$ & 0.57 & 0.032 & 0.038 \\
\hline $\mathbf{4}$ & 0.51 & 0.044 & 0.044 \\
\hline $\mathbf{5}$ & 0.27 & 0.054 & 0.065 \\
\hline
\end{tabular}

Table 4.1: Best Estimate Earthquake Budgets of Earthquakes with M agnitudes greater than 3.5 within 33km of Watts Bar in the 1998-TIP Study, for Bollinger alone and for the1998-TIP Composite Seismicity M odel.

The zone number is an arbitary labelling system used in the computations. The zone name refers to the names in Figures 4.1 and 4.2. (Additional details can be found in (Savy et al., 1998). Bender Cylinder refers to a type of zone with uncertain (fuzzy) boundaries, modeled by a series of cylinders of constant seismicity rates.

\begin{tabular}{|c|c|c|c|c|c|c|c|cc|}
\hline Zone \# & Bol Rate & Tip Rate & Map1 & Map2 & Map3 & Map4 & Map5 & Zone & Name \\
\hline 28 & 0.006 & 0.0096 & & Yes & & Yes & & $\{5-1\}+$ & $\{5-2\}$ \\
\hline 29 & 0.012 & 0.0094 & Yes & Yes & & & & B1 & \\
\hline 30 & 0.054 & 0.017 & Yes & Yes & & & & B2 & \\
\hline 32 & 0.014 & 0.017 & & & & & Yes & 4A-1 Bender & Cylinder \\
\hline 33 & 0.026 & 0.03 & & & & & Yes & 4 A-2 Bender & Cylinder \\
\hline 34 & 0.0084 & 0.01 & & & & & Yes & 4A-3 Bender & Cylinder \\
\hline 35 & 0.023 & 0.027 & & & Yes & Yes & & 4A-1 + & 4A-2 \\
\hline 46 & 0.03 & 0.03 & & & & & & Fault6 & \\
\hline
\end{tabular}

Table 4.2: Contribution of Selected Seismic Zones to the Budget of Earthquakes greater than Magnitude 3.5 within $33 \mathrm{~km}$ of Watts Bar, in the 1998-TIP Study. "Tip Rate" Refers to the rates from the 1998-TIP Composite Seismicity M odel and "Bol Rate" Refers to the Seismicity Rates from Bollinger Only, in the 1998-TIP Study. 
Tables 4.1 and 4.2 show that the most important zones are zones B1, B2 and zone 35 with respect to the hazard at Watts Bar. In Figure 4.2, zone B2 is zone 4A-3 and zone 4A-2 combined into a single zone. Zone B1 is zone $4 \mathrm{~A}-3$ as an independent zone. Zone 35 is made-up of zones 4A-1 and 4A-2. Figure 4.8 shows this zone and the historical seismicity in this zone. (See also Figure 4.1.)

Let us examine the recurrence model in zone 35 . It is a zone with significant seismicity, and the recurrence model should be reasonably well defined by the earthquake data. Figure 4.9 compares the raw counts of earthquakes in zone 35 for three time frames (normalized to a yearly rate) to both the 1998-TIP composite and Bollinger's recurrence models.

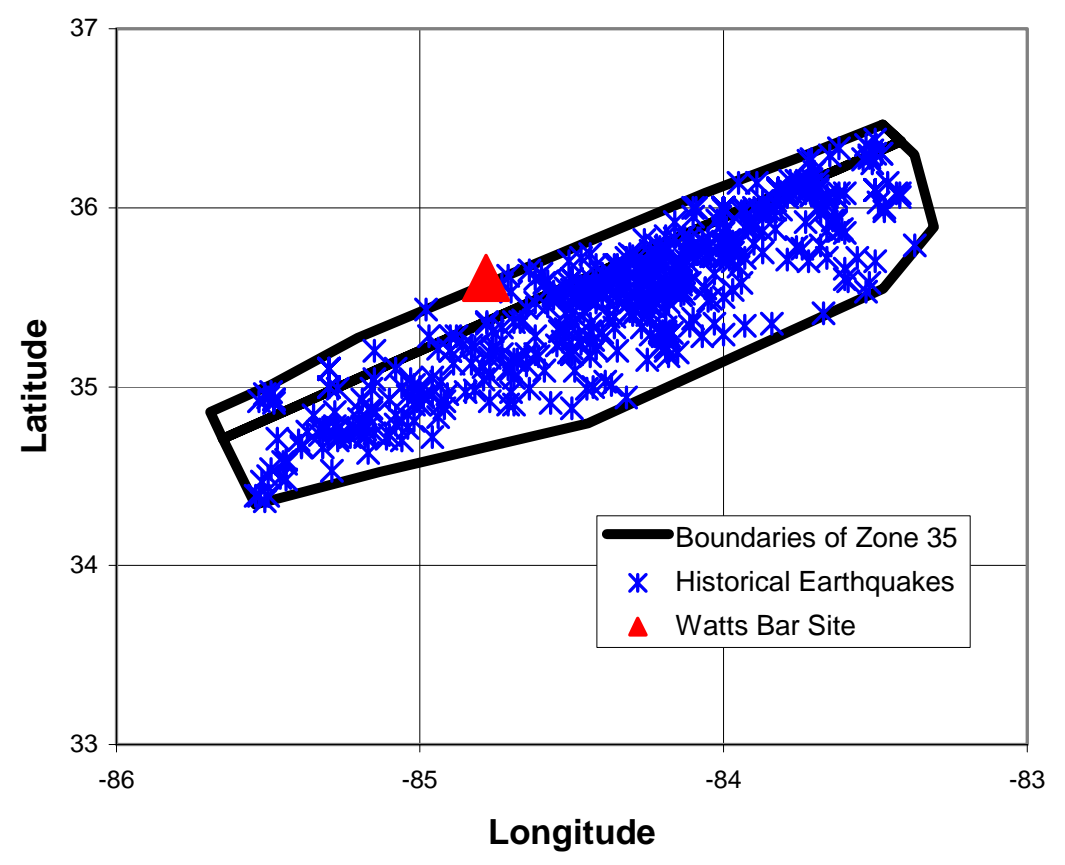

Figure 4.8: Historical Seismicity in Zone 35 of 1998-TIP

Figure 4.9 shows that there is sufficient data in Zone 35 to define the recurrence model. Both Bollinger's and the composite 1998-TIP's models agree reasonably well with each other and with the "budget" of historical earthquakes in the zone.

A similar comparison is shown in Figure 4.9 for Zone B1 (using data from only 2 time frames this time). There is much less data in Zone B1 than in Zone 35 to estimate a recurrence model, however there is sufficient data to make a reasonable estimate of the recurrence model for the zone. Figure 4.10 shows that both Bollinger's and the composite 1998-TIP's models agree reasonably well with each other and the data. 


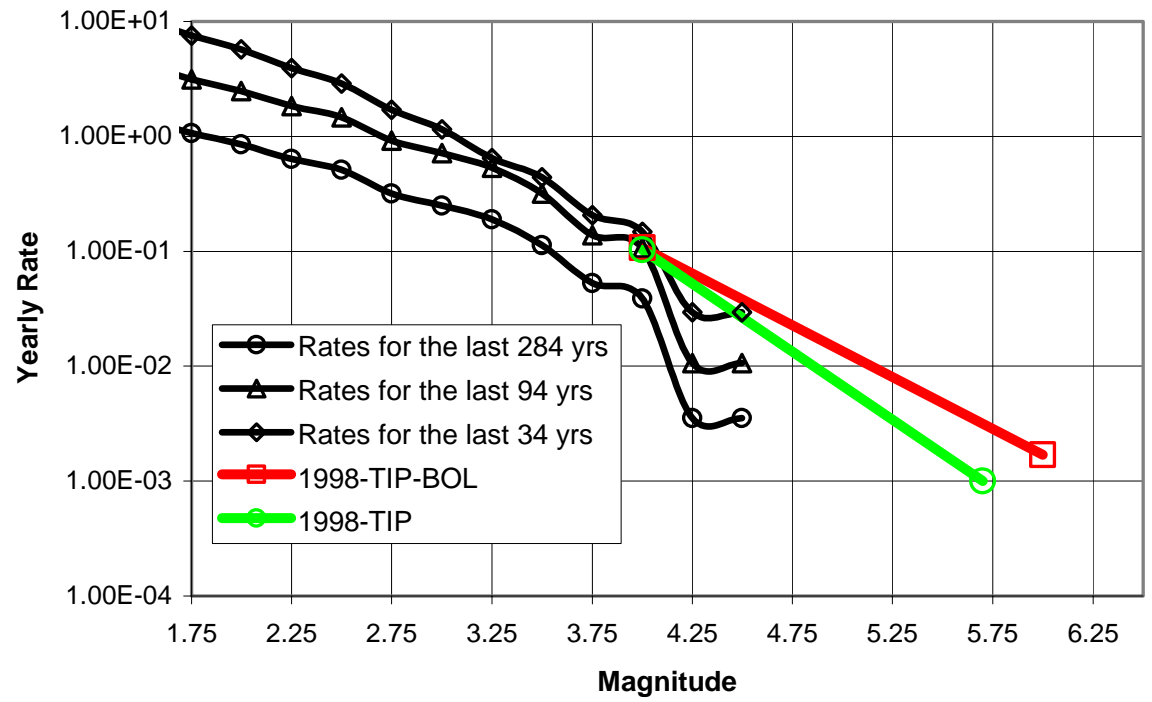

Figure 4.9: Comparison of the Budget of Historical Earthquakes with the Expected Estimates in Zone 35 of 1998-TIP. The Composite Seismicity Model including all Experts' Input is labeled "1998-TIP” and "1998-TIP-BOL” for Bollinger's input only.

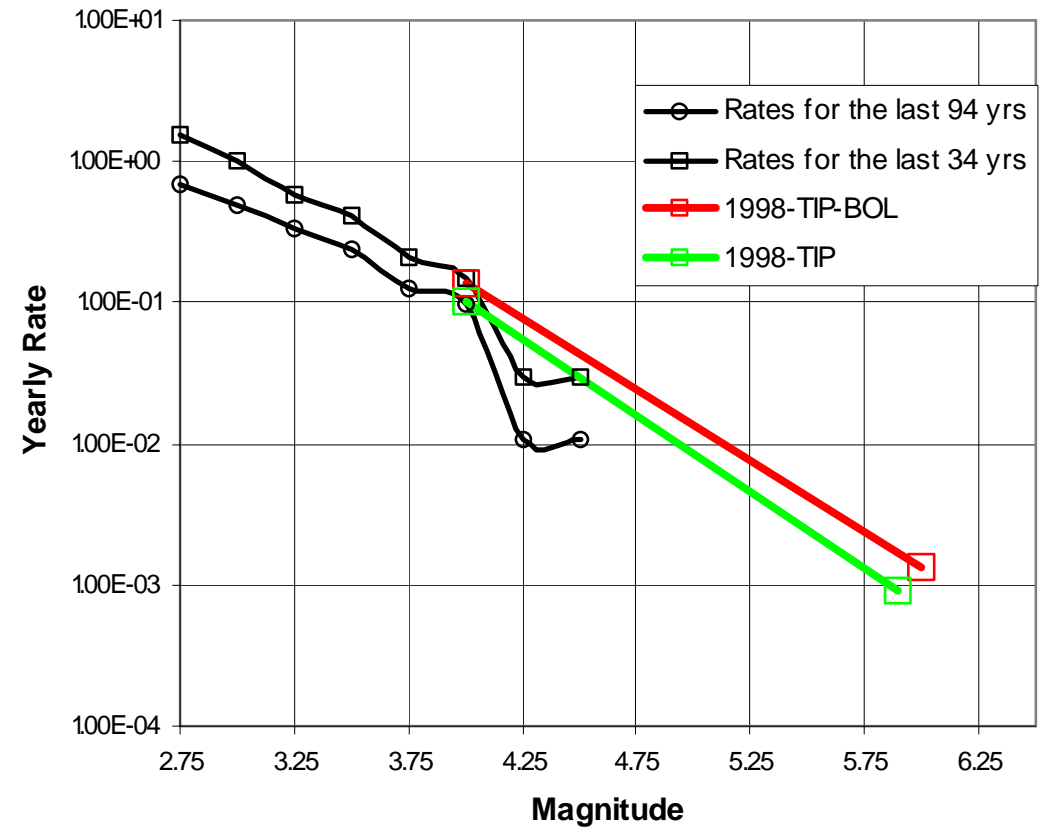

Figure 4.10: Comparison of the Budget of Historical Earthquakes with the Expected Estimates in Zone B1 of 1998-TIP. The Composite Seismicity Model including all Experts' Input is labeled “ 1998-TIP” and "1998-TIP-BOL" for Bollinger's input only. 


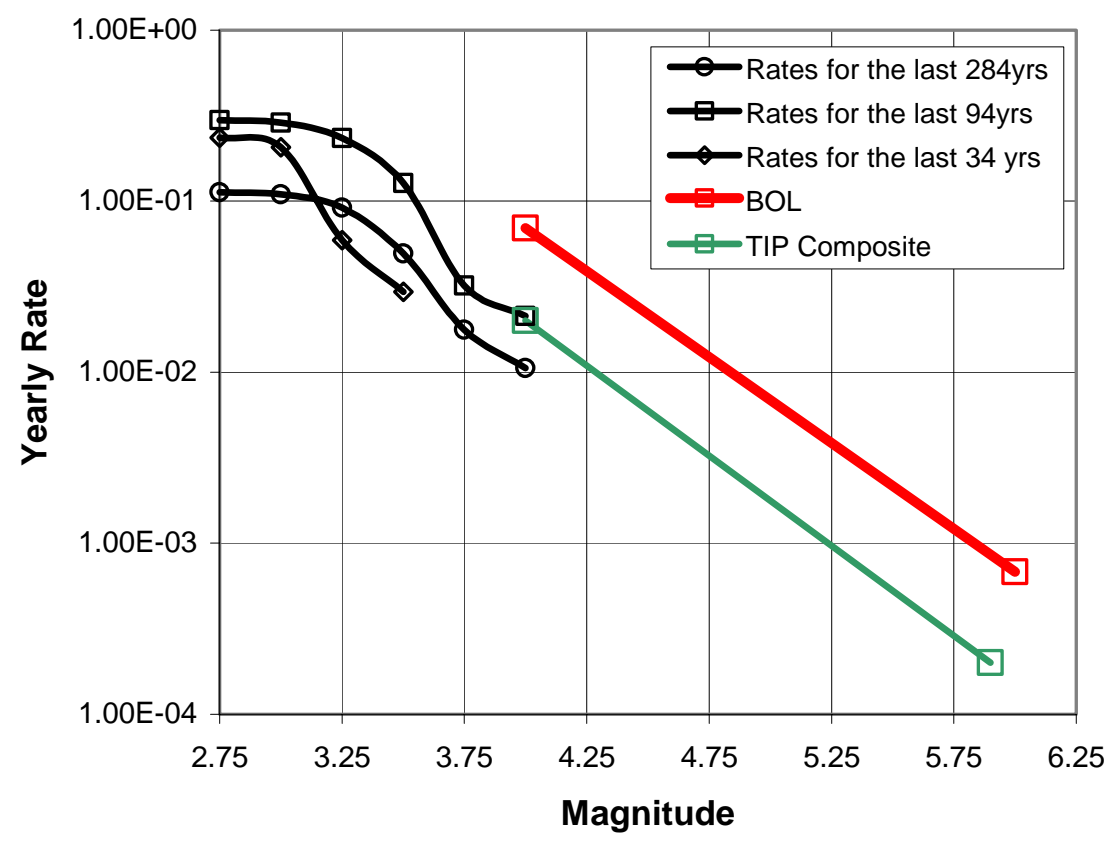

Figure 4.11: Budget of Historical Earthquakes and Modeling for Zone B2 in 1998TIP

Finally, Figure 4.11 gives the data in Zone B2 showing that there are too few earthquakes for completeness, for any of the three time frames, probably due to the relatively small size of the zone. Because there is so little data in Zone B2, it is not meaningful to talk about a "budget" of earthquakes. To develop a recurrence model for this zone the Experts must bring other factors into their estimates for the recurrence model. This leads to a considerable difference between Bollinger's model and the composite 1998-TIP recurrence models as was discussed in Savy et al. (1998) in Section 4.2.6.3.

In Figure 4.12, the recurrence model for Expert 3 in the 1993-EUS-Update study is compared to the "budget" of earthquakes in zone 5 (see Figure 4.3), showing that the recurrence model reasonably fits the "budget" of earthquakes in this zone. 


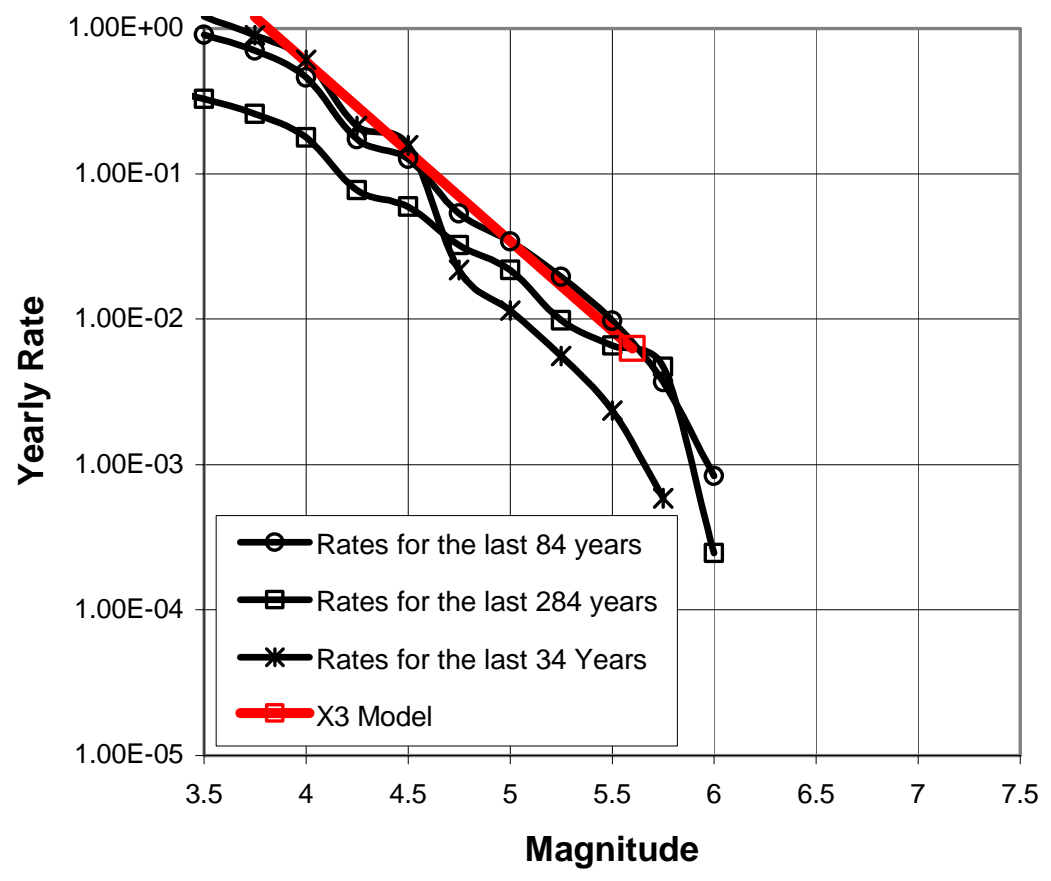

Figure 4.12: Yearly Rates in Zone 5 for Expert 3 of the 1993-EUS-Update Study. "X3 Model" Refers to Expert's 3 Estimates. The Other Curves are for Historical Earthquakes.

Figures 4.9 to 4.12 show that for the zones where there is sufficient data to establish a budget of earthquakes, the recurrence models developed by the Experts are in reasonable agreement and with the data. However, in a site-specific study, small seismic zones can be defined on the basis of geological or geophysical data that are not necessarily associated with sufficient seismicity in the historical record to adequately define the recurrence model. This has been the case in previous studies (eg. SRS hazard study, 1992), and was extensively discussed at the SSHAC interactive working meetings (NRC, 1997). The lack of knowledge in the characteristics of Zone B2 leads to a single expert's higher uncertainty and consequently higher mean hazard estimate than in the composite. Zone B2 is such a zone. The Experts highly weighted this zone so it appeared in the most important maps and thus has a significant impact on the estimation of the seismic hazard. This point is illustrated in Figure 4.13, where the mean estimates of the seismic hazard at the Watts Bar site based on the 1998-TIP composite model are compared with Bollinger's model that appear to be the highest, simply due to the impact of Zone B2. 


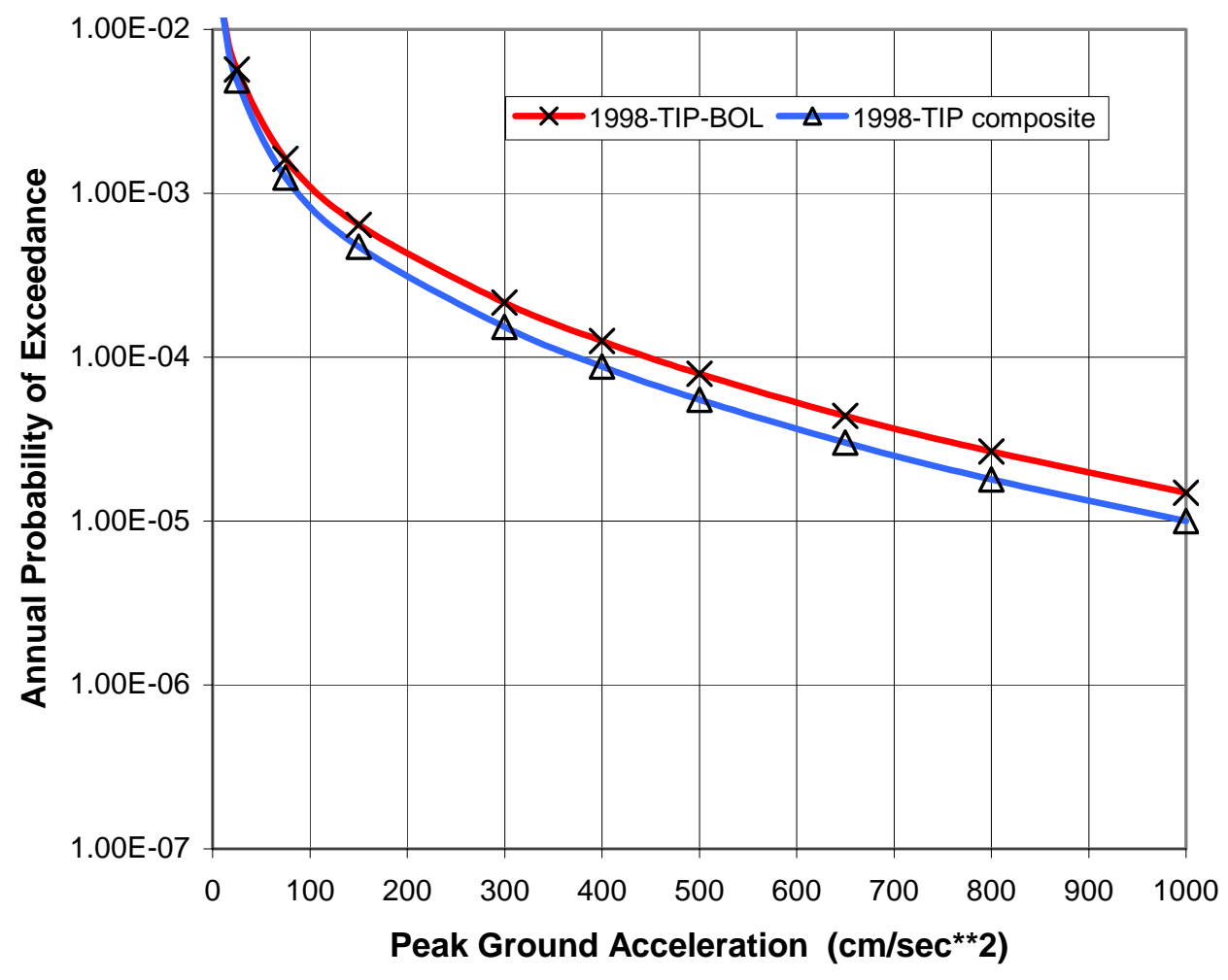

Figure 4.13: Mean Estimates of the Seismic Hazard at Watts Bar using the 1998TIP Composite Seismicity Model (1998-TIP composite) and Bollinger's Model (1998-TIP-BOL). The Ground Motion Model is the 1998-TIP Model 


\section{UNCERTAINTIES AND SENSITIVITY STUDIES.}

\subsection{Parameters of Interest}

The methodological differences between the two studies lead to differences in the modeling of the epistemic uncertainty in the formulation of the zonation maps. In this section, the impacts of those differences are analyzed as well as other causes of differences such as whether an analysis is regional or local. The level of refinement of the seismicity and zonation model is examined by evaluating the impact of considering faults, rather than area zones, for modeling the seismicity in the ETSZ. Finally the issue of saturation in the GM models is evaluated.

Figure 5.1 shows the predicted mean annual rate of occurrence within a $33 \mathrm{~km}$ radius of Watts Bar, for the 5 highest weight zonation maps of the 1998-TIP study (see relative weights in Table 4.1.) This figure shows that the difference between the lowest curve (Map1) and the highest (Map 4), in the magnitude range of 4.5 to 6 is a factor of 2 to 3 , which is reasonably small, and not likely to generate a large uncertainty in the hazard estimates.

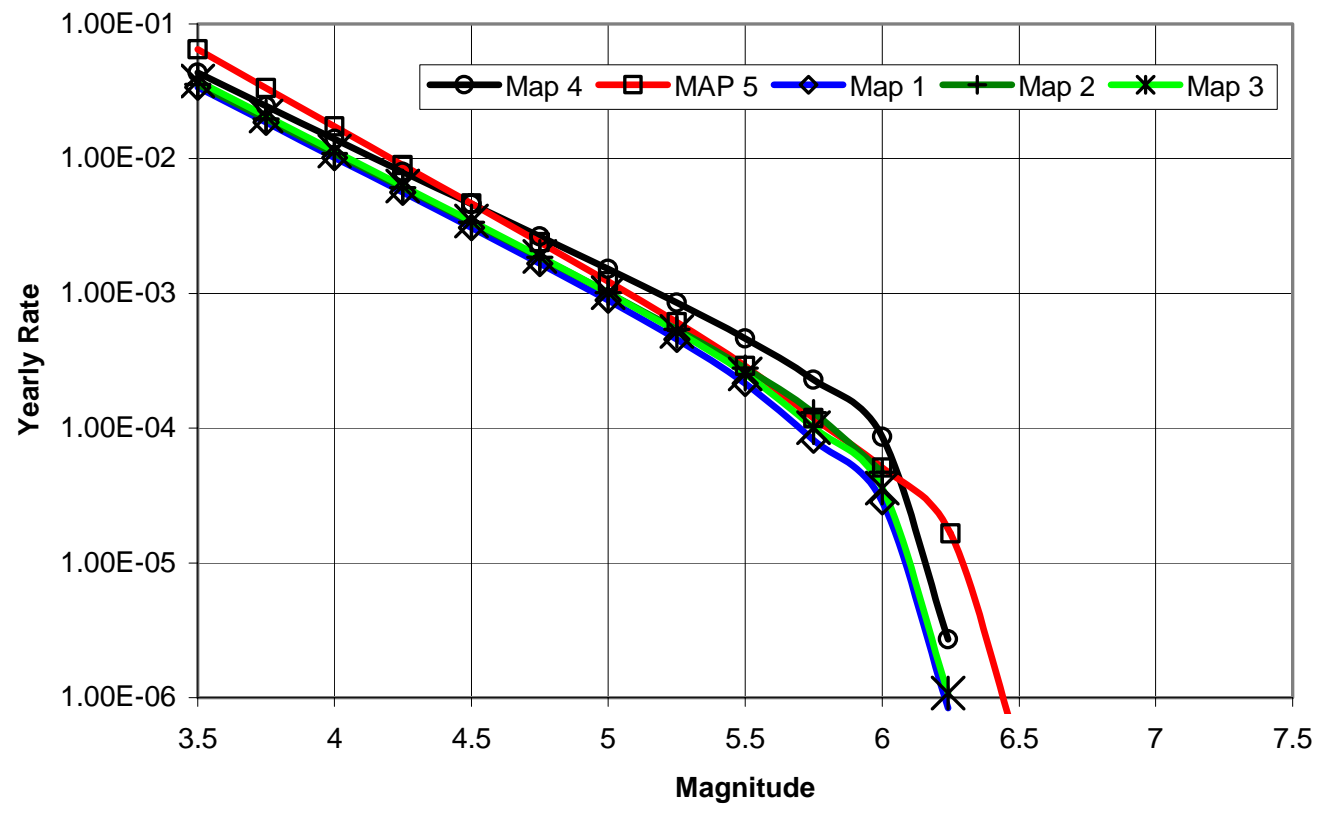

Figure 5.1: Comparison of the Annual Rates of Occurrence of Earthquakes within $33 \mathrm{~km}$ of Watts Bar, for the 5 Highest Weighted Zonation Maps of the 1998-TIP Study. The Relative Weights of the Maps are given in Table 4.1. 


\subsection{Sensitivity to the Formulation of the Zonation Maps}

The general approach to model the epistemic uncertainty in the estimation of the seismicity is to use a range of zonation maps with the seismicity rates probablility distributions corresponding to each seismic zone, or fault. Table 4.1 gives an example of 5 such maps used in the 1998-TIP study. The set of maps, with the associated weights, constitutes the discrete probability distribution of maps and thus quantifies the uncertainty in the zonation. The total seismic hazard is a weighted average of the hazard calculated for each map.

It is seen that although Map 5 has the highest rate at $M>=3.5$, Map 4 has the highest rate in the range of interest of M5 to H6.25. Figure 5.2 compares the mean estimate of the hazard for each of the five highest weighted maps as well as the total mean hazard curve. When the weights are applied to each of the maps, actual impact on the hazard is smaller than shown in Figure 5.2. Hence, the various alternative maps do not introduce significant uncertainty in the final hazard estimates.

The actual uncertainty introduced by the different maps might even be less than the amount implied by Figure 5.2, as some of it is actually introduced by the simulation process itself (see the discussion in section 5.3 below.)

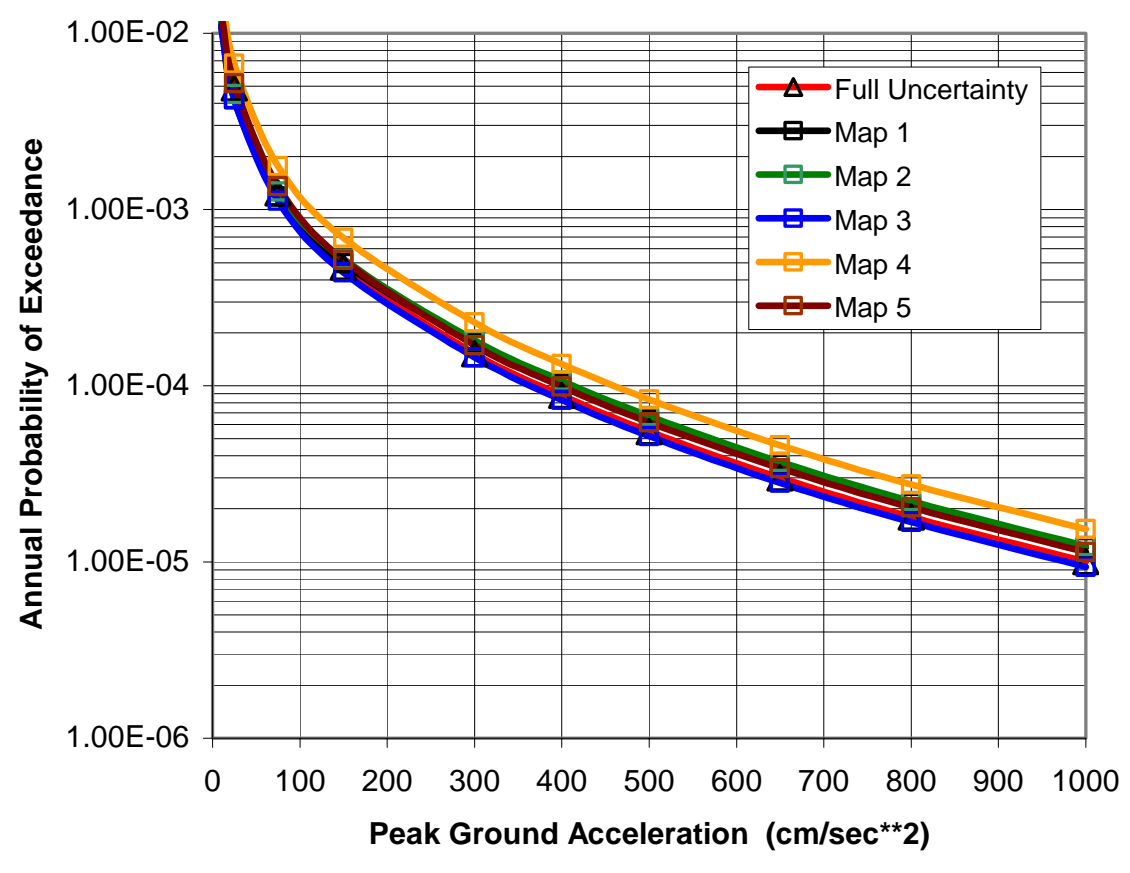

Figure 5.2: Comparison of the Mean Estimates of the Hazard for each of the Five Highest Weighted Maps with the Overall Mean Hazard.. 


\subsection{Sensitivity to the parameters of the Monte-Carlo Simulation}

In performing the simulations, the size of the samples were determined by the limits of the computation capabilities in 1993. Given this limited number of simulations, the choice of the seed introduced some variability in the estimates of the hazard. At the time this number of simulation was selected after a careful consideration of that variability, with sensitivity analyses showing that the selected seeds were adequate for the purpose (see Bernreuter et al., 1989.)The order of magnitude of this uncertainty is shown in Figure 5.3 in the comparison of the mean hazard curves for four different random seeds. It shows that this variability in the mean hazard curve is small but must be considered before drawing conclusions, such as in section 5.2 above.

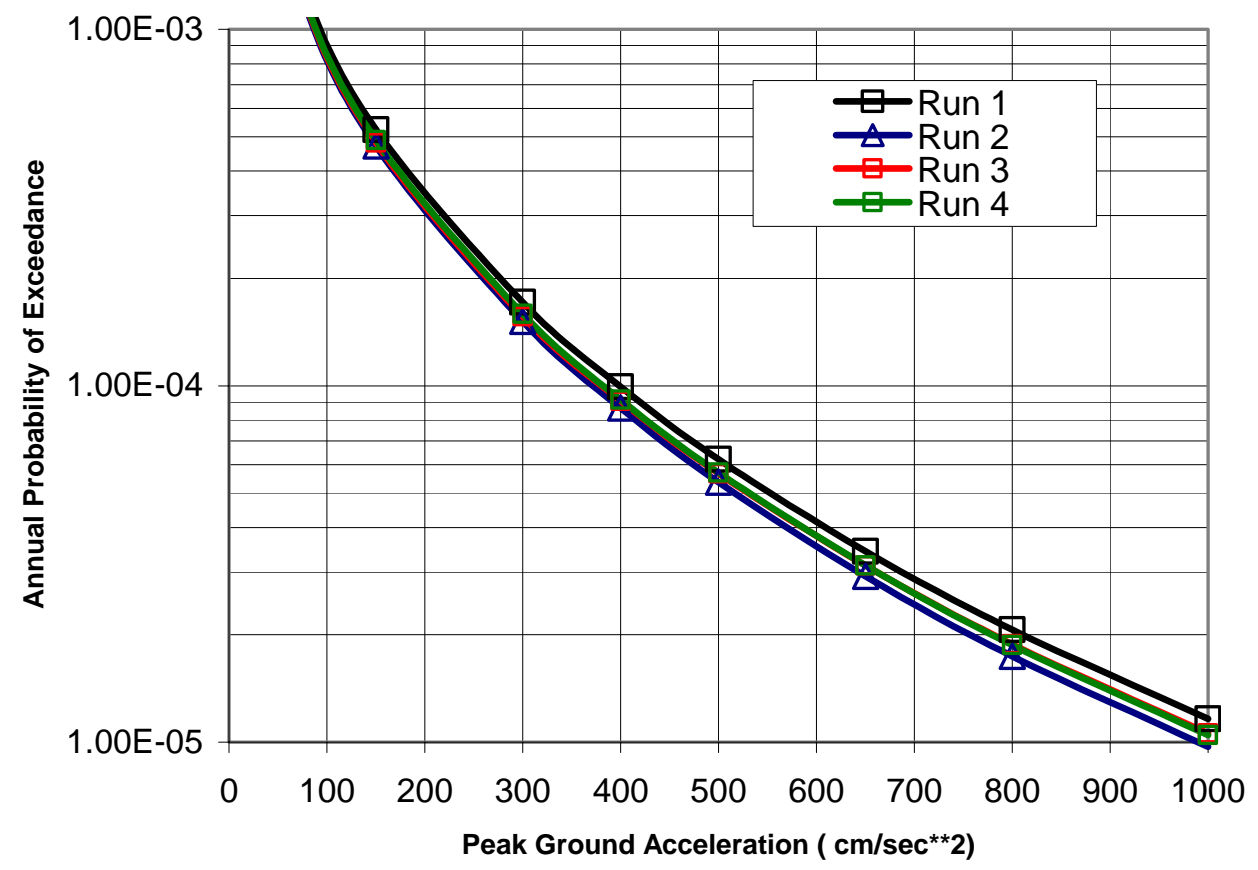

Figure 5.3: Sensitivity of the Mean Estimates to the Seed of the Monte-Carlo Simulation 


\subsection{Site Specific versus Regional Studies}

One important difference between the 1993-EUS-Update study and the1998-TIP study was the introduction of the ETSZ in the 1998-TIP study.

Would the experts of the 1993-EUS-Update study have introduced an ETSZ if it had been a site specific study that focused on the Watts Bar site?

To answer that question, the issue of modeling the seismicity of the region around the site is examined. Figure 5.4 shows the earthquake locations in zone 5 of Expert 3 of the 1993-EUS-Update study. The figure shows that there is a high density of earthquakes in the region assigned to the ETSZ. This points out one the possible differences between a site-specific study and a broad regional study-namely; a broad regional study might miss a small zone of increased seismicity near a specific site. On the other hand, as discussed above, site-specific studies can introduce problems by defining zones too small to have sufficient data to adequately develop a recurrence model and other less reliable methods might have to be used to develop the recurrence model.

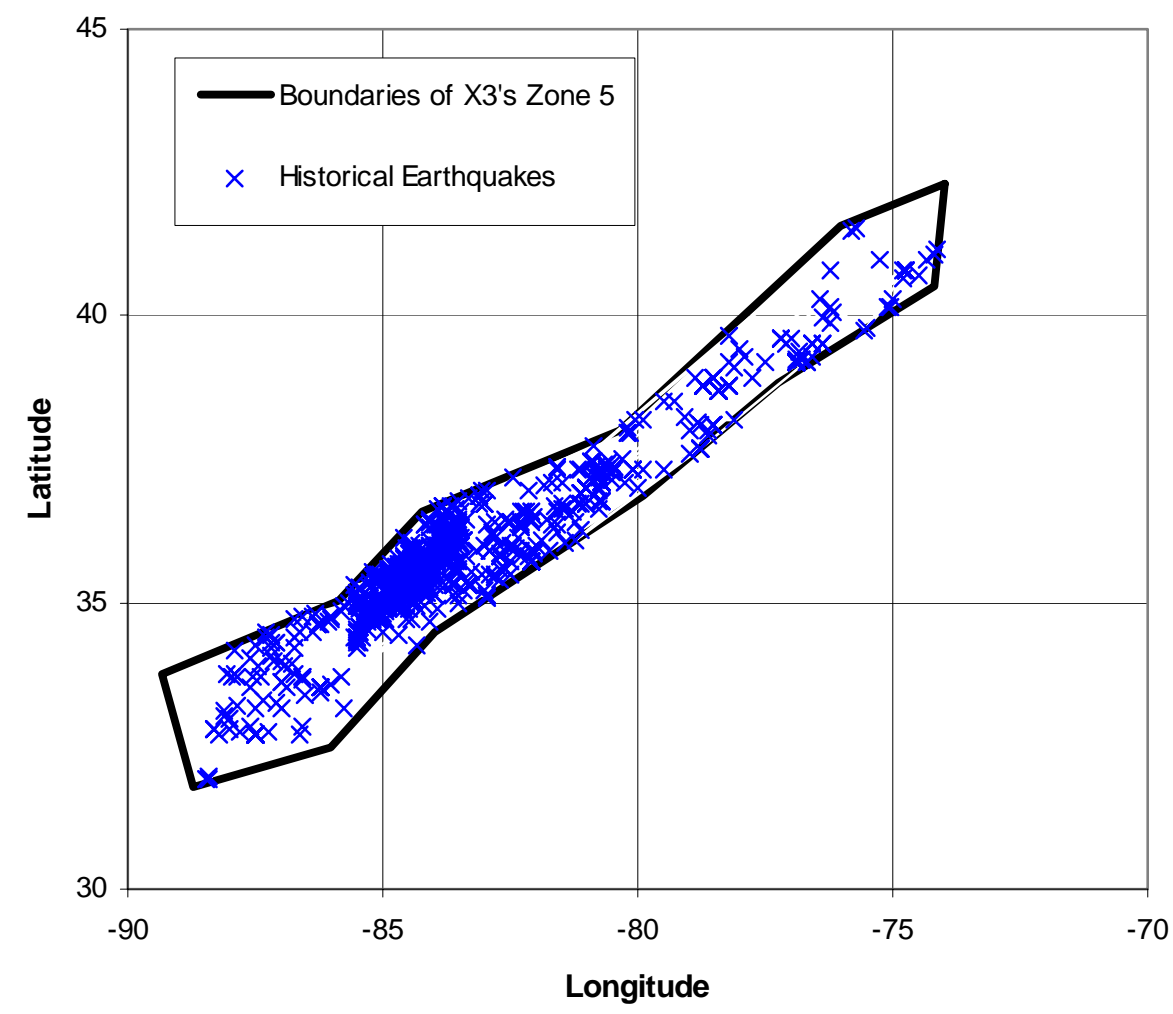

Figure 5.4: Historical Seismicity in Expert 3's Zone 5 of the 1993-EUS-Update Study. 


\subsection{ETSZ versus Local Faults}

One interesting feature of the 1998-TIP seismicity model was the introduction of faults to replace the ETSZ (see Figure 5.5.) The estimate of the hazard at the site could possibly be increased by the fact that Fault 6 is very near to the site. Little is known about these possible faults and the Experts had no additional data to use to model the recurrence model for Fault 6, other than distribute the seismicity of the zone among the faults. Because of this, introduction of the faults into the seismicity model did not have a significant impact on the estimate of the hazard at the Watts Bar site. Figure 5.6 compares the BE estimate of the hazard based on the highest weighted map to the BE estimate of the hazard based on a typical fault map.

\begin{tabular}{|c|c|c|c|}
\hline fault 1 & $\begin{array}{r}0 \\
\end{array}$ & fault 3 & $\longrightarrow$ fault 4 \\
\hline fault 9 & Site & Zone B1 & - $\quad$ Zone B2 \\
\hline
\end{tabular}

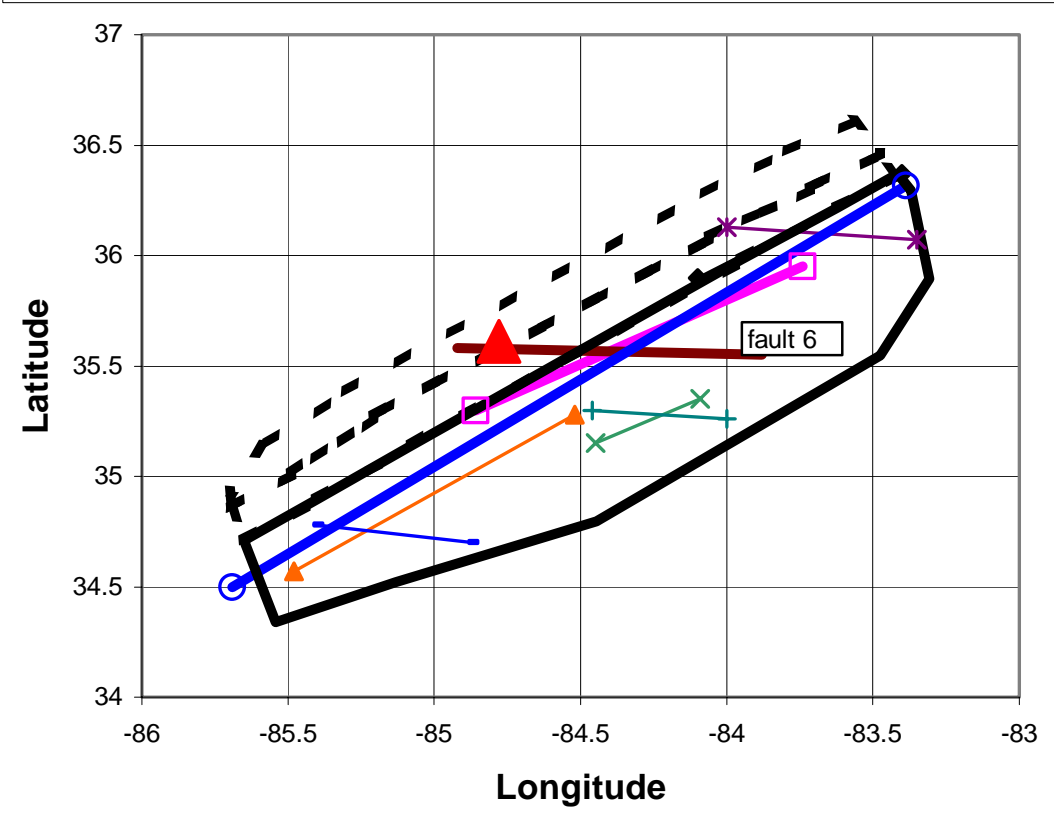

Figure 5.5: Location of the Faults Relative to the Site and the Eastern Tennessee Seismic Zone (ETSZ). 


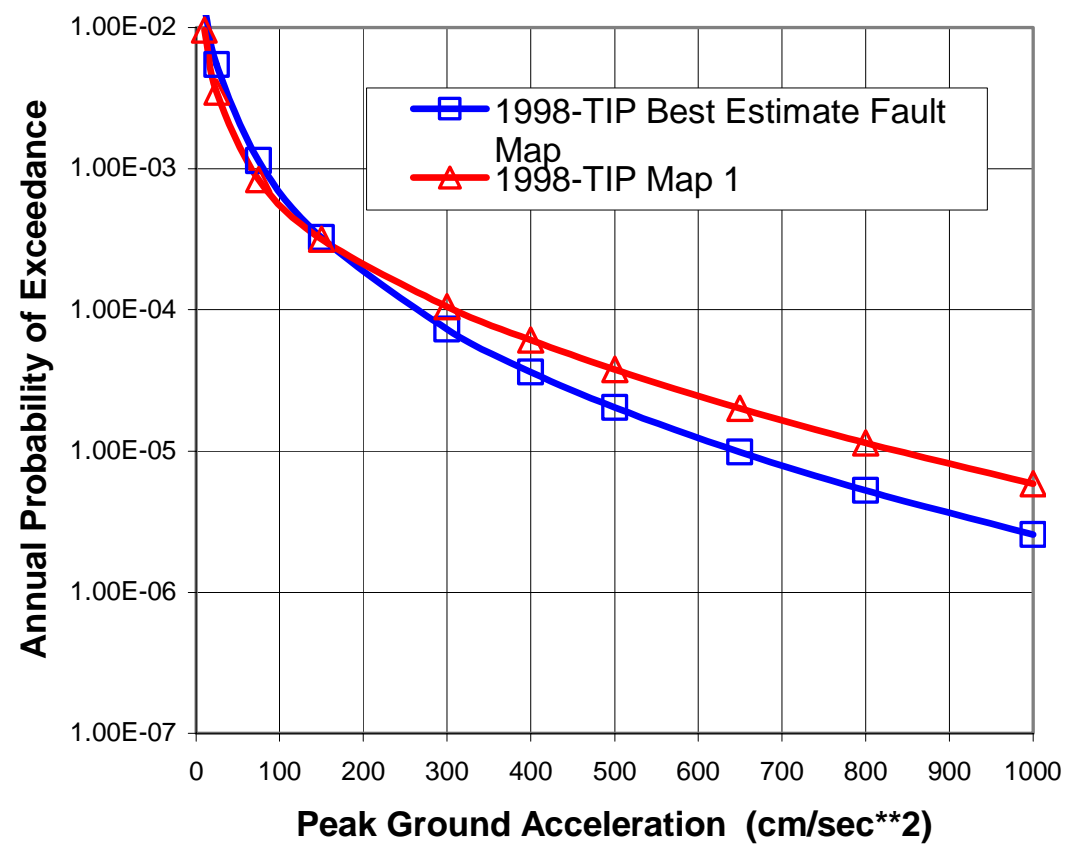

Figure 5.6: 1998-TIP Study. Comparison of the Best Estimate Hazard Curves Obtained Using the Highest Weighted Map (Map 1) to that of a Typical Fault Map.

It is seen from Figure 5.6 that the hazard estimate is lower for the fault model than for the zone model. This is in part an artifact of the way the recurrence model was assigned to the fault. If there had been sufficient information about Fault 6 to make an independent assessment of the recurrence model for the fault then the fault model might have supplied a better estimate of the hazard than the zone model.

\subsection{Ground Motion Saturation}

Figure 3.1 shows one major difference between the GM models. The 1993-EUS-Update GM model saturates at $10 \mathrm{~km}$ and the 1998-TIP GM model does not. To see what impact this has we ran a sensitivity study modifying the 1998-TIP GM model so that it saturated at $10 \mathrm{~km}$. Figure 5.7 shows a comparison of the BE hazard estimates between the 1998TIP GM model and the modified (saturation of PGA at 10km) 1998-TIP GM model. This figure shows that saturation of the GM at $10 \mathrm{~km}$ has little effect on the estimated hazard. 


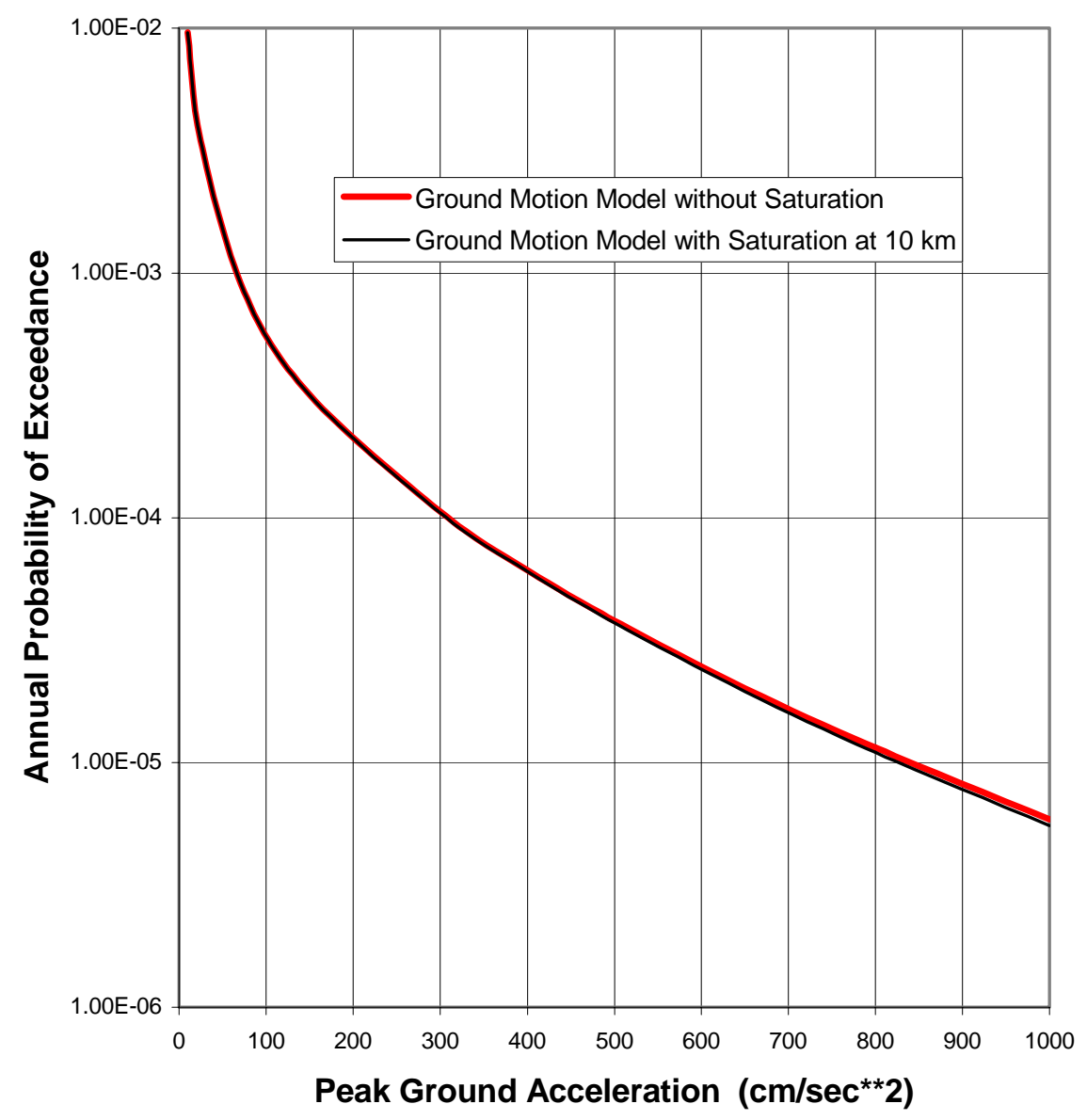

Figure 5.7: Effect of the Ground Motion Saturation at $10 \mathrm{~km}$ in the Ground Motion Model. Comparison of Best Estimate Hazard Estimates with and without Saturation.

At first, it may seem surprising that there is so little impact on the hazard between the saturated version of the 1998-TIP GM model and the unsaturated version. However, refering to Figure 3.3 shows that only approximately 15 percent of the hazard comes from the distance range $0-10 \mathrm{~km}$. In addition, in this same distance range the saturated 1998-TIP GM model also contributes almost a similar amount to the hazard. Figure 5.8a, gives a plot of the percent contribution to the hazard as a function of the distance to the site, using the 1998-TIP GM model, for a range of return periods. Figure 5.8b gives the same information for the saturated 1998-TIP GM model. These two figures show that the shapes of the percent contribution curves are similar. The net effect is that the resultant hazard curves are very similar with the hazard for the saturated GM model being slightly lower. 


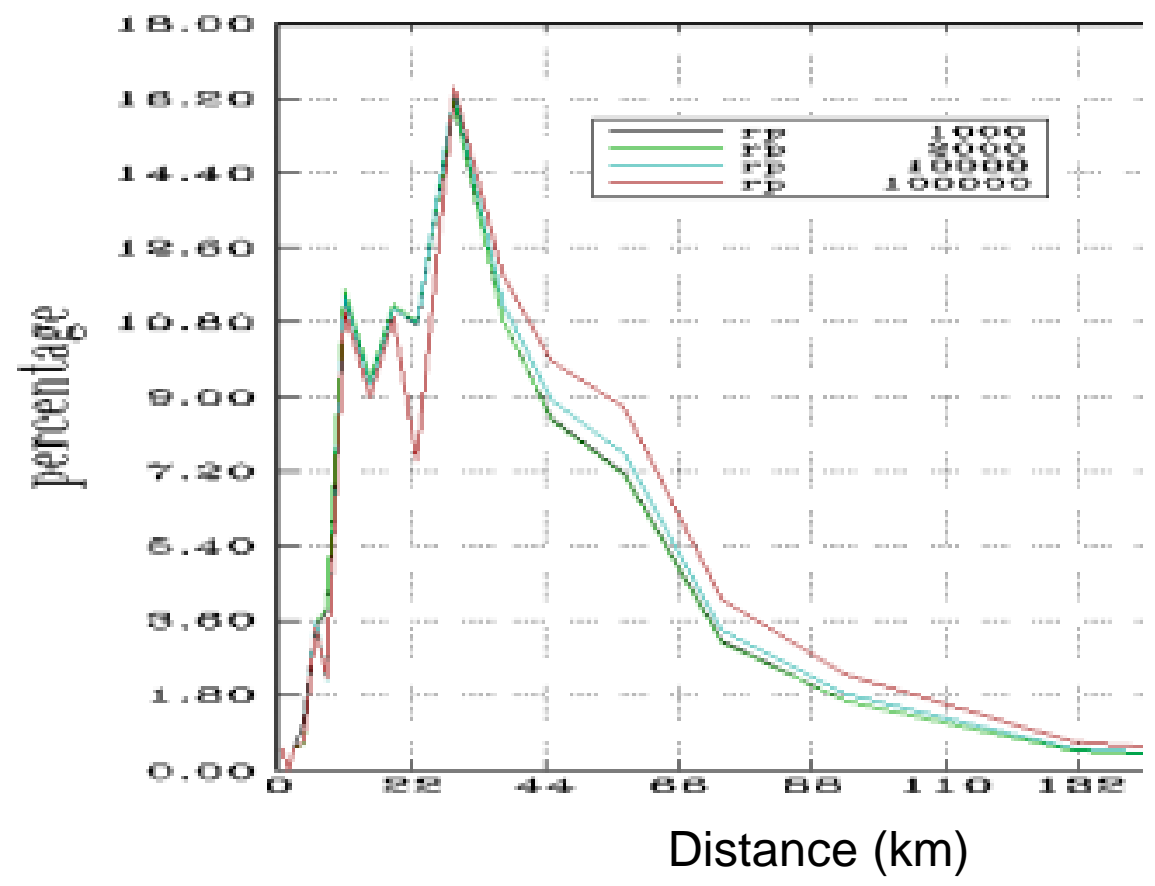

Figure 5.8a: 1998-TIP Study. Contribution of the Bins of Distance to the Total Hazard at the Watts Bar Site with the non-Truncated Ground Motion Model.

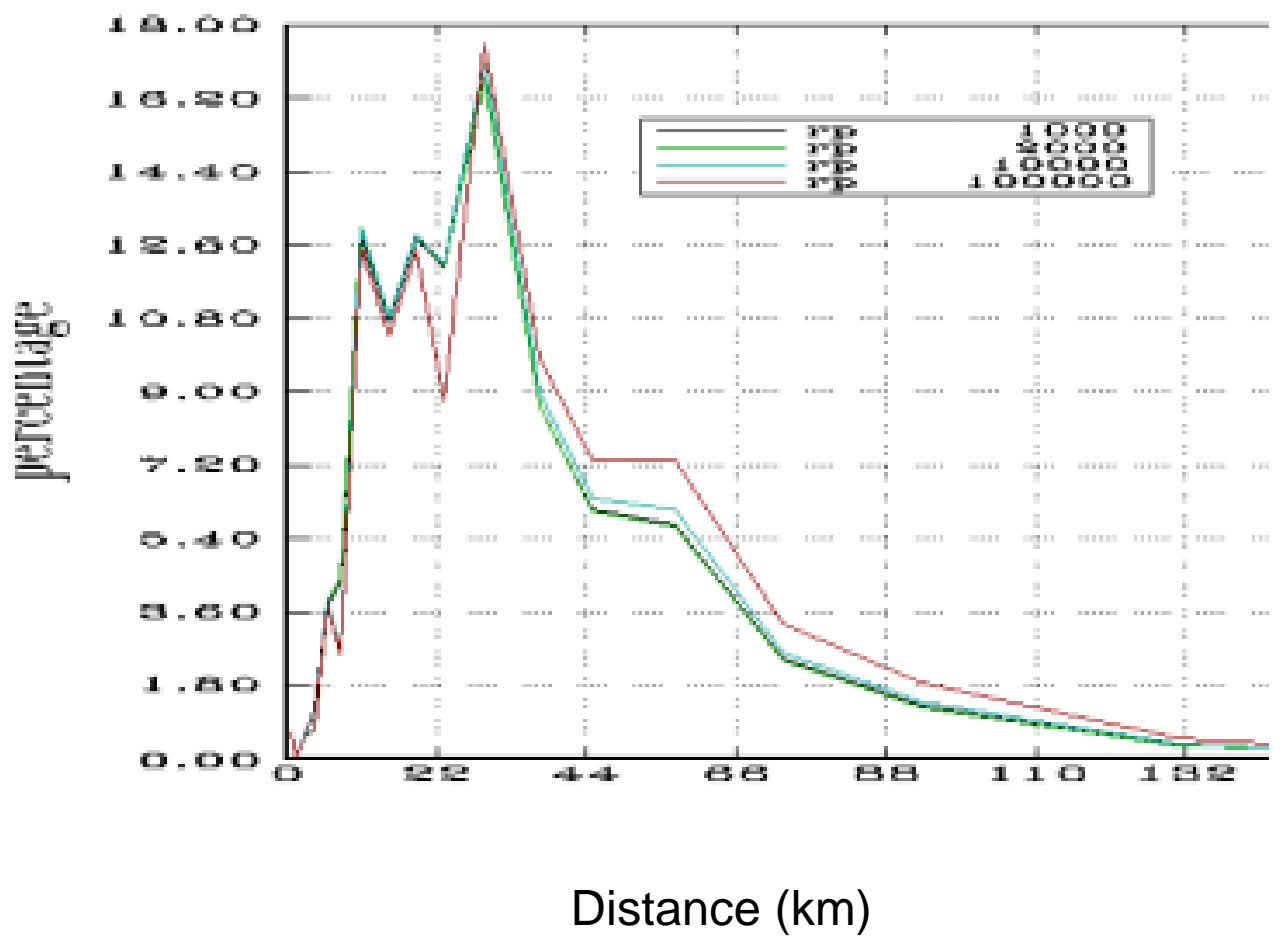

Figure 5.8b: 1998-TIP Study. Contribution of the Bins of Distance to the Total Hazard at the Watts Bar Site with the Ground Motion Model Truncated at distances below $10 \mathrm{~km}$. 


\subsection{Uncertainty in the Ground Motion Models Estimates}

Figure 3.1 showed a significant difference in the rate of attenuation of PGA for distances greater than $200 \mathrm{~km}$. However, Figure 3.3 also showed that over 99 percent of the hazard comes from the earthquakes within $100 \mathrm{~km}$ of the site. Thus, the difference in attenuation has little impact on the hazard at the Watts Bar site.

In Section 3, it was noted that the uncertainty in the 1998-TIP GM model is greater than that of the 1993-EUS-Update GM model. This difference in uncertainty models can impact the identification of those factors that contribute most to the hazard.

For example, Figure 5.9 shows the range of earthquake magnitudes that contribute to the hazard for the 1998-TIP seismicity model combined with the 1993-EUS-Update GM model. This should be compared to Figure 3.10 where the 1998-TIP seismicity model was combined with the 1998-TIP GM model.

It is seen that at longer return periods (higher PGA levels) the range of magnitudes that contribute most to the hazard changes depending on which uncertainty model is used for the GM model.

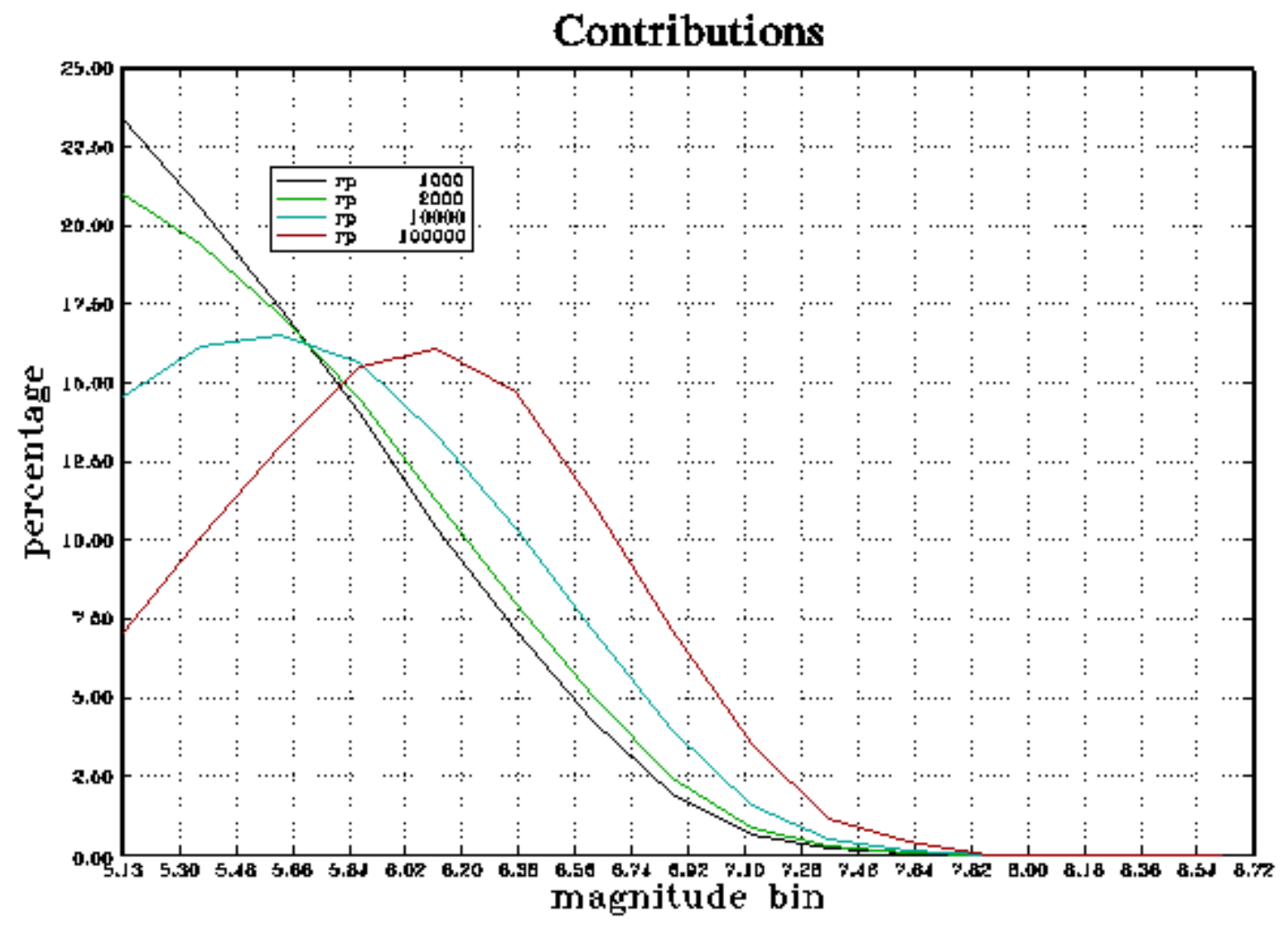

Figure 5.9: Range of Earthquake Magnitudes that Contribute to the Hazard for the 1998-TIP Seismicity Model Combined with the 1993-EUS-Update Ground Motion Model 


\section{CASES OF THE 2.5 AND 25.0 HZ RESPONSE SPECTRAL VELOCITIES}

Up to this point the two studies were evaluated on the basis of comparisons of the hazard of the ground motion at high frequency, namely the PGA. This section examines the case of lower frequency ground motion, for $2.5 \mathrm{~Hz}$ and $25 \mathrm{~Hz}$. Certainly it is expected that more distant larger magnitude earthquakes will be more important because smaller magnitude earthquakes do not generate as much long period ground motion as larger earthquakes.

The uniform hazard spectra for return periods of 100000 and 10000 years between the 1998-TIP seismicity model and Expert 3 of the 1993-EUS-Update study both using the 1998-TIP GM model are shown in Figure 6.1.

The spectral velocities of the 1998-TIP study are a factor of 2 higher than those of the 1993-EUS-Update study at $1 \mathrm{~Hz}$. They are only a factor of 1.5 at $25 \mathrm{~Hz}$, and approximately 1.8 at $2.5 \mathrm{~Hz}$.

Figure 6.2 gives the mean spectral hazard curves for $2.5 \mathrm{~Hz}$ and $25 \mathrm{~Hz}$ using the 1998-TIP GM model and both the 1998-TIP and Expert 3 seismicity models.

For a spectral velocity of $21 \mathrm{~cm} / \mathrm{s}$ at $2.5 \mathrm{~Hz}$, the 1998 -TIP hazard curve is about a factor of 3.4 times larger than Expert 3's hazard curve. At $41 \mathrm{~cm} / \mathrm{s}$ it is a factor of about 3.8 larger. To understand why the $2.5 \mathrm{~Hz}$ hazard curves are so different we need to examine both the distance ranges and magnitude ranges that contribute to the hazard at this frquency. The distance and magnitude ranges that contribute to the $2.5 \mathrm{~Hz}$ hazard curve are similar to the PGA shown in Figures 3.3 and 3.4. Figure 6.3 shows cumulative distribution of the contribution of magnitude to the $2.5 \mathrm{~Hz}$ hazard curve for the 1998-TIP seismicity model and Figure 6.4 shows the cumulative distribution of distance to the $2.5 \mathrm{~Hz}$ hazard curve. 


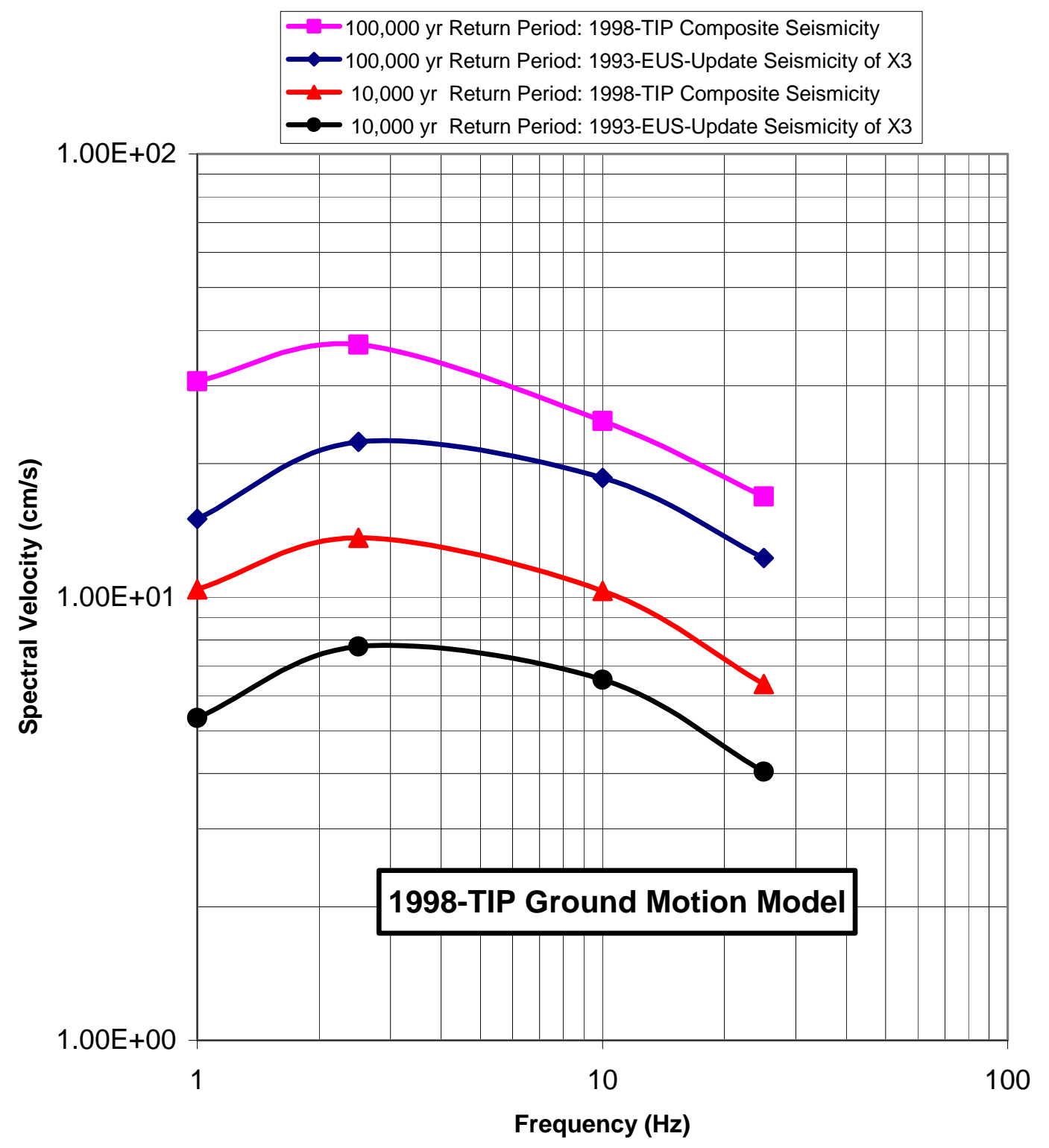

Figure 6.1: Comparison of the Mean Uniform Hazard Spectra for Return Periods of 100,000 and 10,000 years between the1998-TIP Seismicity Model and Expert 3 of the 1993-EUS-Update study both using the TIP Ground Motion model. 


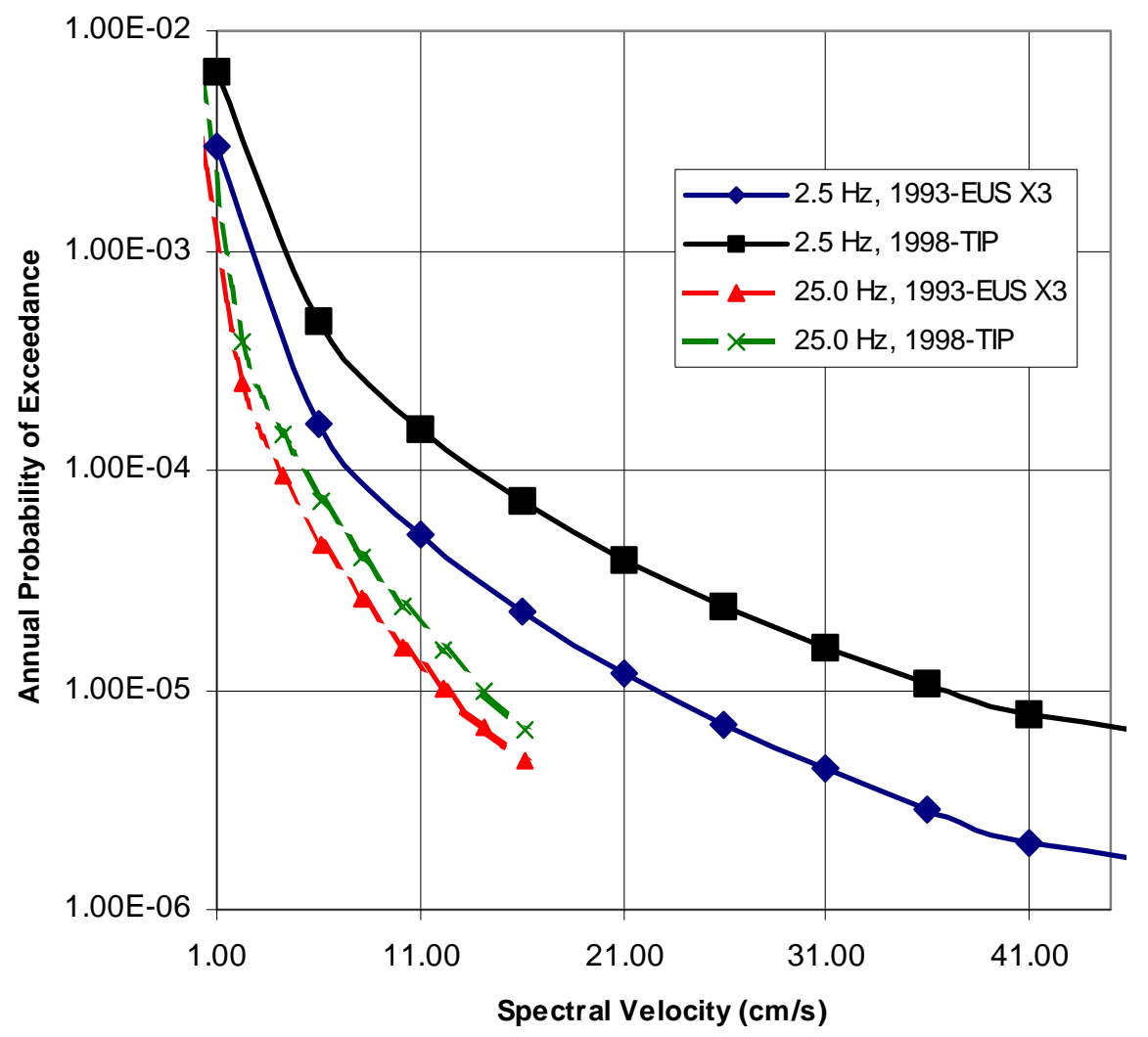

Figure 6.2: Mean Spectral Hazard Curves for $2.5 \mathrm{~Hz}$ and $25 \mathrm{~Hz}$ using the 1998-TIP Ground Motion Model and both the 1998-TIP and 1993-EUS-Update Expert 3 Seismicity Models.

Figures 6.3 and 6.4 show that larger distant earthquakes contribute much more significantly to the $2.5 \mathrm{hz}$ hazard curve than to the PGA and $25 \mathrm{hz}$ hazard curves. Thus, in order to understand why the there is such a large difference between Expert 3's and the 1998-TIP $2.5 \mathrm{hz}$ hazard curves there is a need to examine the rate of earthquakes in regions around the site larger than the $35 \mathrm{~km}$ radius region used in Section 3. Figure 6.5 shows a comparison between the yearly rate of earthquakes within $75 \mathrm{~km}$ around the Watts Bar site for the BE 1998-TIP seismicity model, the median BE 1993-EUS-Update seismicity model and the Expert 3 seismicity model. 


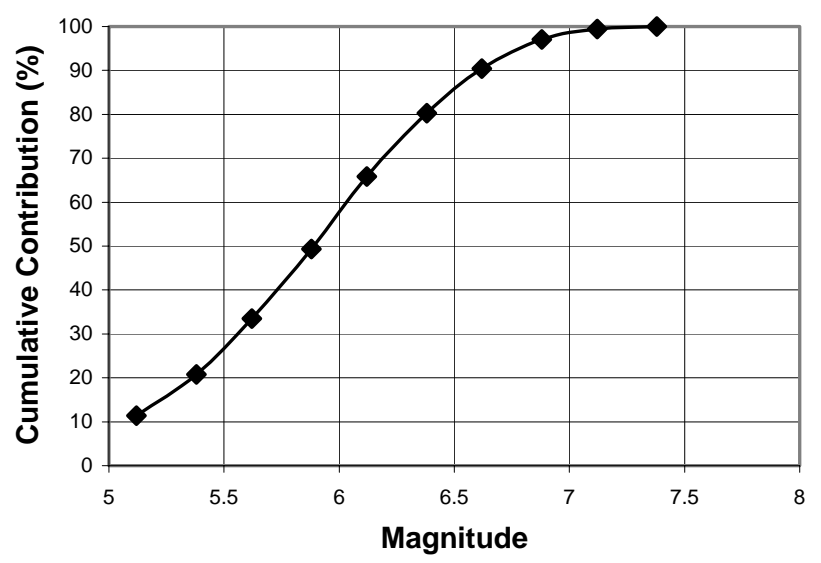

Figure 6.3: Cumulative Contribution of the Magnitude Bins to the Total Hazard for a 100,000 yr Return Period at $2.5 \mathrm{~Hz}$.

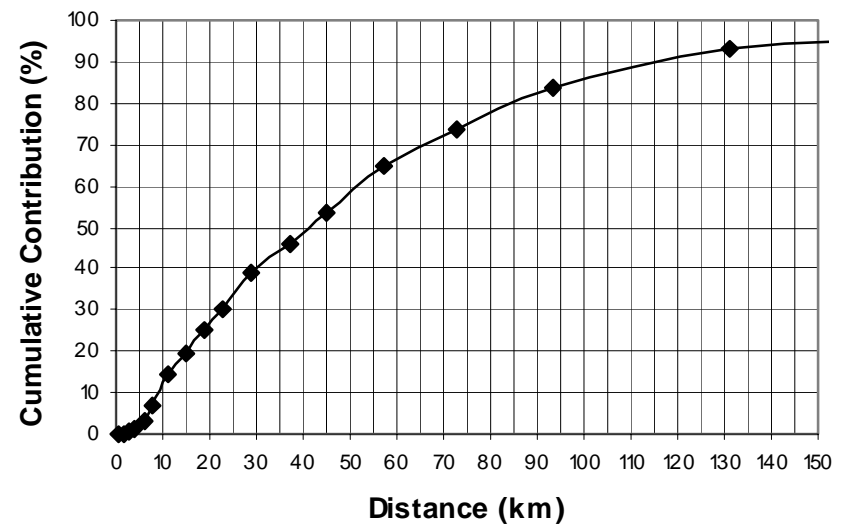

Figure 6.4: Cumulative Contribution of the Distance Bins to the Total Hazard for a 100,000 yr Return Period at 2.5 Hz. 


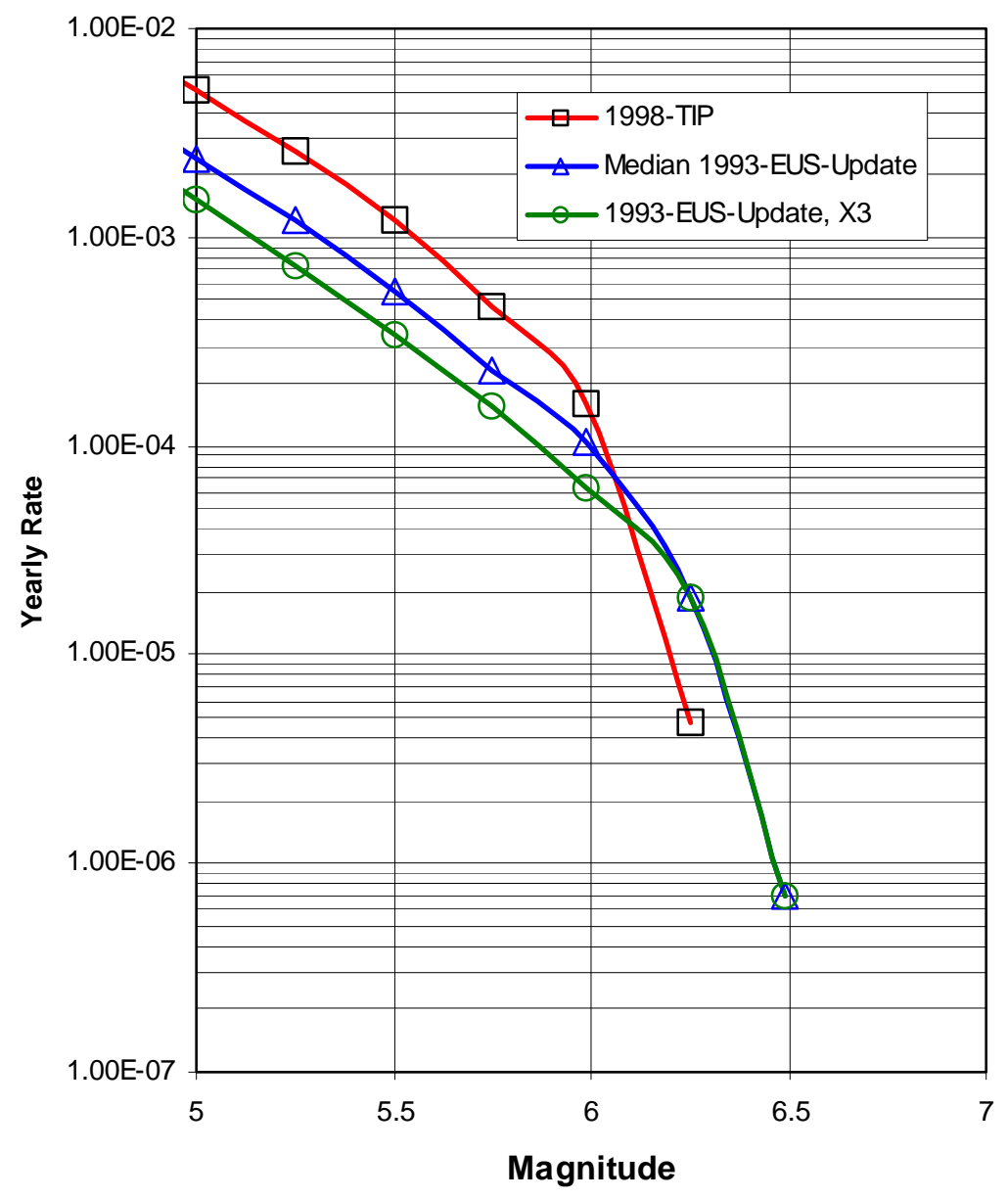

Figure 6.5: Comparison of the Yearly Rate of Earthquakes Occurrence within $75 \mathrm{~km}$ of the Watts Bar site between the Best Estimate 1998-TIP Seismicity model (Map 1), the Median Best Estimate 1993-EUS-Update Seismicity Model and Expert 3's Seismicity model

Figure 6.5 shows that Expert 3's rate of earthquakes is lower in the $75 \mathrm{~km}$ region around the site than the median rate of earthquakes based on the 1993-EUS-Update seismicity model. Referring to Section 3, the region within $35 \mathrm{~km}$ of the site, Expert 3's rates were about the same as the combined 1993-EUS-Update seismicity model. This is illustrated in Figures 6.6 and 6.7. In Figure 6.6, the rate of earthquakes around the site using the TIP seismicity model for distance of $33 \mathrm{~km}, 81 \mathrm{~km}$ and $156 \mathrm{~km}$ all normalized to $35 \mathrm{~km}$. This is compared to Figure 6.7, for a similar plot using Expert 3's seismicity model for distances of $35 \mathrm{~km}, 75 \mathrm{~km}$ and $150 \mathrm{~km}$. 
Note the differences in radius of the areas considered: 33 and $35 \mathrm{~km}, 75$ and $81 \mathrm{~km}$, and finally 150 and $156 \mathrm{~km}$. Due to some selection of parameters when performing the calculations of the 1993-EUS-Update study, it was not possible to have a perfect match of these radii. In each case, the closest radius was selected. Therefore, being tied by the 1993 values of 35,75 and $150 \mathrm{~km}$, the closest 1998 -TIP values were 33,81 and $156 \mathrm{~km}$ radii. Although the comparison is therefore not perfect, the differences in yearly rates normalized is still meaningful due to the relatively minute error introduced by this approximation.

Comparison of rates from TIP Seismicity Model Normalized to $35 \mathrm{~km}$

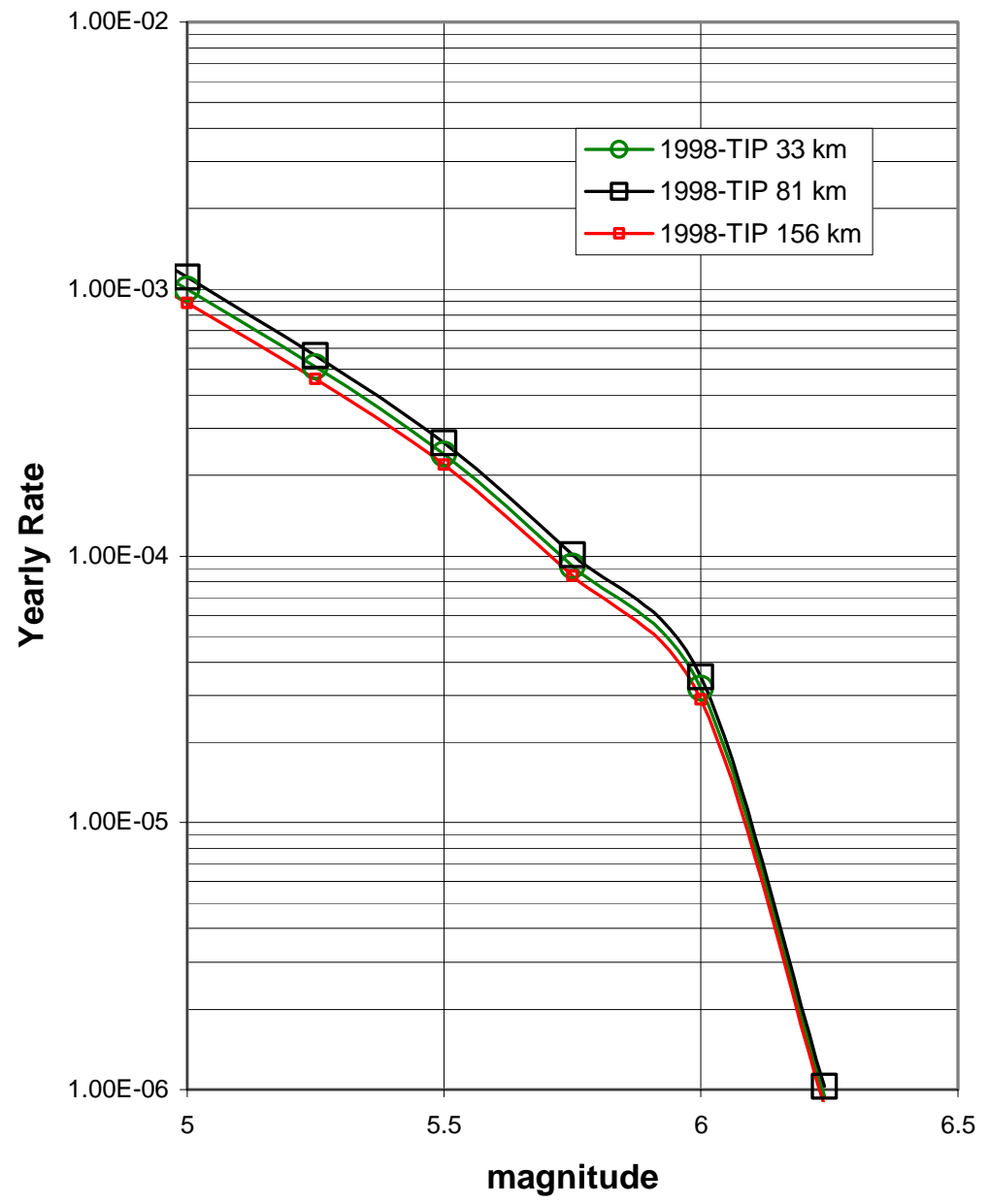

Figure 6.6: Rate of earthquakes versus Magnitude around the site using the 1998TIP Seismicity model for Distances of $33 \mathrm{~km}, 81 \mathrm{~km}$ and $156 \mathrm{~km}$ all normalized to $35 \mathrm{~km}$. 


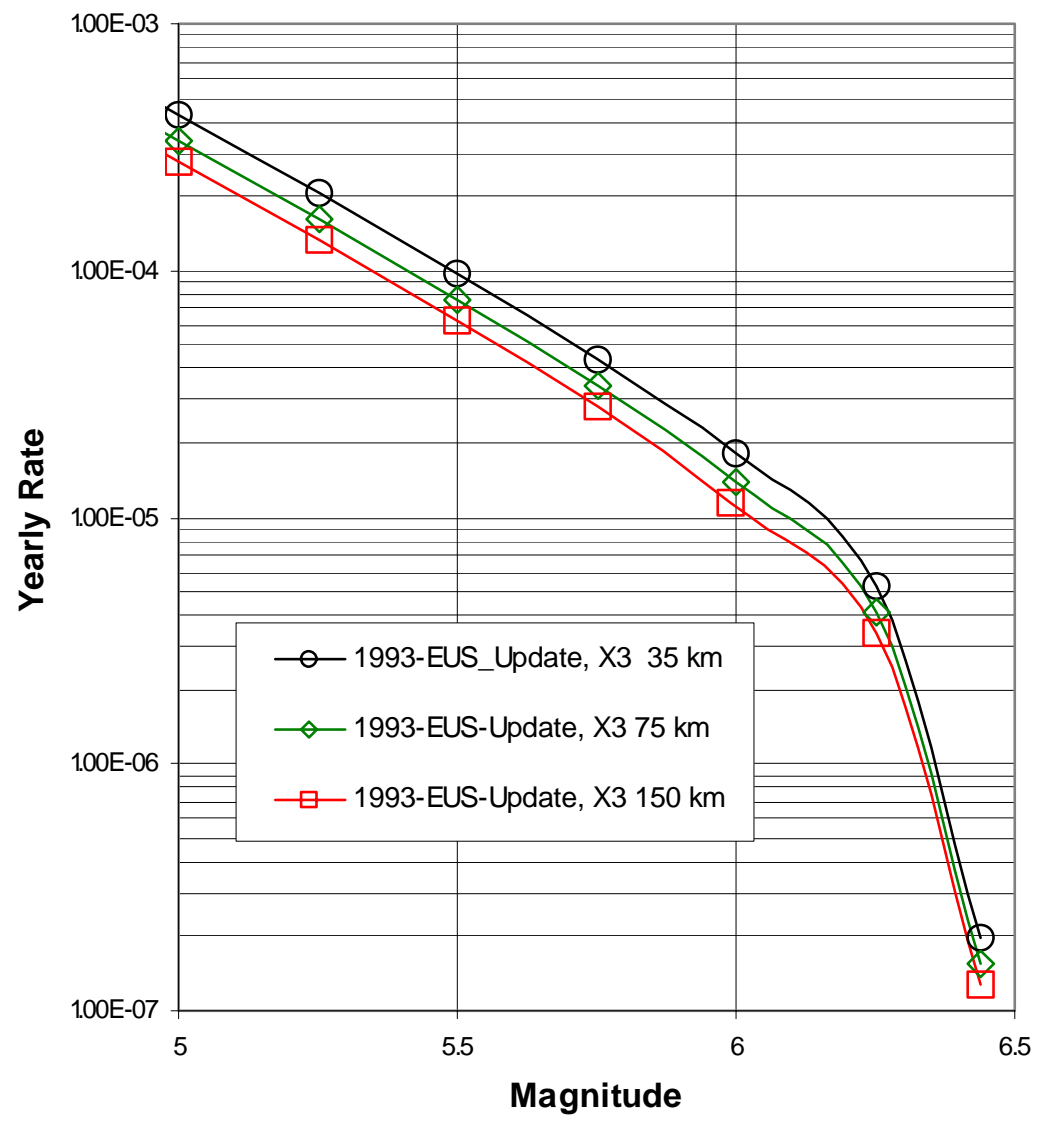

Figure 6.7: Rate of Earthquakes around the Site using the 1993-EUS-Update Expert 3's Seismicity Model (X3), for distances of $35 \mathrm{~km}, 75 \mathrm{~km}$ and $150 \mathrm{~km}$ all normalized to $35 \mathrm{~km}$.

Figure 6.6 shows that, for the TIP seismicity model, the rate of earthquake activity around the Watts Bar site stays relatively constant with increasing distance. On the other hand, Figure 6.7 shows that the rate of activity around the site based on Expert 3's seismicity model decreases with increasing distance. For example, at magnitude 5.5 there is a factor of 3.5 difference between the rates using the largest distance. Thus the difference between Expert 3's 2.5hz hazard curve and the 1998-TIP 2.5hz hazard curve is primarily due to the difference in the rate of activity between the two seismicity models around the Watts Bar site. Why Expert 3's seismicity model shows such a strong 
dependence on the radius of the region around the Watts Bar site is an issue needing special examination. This is done by examining Expert 3's complete seismic zone map shown in Figure 6.8. Where zone 1 is a very large background zone. Because of this, the activity rate in this zone is very low compared to zone 5. Thus, as the radius of the region used to evaluate the rate of activity is increased for Expert 3 more and more of zone 1 is included. By contrast Figures 4.1 and 4.2, show that the 1998-TIP seismicity model introduced a zone 5-2 which has a much higher seismicity rate than Expert 3's zone 1.

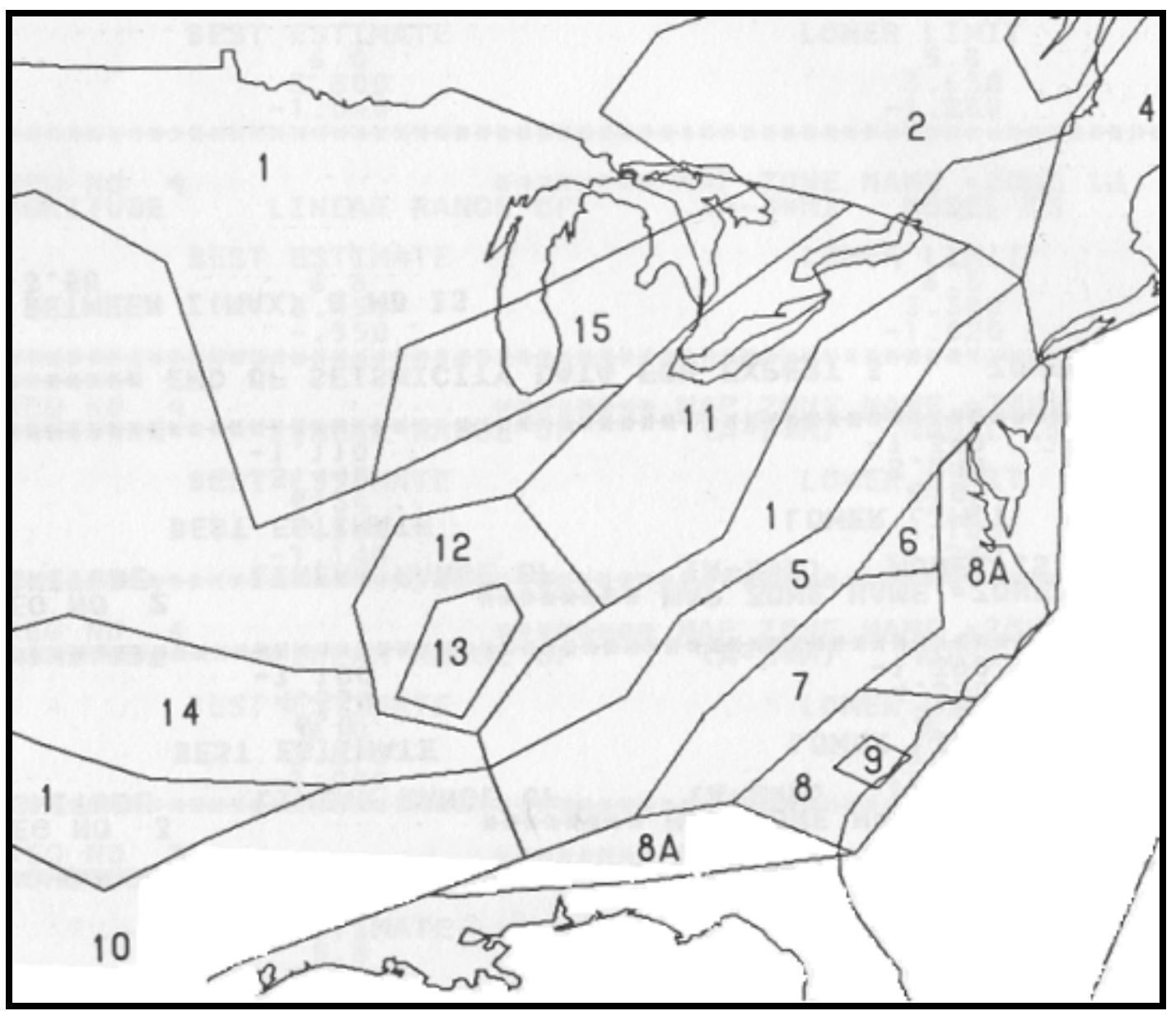

Figure 6.8: Enlarged view of Expert 3's Seismic Source Map Showing Zone 1 as a Large Background Zone with Low Rate of Seismicity

Examining Figures 6.3 and 6.5 show that the uncertainty in the maximum magnitude is important as Figure 6.5 indicates that the BE for the maximum magnitude is about 6. However, Figure 6.3 shows that larger magnitude earthquakes contribute to the hazard. 


\section{DISCUSSION AND CONCLUSIONS}

The differences between the estimates of the seismic hazard at the Watts Bar site between the 1993-EUS-Update study and the 1998-TIP study are due to two main factors:

- Differences between the GM models used in the two studies.

- The introduction of the ETSZ in the 1998-TIP study.

We found that these two factors lead to about a factor of six difference between the two studies for the mean estimate of the PGA hazard at high GM levels. At, $100 \mathrm{~cm} / \mathrm{sec}^{* * 2}$ the agreement between the two studies was much better. We also found that if the same GM model was used in each seismicity model the results were in better agreement and only differed by about a factor of two at high GM levels. The composite rate of earthquakes around the Watts Bar site was about a factor of two higher for the 1998-TIP composite seismicity model than the rates in the 1993-EUS-Update averaged over the Eleven expert's seismicity model.

In the 1998-TIP study, we found that the ETSZ enhanced the activity rate around the Watts Bar site as compared to the 1993-EUS-Update study by about a factor of two. If the 1993-EUS-Update study had been a site-specific study like the 1998-TIP study, it is very likely that most, if not all, of the 1993-EUS-Update Seismicity Experts would have included a more detailed model representing the ETSZ. This would have brought the composite seismicity models between the studies into even better agreement because, as was shown in Figure 5.2, the various models for the ETSZ did not result in significant changes for the estimated hazard.

Although there was a significant difference in the hazard estimates for the Watts Bar site between the two studies when examined in detail there is stability to the estimate of the hazard. We found that the largest contributor to the difference in the GM models used was resting in the uncertainty models. The estimate of the hazard at a site is very sensitive to the uncertainty in the GM model. There is little hope of reducing or stabilizing the uncertainty in the GM model because very little GM data exits from EUS earthquakes. It is unlikely that this will improve in the near future because of the relatively low rate of activity in the EUS and the low density of strong ground motion data recorders. Considering the actual length of time between the time when the seismic zones were identified (mid 1980s) for the 1993-EUS-Update study and the time when the 1998-TIP study was performed, the seismicity models between the two studies were in good agreement. It appears that one possible cause of the differences between the two studies was the difference in scale between the two studies. Namely, the 1993-EUSUpdate study was a large regional study covering the entire region east of the Rocky Mountains, whereas the 1998-TIP study was site specific.

The last point was also demonstrated to be associated with a possible overestimation of the uncertainty in site specific analyses due to the possible creation of myriads of poorly defined zone with large uncertainties in their characteristics. One possible remedy to such 
a situation is to impose criteria on the budget of earthquakes, and on it uncertainty for a small region around the site (say, 15km) in these studies. 


\section{REFERENCES}

Bernreuter, D.L., Savy, J.B., Mensing R.W., and Chen J.C (1989). "Seismic Hazard Characterizatin of 69 Nuclear Plant Sites East of the Rocky Mountains", NUREG/CR-5250, UCID-21517, Vol. 1 to 8.

EPRI (1989). “Seismic Hazard Methodology”, NP-4726, Vol. 1 to 10,

EPRI (1993). “Guidelines for Site Specific Ground Motions”, Palo Alto, California, Electric Power Research Institute, November 1993. TR-102293.

Frankel, A., Burnhard, C., Perkins, D., Leyendecker, E.V., Dickman, N., Hanson, S. and Hopper, M. (1996). "National Seismic Hazard Maps: Documentation" June 1996, U.S. Geological Survey Open-File Report 96-532, 110p.

National Research Council, NAS/NRC, (1997). "Review of: Recommendations for Seismic Hazard Analysis: Guidance on Uncertainty and Use of Experts," National Academy Press.

NRC (1993) "Revised Livermore Seismic Hazard Estimates for 69 Nuclear Power Plant Sites East of the Rocky Mountains”, NUREG-1488, October 1993.

NRC (1996). "Branch Technical Position on the Use of Expert Elicitation in the High Level Radioactive Waste Program". NUREG-1563.

NRC (1997). "Recommendations for Probabilistic Seismic Hazard Analysis: Guidance on Uncertainty and Use of Experts", Nuclear Regulatory Commission, NUREG/CR-6372.

Savy, J., Boissonnade, A., Mensing, R. and Short, S., (1993). "Eastern U.S. Seismic Characterization Update" UCRL-ID-115111.

Savy, J, Foxall, W and Abrahamson, N.(1998)."Guidance for Performing Probabilistic Seismic Hazard Analysis for a Nuclear Plant Site: Example Application to the Southern United States", UCRL-ID-133494, and NUREG/CR-6607. 